\title{
Molecular imaging of large arteries by ultrasound
}

\author{
Citation for published version (APA):
}

Kornmann, L. (2010). Molecular imaging of large arteries by ultrasound: Potentials and pitfalls. [Doctoral Thesis, Maastricht University]. Datawyse / Universitaire Pers Maastricht. https://doi.org/10.26481/dis.20100908lk

Document status and date:

Published: 01/01/2010

DOI:

10.26481/dis.20100908lk

Document Version:

Publisher's PDF, also known as Version of record

\section{Please check the document version of this publication:}

- A submitted manuscript is the version of the article upon submission and before peer-review. There can be important differences between the submitted version and the official published version of record.

People interested in the research are advised to contact the author for the final version of the publication, or visit the DOI to the publisher's website.

- The final author version and the galley proof are versions of the publication after peer review.

- The final published version features the final layout of the paper including the volume, issue and page numbers.

Link to publication

\footnotetext{
General rights rights.

- You may freely distribute the URL identifying the publication in the public portal. please follow below link for the End User Agreement:

www.umlib.nl/taverne-license

Take down policy

If you believe that this document breaches copyright please contact us at:

repository@maastrichtuniversity.nl

providing details and we will investigate your claim.
}

Copyright and moral rights for the publications made accessible in the public portal are retained by the authors and/or other copyright owners and it is a condition of accessing publications that users recognise and abide by the legal requirements associated with these

- Users may download and print one copy of any publication from the public portal for the purpose of private study or research.

- You may not further distribute the material or use it for any profit-making activity or commercial gain

If the publication is distributed under the terms of Article $25 \mathrm{fa}$ of the Dutch Copyright Act, indicated by the "Taverne" license above, 

Molecular imaging of large arteries by ultrasound

Potentials and pitfalls 
ISBN 9789052789644

(C) copyright Liselotte Kornmann, Maastricht 2010

Cover illustration modified from "River water flowing past moss covered rocks, Jiuzhaigou, N.Sichuan province, China" (C) Copyright Wild Encounters, Paul \& Paveena Mckenzie (www.wildencounters.net).

Printing: Datawyse / Universitaire Pers Maastricht 
Stellingen behorende bij het proefschrift

\title{
Molecular imaging of large arteries by ultrasound
}

\section{Potentials and pitfalls}

\author{
Liselotte M Kornmann
}

8 september 2010

1. Moleculaire beeldvorming van geactiveerd endotheel in grote en middelgrote slagaders door selectieve hechting van hedendaagse ultrageluid contrastmiddelen is niet haalbaar door het design van het contrastmiddel en de wrijvingskrachten van het stromende bloed. (Hoofdstuk 3 van dit proefschrift)

2. De mate van akoestische reflectie van een ultrageluid contrastmiddel op een oppervlak is afhankelijk van de diameter van het deeltje en de hoeveelheid deeltjes aan dat oppervlak. (Hoofdstuk 4 en 5 van dit proefschrift)

3. Met behulp van membraan emulsificatie technieken kan men perfluorohexaan emulsies creeren met een nauwe grootte verdeling en een vooraf gekozen diameter. (Hoofdstuk 4 van dit proefschrift)

4. Perfluorohexaan geladen macrofagen bieden een goed alternatief voor hedendaagse moleculaire ultrageluid contrastmiddelen. (Hoofdstuk 5 en 6 van dit proefschrift)

5. Alle zoogdieren hebben een ongeveer gelijke bloedsnelheid in hun grote slagaders en dus hebben kleine zoogdieren een grotere afschuifspanning. Muizen zign daardoor minder geschikt voor het uittesten van moleculaire beeldvorming met behulp van ultrageluid contrastmiddelen.

6. De natuur kan men alleen overwinnen door zich ernaar te schikken. Francis Bacon

7. In the final analysis very little is known about anything, and much that seems true today turns out to be only partly true tomorrow. Fuller Albright

8. Publicatie of een andere vorm van openbare registratie van "negatieve" onderzoeksresultaten leidt tot verbetering van de kwaliteit en efficientie van wetenschappelijk onderzoek.

9. Life is what happens to you while you're busy making other plans. John Lennon

10. Het stapelen van diploma's kan goed uitpakken. 


\section{Molecular imaging of large arteries by ultrasound Potentials and pitfalls}

\section{PROEFSCHRIFT}

ter verkrijging van de graad van doctor aan de Universiteit Maastricht, op gezag van de Rector Magnificus, Prof. mr. G.P.M.F. Mols, volgens het besluit van het college van Decanen, in het openbaar te verdedigen, op woensdag 8 september 2010 om 14:00 uur

door

Liselotte Marianna Kornmann

Geboren op 23 mei 1979

te Curaçao

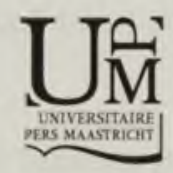




\section{Promotores}

Prof. dr. ir. A.P.G. Hoeks

Prof. dr. R.S. Reneman

\section{Copromotor}

Dr. ir. K.D. Reesink

\section{Beoordelingscommissie}

Prof. dr. T. Hackeng (voorzitter)

Dr. A. Duijvestijn

Prof. dr. ir. N. de Jong (Erasmus MC Rotterdam)

Prof. dr. E. Lutgens

Prof. dr. J. Wildberger

Financial support by the Netherlands Heart Foundation for the publication of this thesis is gratefully acknowledged.

Additional financial support was kindly provided by Esaote - Pie Medical Benelux B.V.

The scientific work was financially supported by SenterNovem of the Dutch Ministry of Economic Affairs (BSIK03033). 


\section{CONTENTS}

Chapter 1 General introduction 9

Chapter 2 Basic principles of ultrasound, contrast imaging, 15

hemodynamics and particle adhesion

Chapter 3 Critical appraisal of artificial targeted ultrasound contrast agents for molecular imaging in large arteries

Chapter 4 Monodisperse perfluorohexane emulsions for targeted ultrasound contrast imaging

Chapter 5 Perfluorohexane-loaded macrophages as a novel ultrasound contrast agent: a feasibility study

Chapter 6 The in vivo potential of echogenic perfluorohexane-loaded macrophages to detect activation of vascular adhesion

Chapter 7 General discussion

Summary

Dankwoord 


\section{List of abbreviations}

\begin{tabular}{|c|c|}
\hline Ao & Aorta \\
\hline BFS & Biotinylated fluoro-surfactant \\
\hline BMM & Bone marrow derived macrophages \\
\hline CT & Computer tomography \\
\hline DMEM & Dulbecco's Modified Eagle Medium \\
\hline EC & Endothelial cell \\
\hline FBS & Fetal bovine serum \\
\hline FITC & Fluorescein isothiocynatae \\
\hline ICAM & Intracellular adhesion molecule \\
\hline IVUS & Intravascular ultrasound system \\
\hline $\mathrm{MHz}$ & Megahertz \\
\hline MRI & Magnetic resonance imaging \\
\hline LCM & L929-cell-conditioned medium \\
\hline LDL & Low density lipoproteines \\
\hline LFA & Lymphocyte function-associated antigen \\
\hline LV & Left ventricle \\
\hline MAC & Macrophage antigen complex \\
\hline PA & Pulmonary artery \\
\hline PBS & Phosphate buffer saline \\
\hline PE & Phycoerythrin \\
\hline PET & Photon emission tomography \\
\hline PFC & Perfluorocarbon \\
\hline PFH & Perfluorohexane \\
\hline PSGL & P-selectin glycoprotein ligand \\
\hline RF & Radio frequency \\
\hline SD & Standard deviation \\
\hline SDBS & Dodecyl benzene sulfonic acid sodium salt \\
\hline SPECT & Single photon emission computer tomography \\
\hline TNF & Tumor necrosis factor \\
\hline VCAM & Vascular adhesion molecule \\
\hline
\end{tabular}


CHAPTER 1

\section{General introduction}


Atherosclerosis, an inflammatory disease of large and middle-sized arteries, is the primary cause of events like stroke or acute myocardial infarction (Lusis 2000). In 2007, about one third of all deaths in the Netherlands was caused by these events, which makes the disease a very important cause of death in the Netherlands ( $w$ ww.cbs.nl). One of the main biological processes in atherosclerosis is the leukocyte adhesion cascade that involves recruitment to activated endothelium and migration into the subendothelial space. In the intima, monocytes accumulate oxidized low density lipoproteines (LDL) and other lipids and transform into foam cells, which are involved in the formation of early plaques (Gimbrone et al. 2000; Hansson 2005; Lusis 2000; Ross 1999).

During the past years, research in the field of atherosclerosis has resulted in better insights into the development of atherosclerotic plaques, the major source of cardiovascular and cerebrovascular events, either due to thrombotic artery occlusion or the shedding of emboli from the thrombus. Changes in molecular and cellular processes in atherosclerosis and plaque formation have been mostly assessed by means of ex vivo evaluation of isolated arteries and plaques. These studies, however, do not provide information about structural and functional changes gradually occurring in the walls of intact arteries during disease processes.

Selective imaging of a molecular target, known as molecular imaging, attempts to reveal detailed information about the molecular and cellular processes underlying disorders such as atherosclerosis. Molecular imaging is a rapidly growing field of medicine and utilizes targeted contrast agents in combination with specific imaging modalities. These contrast agents are developed to adhere to and thereby detect pathological tissue, which otherwise would be difficult to distinguish from surrounding normal tissue.

To achieve effective cellular and molecular imaging, a targeted contrast agent must comply with the following criteria: long circulation half-life, low toxicity, sensitive and selective binding to the molecular marker of interest, long lifetime at the target site, structural stability during imaging, differentiable from non-adherent contrast agents, rapid and high target-to-background contrast ratio, and biodegradability to allow follow-up examinations (Klibanov et al. 1999; Lanza and Wickline 2003). Once these criteria are met, targeted contrast agents become a vital tool in molecular imaging.

Several imaging modalities are used for molecular imaging, such as computer tomography (CT) (Hyafil et al. 2007), single photon emission computer tomography (SPECT) (Kietselaer et al. 2004; Ohshima et al. 2009), positron emission tomography (PET) (Rudd et al. 2002), magnetic resonance imaging (MRI) (Kooi et al. 2003; Lanza 
et al. 2002), optical imaging (Douma et al. 2009), and ultrasound (Dayton and Rychak 2007; Lanza and Wickline 2003). Each modality has specific advantages and disadvantages and selection of the modality depends on the study question to be addressed. PET, SPECT and optical imaging have a high sensitivity and are not bothered by background interference from living tissue. The downside of both PET and SPECT is that their spatial resolution is very limited and patients are exposed to ionizing radiation after injection of radioactive tracers into the bloodstream. Besides an equally limited spatial resolution, optical imaging also suffers from a limited penetration depth. Ultrasound and MRI utilize the inherent echogenic and paramagnetic properties of living tissue, respectively, to produce an image. MRI offers three-dimensional visualization of large structures with an excellent tissue discrimination and good image resolution. Compared to the other imaging modalities, diagnostic ultrasound has many advantages, like ease use (speed and portability), safety (no ionizing radiation), real time imaging with high spatial and especially high temporal resolution and relatively low costs (Dayton and Rychak 2007; Lecchi et al. 2007).

Ultrasound molecular imaging may become increasingly important, if site-targeted contrast agents are available to detect early atherosclerosis in large arteries. To achieve this, the ability of ultrasound contrast agents to selectively adhere to dysfunctional or activated endothelium, while withstanding the prevailing shear forces, is of paramount importance. In this thesis we focus on some basic aspects of contrast agent biophysics and ultrasound imaging.

\section{Aim of this thesis}

To increase our insight into molecular imaging by means of targeted ultrasound contrast agents to endothelial markers in large arteries, we address the following questions:

1. How do ultrasound contrast agent size and surface density relate to echogenicity? A specific question regards the production of echogenic monodisperse perfluorocarbon emulsions.

2. Is it feasible to load circulating blood cells, like monocytes/macrophages, with ultrasound contrast material to enhance echogenicity without sacrificing adhesive properties?

3. Is it feasible to target contrast loaded macrophages in vivo, given the physiological shear stress conditions present in larger arteries? 


\section{Outline of thesis}

As an introduction to the other chapters, in Chapter 2 a brief overview of the basic principles of ultrasound, ultrasound imaging of locally concentrated contrast agents and biophysics of particle adhesion in large arteries is given.

In Chapter 3 the literature on in vitro and in vivo adhesion dynamics of current ultrasound contrast agents is reviewed and the ideal contrast agent is described in terms of selectivity and adhesive behavior.

In Chapter 4 of this thesis a method developed to produce monodisperse perfluorocarbon emulsions is described and evaluated. Emulsions with predefined sizes were studied to establish ultrasound reflectivity and the ability to attach ligands to their surface.

In Chapter 5 the feasibility of utilizing macrophages as ultrasound contrast vehicles for targeting is demonstrated. The feasibility of contrast loading, adhesion and reflectivity was studied under in vitro conditions.

In Chapter 6, perfluorohexane loaded macrophages were used for targeting activated endothelium in mouse carotid artery in vivo.

In Chapter 7 the current status of ultrasound molecular imaging and future directions are discussed. 


\section{References}

Dayton PA, Rychak JJ. Molecular ultrasound imaging using microbubble contrast agents. Front Biosci 2007;12:5124-5142.

Douma K, Prinzen L, Slaaf DW, Reutelingsperger CP, Biessen EA, Hackeng TM, Post MJ, van Zandvoort MA. Nanoparticles for optical molecular imaging of atherosclerosis. Small 2009;5:544-557.

Gimbrone MA, Jr., Topper JN, Nagel T, Anderson KR, Garcia-Cardena G. Endothelial dysfunction, hemodynamic forces, and atherogenesis. Ann N Y Acad Sci 2000;902:230-239; discussion 239-240.

Hansson GK. Inflammation, atherosclerosis, and coronary artery disease. N Engl J Med 2005;352:16851695.

Hyafil F, Cornily JC, Feig JE, Gordon R, Vucic E, Amirbekian V, Fisher EA, Fuster V, Feldman $U$, Fayad ZA. Noninvasive detection of macrophages using a nanoparticulate contrast agent for computed tomography. Nat Med 2007;

Kietselaer BL, Reutelingsperger CP, Heidendal GA, Daemen MJ, Mess WH, Hofstra L, Narula J. Noninvasive detection of plaque instability with use of radiolabeled annexin A5 in patients with carotid-artery atherosclerosis. N Engl J Med 2004;350:1472-1473.

Klibanov AL, Hughes MS, Villanueva FS, Jankowski R, Wagner WR, Wojdyla JK, Wible JH, Brandenburger $\mathrm{GH}$. Targeting and ultrasound imaging of microbubble-based contrast agents. Magma 1999;8:177184.

Kooi ME, Cappendijk VC, Cleutjens KB, Kessels AG, Kitslaar PJ, Borgers M, Frederik PM, Daemen MJ, van Engelshoven JM. Accumulation of ultrasmall superparamagnetic particles of iron oxide in human atherosclerotic plaques can be detected by in vivo magnetic resonance imaging. Circulation 2003;107:2453-2458.

Lanza GM, Wickline SA. Targeted ultrasonic contrast agents for molecular imaging and therapy. Curr Probl Cardiol 2003;28:625-653.

Lanza GM, Yu X, Winter PM, Abendschein DR, Karukstis KK, Scott MJ, Chinen LK, Fuhrhop RW, Scherrer DE, Wickline SA. Targeted antiproliferative drug delivery to vascular smooth muscle cells with a magnetic resonance imaging nanoparticle contrast agent: implications for rational therapy of restenosis. Circulation 2002;106:2842-2847.

Lecchi M, Ottobrini L, Martelli C, Del Sole A, Lucignani G. Instrumentation and probes for molecular and cellular imaging. Q J Nucl Med Mol Imaging 2007;51:111-126.

Lusis AJ. Atherosclerosis. Nature 2000;407:233-241.

Ohshima S, Petrov A, Fujimoto S, Zhou J, Azure M, Edwards DS, Murohara T, Narula N, Tsimikas S, Narula J. Molecular Imaging of Matrix Metalloproteinase Expression in Atherosclerotic Plaques of Mice Deficient in Apolipoprotein E or Low-Density-Lipoprotein Receptor. J Nucl Med 2009;50:612-617.

Ross R. Atherosclerosis--an inflammatory disease. N Engl J Med 1999;340:115-126.

Rudd JH, Warburton EA, Fryer TD, Jones HA, Clark JC, Antoun N, Johnstrom P, Davenport AP, Kirkpatrick PJ, Arch BN, Pickard JD, Weissberg PL. Imaging atherosclerotic plaque inflammation with [18F]fluorodeoxyglucose positron emission tomography. Circulation 2002;105:2708-2711. 


\section{CHAPTER 2}

\section{Basic principles of ultrasound,}

contrast imaging, hemodynamics

and particle adhesion 
In the following sections the basic biophysical principles of ultrasound, ultrasound molecular imaging of (targeted) contrast agents, particle adhesion, and hemodynamics in large arteries will be described.

\section{Basic principles of ultrasound}

Ultrasound is sound with a frequency beyond the human audible range, i.e., with a frequency higher than $20 \mathrm{kHz}$. For biomedical applications, frequencies in the range of 1 to $30 \mathrm{MHz}$ are used. Ultrasound systems usually emit a short burst of ultrasonic waves, generated by an electro-acoustic transducer, into the human body, which is reflected by acoustic inhomogeneities, and received back by the same transducer. The propagation speed of an ultrasonic wave is called acoustic velocity $c[\mathrm{~m} / \mathrm{s}]$ (O'Brien 2007) and is determined by the properties of the medium as expressed by the following equation:

$$
c=\sqrt{\frac{1}{\rho_{0} \kappa}}
$$

where $k\left[\mathrm{~m}^{2} / \mathrm{N}\right]$ is adiabatic compressibility and $\rho O\left[\mathrm{~kg} / \mathrm{m}^{3}\right]$ is the mean mass density of the medium.

From this equation it follows that the speed of sound increases with a decreasing compressibility (i.e., increasing stiffness of the medium). For example, the acoustic velocity of dry air is $330 \mathrm{~m} / \mathrm{s}$ while water and tissues exhibit a considerably higher velocity in the order of $1500 \mathrm{~m} / \mathrm{s}$.

The wavelength $\lambda[\mathrm{m}]$ of an ultrasonic wave is determined by the frequency $f[\mathrm{~Hz}]$ and the acoustic velocity:

$$
\lambda=\frac{c}{f}
$$

The wavelength determines largely the spatial resolution of ultrasound systems. A frequency of $6 \mathrm{MHz}$ corresponds to a $\lambda$ of about $250 \mu \mathrm{m}$.

The interaction between acoustic pressure amplitude of the wave $p\left[\mathrm{~N} / \mathrm{m}^{2}\right]$ and particle velocity $v[\mathrm{~m} / \mathrm{s}]$ in a medium is described by:

$$
p=Z \cdot v
$$

where $Z\left[\right.$ Rayl=kg/(s/ $\left.\left.\mathrm{m}^{2}\right)\right]$ is the acoustic impedance of the medium, and equals the mass density times the acoustic velocity: 
The sound energy passing through a unit area in a unit time is the intensity $\left[\mathrm{kg} / \mathrm{s}^{3}=\mathrm{W} / \mathrm{m}^{2}\right]$ of the sound wave:

$I=0.5 * z \overline{v^{2}}=0.5 * \overline{p^{2}} / Z$

The propagation of ultrasound is influenced by changes in the acoustic properties of the medium through which the waves are propagating. Ultrasonic waves encountering boundaries of internal structures are partly reflected (echo), transmitted or scattered. Reflection and transmission of sound occur at acoustic impedance transitions with a dimension substantially larger than the wavelength and are expressed in terms of its reflection $(R)$ and transmission $(T)$ coefficients. The reflection coefficient for an acoustic interface between medium 1 and medium 2 will be:

$$
R=\frac{Z_{2}-Z_{1}}{Z_{2}+Z_{1}}
$$

Where $Z_{1}\left(=\rho_{1} c_{1}\right)$ and $Z_{2}\left(=\rho_{2} C_{2}\right)$ are the characteristic impedances of the two media given by equation 2.4 .

The transmission coefficient from medium 1 to medium 2 is:

$$
T=\frac{2 Z_{2}}{Z_{2}+Z_{1}}
$$

For example, the acoustic impedance mismatch between solids (e.g., bone) and soft (e.g., muscle) tissue is large and a major part of the ultrasound wave will be reflected, resulting in a large echo, while transitions between liquids (e.g., blood) and soft tissue will result in a modest echo due to the limited reflection (see table 1).

Sound waves impinging on structures smaller than $\lambda$ (e.g., red blood cells) are scattered in all directions, provided the presence of sufficient interspacing between the cells. Due to absorption, scattering, reflection, beam divergence and refraction, sound is attenuated as it propagates through tissues. The relative attenuation of the wave pressure amplitude is a function of the frequency $f$ and traveled distance from the source $z[\mathrm{~cm}]$, according to the following equation:

$$
A(z) / A(0)=e^{-\alpha f z}
$$

where $\alpha_{0}$ is the frequency dependent attenuation coefficient $[\mathrm{dB} /(\mathrm{cm} / \mathrm{MHz})]$.

The farther the sound travels and the higher its frequency is the greater the attenuation will be. Attenuation coefficients vary widely for different media (see table 
1). Highly attenuating media, e.g., bone, can only be passed by ultrasound if it is thin (e.g., temporal bone) and the ultrasound frequency is low. As indicated above, ultrasound resolution improves with frequency (shorter wavelength) while attenuation increases. That is why deep lying structures are investigated with relatively low frequencies ( 3.5 or $5 \mathrm{MHz}$ ), while superficial arteries are interrogated with substantially higher frequencies (10 $\mathrm{MHz}$ ) to obtain detailed information.

Table 1. Acoustical properties of biological materials. Values are derived from data published by Goss et al. (Goss et al. 1978); except where otherwise indicated.

\begin{tabular}{|c|c|c|c|c|}
\hline & $\begin{array}{l}\text { Density p } \\
{[\mathrm{kg} / \mathrm{m} 3)}\end{array}$ & $\begin{array}{l}\text { Velocity c } \\
{[\mathrm{m} / \mathrm{s} 2]}\end{array}$ & $\begin{array}{l}\text { Acoustic Impedance } \\
Z * 106 \text { [Rayl] }\end{array}$ & $\begin{array}{l}\text { Attenuation } \alpha \\
{[\mathrm{dB} / \mathrm{cm} / \mathrm{MHz}]}\end{array}$ \\
\hline Blood (at $36^{\circ} \mathrm{C}$ ) & 1025 & 1580 & 1.62 & 0.2 \\
\hline Skin & $1100^{\dagger}$ & $1631 \dagger$ & $1.79+$ & $0.22 t+$ \\
\hline Fat & 952 & 1450 & 1.38 & 0.6 \\
\hline Muscle & 1042 & 1580 & 1.7 & 1.5 \\
\hline Arterial wall & $1066 t$ & $1616^{\dagger}$ & $1.72^{+}$ & $1.03^{t}$ \\
\hline Bone & 2229 & 3500 & 7.8 & 10 \\
\hline
\end{tabular}

+ From Duck et al. (Duck 1990).

t+ From Moran et al. (Moran et al. 2006).

\section{Medical imaging with ultrasound}

In its most simple application ultrasound is emitted as a short burst (2-3 periods) by a single transducer. The same transducer picks up the reflected and backscattered signals where the delay $\Delta t$ with respect to emission corresponds to the depth $d$ the signals are originating from:

$$
\Delta t=\frac{2 d}{c}
$$

where the factor 2 is explained by the round trip distance.

The conversion from time to distance assumes that the propagation speed is (almost) constant along the propagation path, which is true for biological tissues except bone (table 1). Because the emitted ultrasound burst meets many acoustic inhomogeneities on its path the received signal is a summation of all returned signals. The amplitude of the received radio-frequency (RF) signal, i.e., its envelope, is a direct measure of the reflectivity of a particular inhomogeneity. Displaying the amplitude as a function of depth (time delay) is called A-mode (A stands for amplitude) and enables direct evaluation of the relative amplitudes (figure 1). Repetitive emission and reception along the same line and displaying the amplitudes coded in 
grey levels along each other is called M-mode, because it reveals the slight motion (M-mode) of structure boundaries over time.

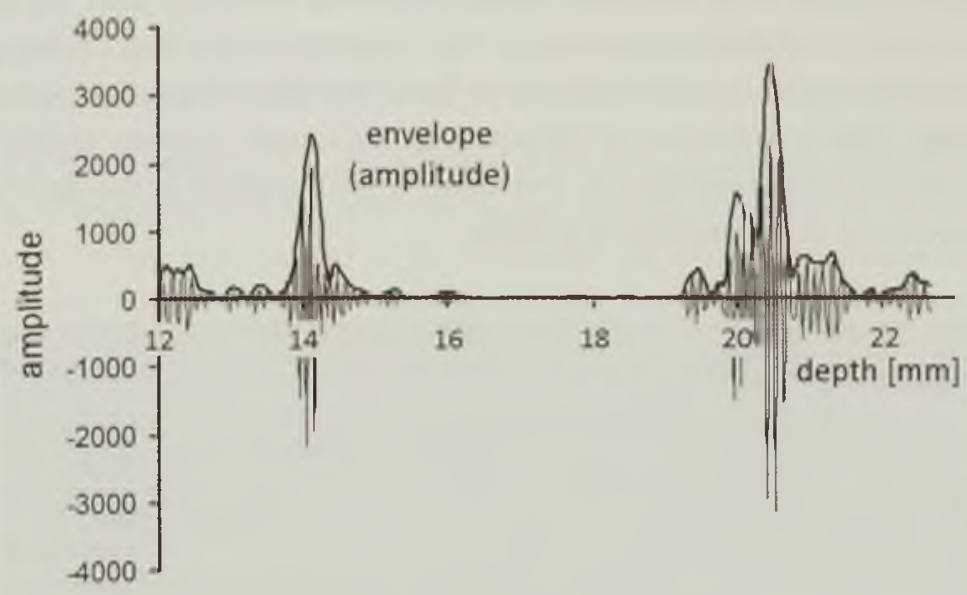

Figure 1. Characteristic radiofrequency (RF) signal received from a carotid artery and its envelope. The anterior and posterior adventitial walls (high amplitude) are located at a depth of 4 and $11 \mathrm{~mm}$ (first 10 $\mathrm{mm}$ from skin have been discarded).

In a further development ultrasound is emitted and received along adjacent lines requiring transducers composed of many transducer elements. In this way an area is scanned and the received amplitudes are displayed coded in grey levels as an image (brightness or B-mode) with (in the standard presentation) the transducer always on top (figure 2). It should be realized that grey level encoding is performed in a non-linear fashion: high amplitudes are compressed to accommodate the large dynamic range of echo amplitudes. Signals received from structural interfaces that are oriented perpendicularly to the ultrasound beam exhibit generally large amplitude peaks (reflection) while those received from tissue (mainly scattering) have moderate amplitudes. A major difference between ultrasound echo imaging and other imaging modalities is that the former is based on transition in acoustic properties, so structures with (nearly) homogeneous characteristics will not generate signals. For example, for sound whole blood is almost homogeneous and will appear as black in the image. The achievable frame rate for B-mode images composed of 128 lines easily exceeds the video frame rate of $25 \mathrm{~Hz}$ (real-time). Parallel shifting of the echo lines is realized with a linear array of transducer elements. Splitting elements into small rectangular elements and activating those elements group wise with small respective delays allows focusing at a preselected depth. At reception the delays can be varied over depth (time), allowing dynamic focusing over a depth range within the plane of observation. Perpendicular to the scan plane focusing is 
achieved mechanically by an acoustic lens, composed of material with a sound propagation speed that highly deviates from that of biological tissues. A common value for the width of focused beams is 4-6 wavelengths (lateral resolution), which is substantial larger than the axial resolution along the echo line. As indicated above, the best resolution is obtained for high frequencies, but that implies that the target should be close to the transducer to keep the depth-dependent attenuation manageable. This is achieved by intravascular ultrasound systems (IVUS), with a mechanically rotating transducer or transducer array, mounted at the tip of a catheter and operating at a frequency of $30 \mathrm{MHz}$.

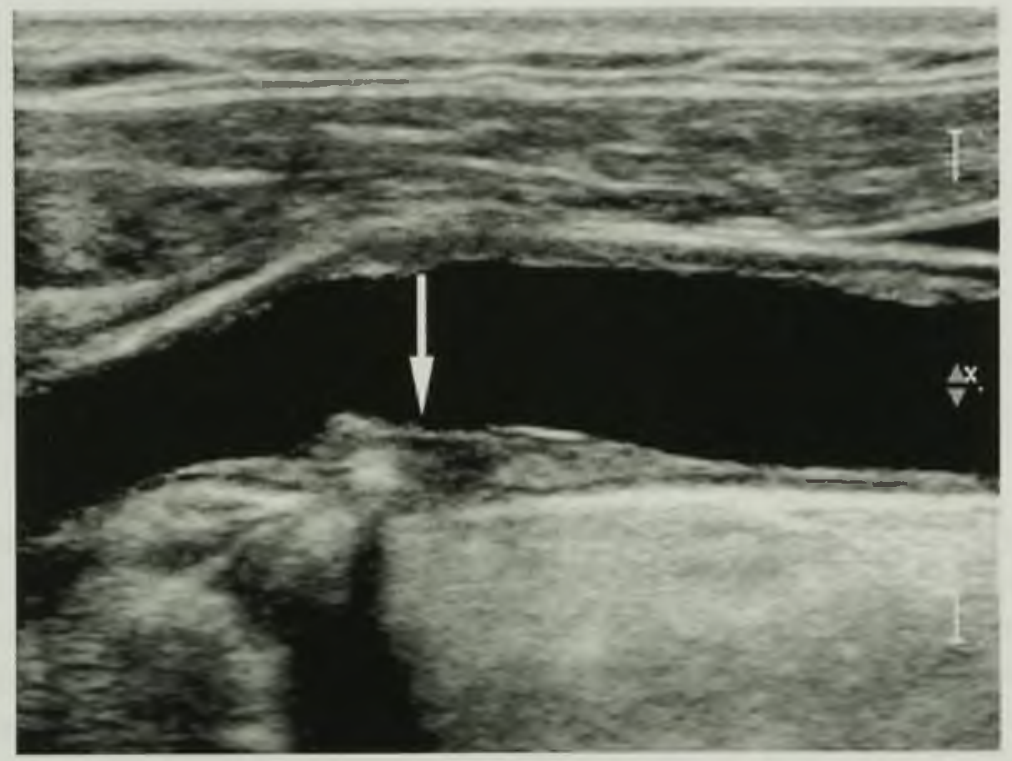

Figure 2. Transcutaneous ultrasound B-mode image of an advanced plaque on the posterior wall, indicated by a white arrow, at the transition from common to internal carotid artery.

\section{Imaging of targeted contrast agents}

Ultrasound molecular imaging of targeted contrast agents requires insight into the relationship between local expression of molecular markers on endothelial surfaces, especially in early atherosclerosis, and the local concentration of ultrasound contrast agents. Several theoretical models to determine the reflectivity of ultrasound contrast agents adhered to a target surface have been described in literature. 
According to the Born approximation the scattering cross-section (SCS) of a single contrast agent, defined as the scattered power divided by the incident power, is proportional to:

$$
S C S=d^{2}\left(\frac{d}{\lambda}\right)^{4}
$$

where $d$ is the diameter of a particle and $\lambda$ the ultrasound wavelength (given by equation 2). It implies that the scattered power strongly increases for either a larger sphere size (to the sixth power) or by increasing the ultrasound frequency (to the fourth power). Therefore, experiments quantifying the signal gain of contrast agents should also report the ultrasound frequency employed.

A related question pertains to the selection of agent size for a given volume quantity: will it be better to have a large number of small rather than a small number of large particles, assuming that all particles are located within the ultrasound beam? Let us consider a small particle with diameter $d_{s}$ and volume $v_{s}$ and a large particle with diameter $d_{1}$ and volume $v_{1}$. Suppose that $d_{i}=k d_{s}$. For this diameter relationship the volume relationship converts into $v_{l}=k^{3} v_{s}$, which indicates that we need $k^{3}$ small particles to obtain an equivalent volume. In practice a factor $k=10$ in diameter 10.5 vs $5 \mu \mathrm{m}$ ) is quite realistic for ultrasound contrast agents In terms of bioavailability, preference should likely be given to the small particles because relatively large red blood cells will push those particles towards the wall, favoring adhesion. However, because of the large number of particles involved and the limited number of free adhesion sites, a larger particle size might be advantageous, if the effect of wall shear and entrapment by the microcirculation can be ignored.

Now let us return to the backscattered ultrasound signal level for either large or small particles when both collections have the same total volume. Assuming independent scattering (large interspacing) we may sum the backscattered power of the individual particles, resulting for the small particles $\left(d_{s}^{2}\left(d_{s} / \lambda\right)^{4}\right.$ per particle) in a total of $k^{3} d_{s}^{2}\left(d_{s} / \lambda\right)^{4}$ or a signal amplitude of $k^{1.5} d_{s}\left(d_{s} / \lambda\right)^{2}$. Similarly, large particles $\left(d_{1}^{2}\left(d_{1} / \lambda\right)^{4}\right)$ will produce a backscattered power of $k^{6} d_{s}^{2}\left(d_{s} / \lambda\right)^{4}$, or a signal level of $k^{3} d_{s}\left(d_{s} / \lambda\right)^{2}$. We may conclude that for a given volume of material the highest ultrasound signal is obtained from large particles.

Couture et al. (Couture et al. 2006) described a linear scattering model, which accounts for transducer diffraction patterns, particle and substrate physical properties, and density of particle coverage. The perfluorocarbon particle model assumes a random distribution of scatterers with a known size distribution and predicts the surface density or frequency dependence of the reflectivity coefficient very well, especially at low particle concentrations. For perfluorocarbon emulsions, an essen- 
tial contrast agent in this thesis, this model does not work beyond a certain density due to interaction of these particles with each other, which causes multiple scattering, phase interference and saturation. However, in vivo, this situation will probably not occur because of a sparse number of molecular markers at the targeted surface.

Marsh et al. (Marsh et al. 2007) related the echogenicity to density with a simple asymptotic exponential model. The reflectivity enhancement is expressed as the difference between the backscatter of a surface, coated with contrast material, and the mean value of the backscatter of all samples in the non-coated surface group. This model assumes a considerably higher particle density than the particle model of Couture (see above), explaining the saturation effect described by Couture et al. (Couture et al. 2006).

Lanza et al. described a simple acoustic transmission line model that is less complex than the particle model of Couture et al. It predicts the reflectivity coefficient of a layer of perfluorocarbon emulsions attached to a substrate (Lanza et al. 1998) and is based on a three layer system of a host medium (water or blood), a thin $(-250 \mathrm{~nm})$ homogeneous layer of emulsions, and the substrate. This model implicitly suggests that contrast agents adhere as a continuous uniform layer (Lanza et al. 1998).

Couture et al. developed an additional model that predicts the reflection of ultrasound from multiple layers of scattering particles (Couture et al. 2007). Instead of determining the acoustical impedance of a single layer itself, this model determines first the reflection of a single layer, using the scattering cross-section of the particles, and then sums the phase-shifted contributions of all layers. This model demonstrates that the reflection coefficient for two types of scatterers, glass beads and cells $(-5$ and $-10 \mu \mathrm{m}$ in size, respectively), increases as function of their density on the surface for less than three stacked layers. Above three layers, oscillations of the reflection coefficient, due to constructive or destructive phase interference between layers, are accurately predicted by the model as confirmed experimentally.

In reality, we are always dealing with sparse numbers of targeted contrast agents at the arterial wall, not reaching a single uniform layer as assumed by Lanza et al, (Lanza et al. 1998) or multiple layers as assumed by Couture et al. (Couture et al. 2007).

\section{Basic principles of hemodynamics}

Blood flows through the lumen of a blood vessel and carries oxygen, hormones and nutrients and removes waste products from the various body tissues. Blood is a suspension of red blood cells (erythrocytes), platelets, and white blood cells (leuko- 
cytes) in a solution (called plasma) of lipids, salts, proteins, carbohydrates and gases. Typical characteristics of blood are hematocrit (erythrocyte volume fraction) and viscosity. The latter is subdivided into plasma viscosity and whole blood viscosity. The viscosity of a fluid is its resistance to flow which arises from friction between adjacent fluid layers (Pearson 2001). The force exerted on the liquid layer per unit of area is called shear stress and the velocity gradient between adjacent layers is the shear rate (Pearson 2001). Shear stress can be estimated from shear rate and blood viscosity. The shear stress at the wall-lumen interface, i.e., wall shear stress, is not only an important determinant of endothelial cell function and intimal structure (Reneman et al. 2006), but also plays a major role in rolling speed and adhesion of monocytes (Alon et al. 1995; Marshall et al. 2003).

\section{Shear stress in vivo}

In most theoretical considerations and in nearly all in vitro as well as in vivo experiments, wall shear stress $\tau_{w}[\mathrm{~Pa}]$ is derived from viscosity and wall shear rate $\gamma_{w}[s]$, being the radial derivative of the velocity distribution at the wall. The latter is calculated using Poiseuille's law, which supposes a steady non-pulsatile parabolic laminar flow of Newtonian fluid within a straight circular tube with a constant diameter $d$ [m] or radius $R$ [m] (Figure 3) (Nichols and O'Rourke 2005). Under these conditions the velocity $v[\mathrm{~m} / \mathrm{s}]$ as function of radial position $r[\mathrm{~m}]$ in a circular vessel with radius $R$ can be expressed as:

$$
v(r)=v_{\max }\left(1-\left(\frac{r}{R}\right)^{2}\right)
$$

where $v_{\max }$ is maximum blood flow velocity within the lumen.

Taking the derivative of the velocity distribution:

$$
\gamma_{w}=\left.\frac{d v(r)}{d r}\right|_{r=R}=\frac{4 v_{\max }}{d}=\frac{32 q}{\pi d^{3}}
$$

The right hand side results from conversion from velocity to volume flow $q[\mathrm{ml} / \mathrm{s}]$. It is problematic, however, to measure directly and non-invasively blood volume flow, while the above equation is very susceptible to small errors in the estimated lumen diameter because of its third power. That is why in clinical studies preference is given to shear rate as function of the ratio of center stream velocity and diameter. The center stream velocity is easily measurable with a Doppler system. In a final step, shear stress $\tau[\mathrm{Pa}$ ] follows from shear rate $\gamma[\mathrm{s}]$ and whole blood viscosity WBV $[\mathrm{Pa} / \mathrm{s}]$, which transforms the above expression into: 
$\tau_{w}=W B V \cdot \gamma_{w}=\frac{4 \eta v_{\max }}{d}$

where $\eta[\mathrm{Pa} / \mathrm{s}]$ is the fluid viscosity.

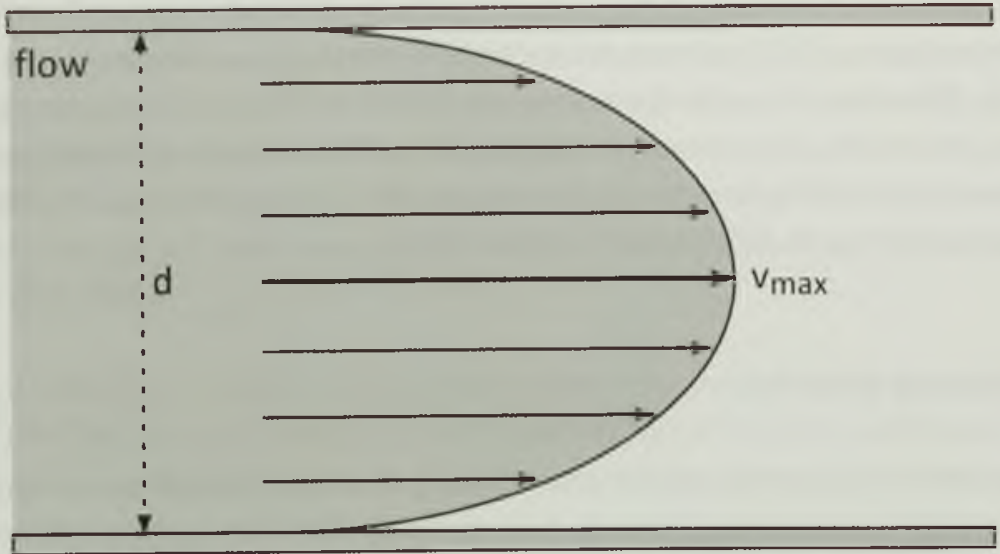

Figure 3. Schematic representation of a parabolic flow profile. The maximum velocity (vmax) is at the centre of the velocity distribution.

However, Poiseuille's law does not hold for large arteries where blood is a nonNewtonian fluid, the vessel is distensible, flow is pulsatile, and the velocity profiles never can fully develop because bifurcations and branches make segments too short for full development. Consequently, the velocity profile is a flattened rather than a fully developed parabola, with a low shear rate in the centre of the artery and a high shear rate towards the wall (Reneman et al. 2006). In straight vessels, the shear stress leads to migration of erythrocytes towards the vessel axis. For shear rates lower than $100 \mathrm{~s}^{-1}$ erythrocytes will aggregate (rouleaux formation), which increases viscosity. Because of their size erythrocytes cannot approach the vesse wall unlimitedly, explaining the thin boundary layer of plasma containing only the relatively small blood platelets. The viscosity of this layer approaches that of blood plasma (shear thinning). Above a shear rate of $100 \mathrm{~s}^{-1}$ whole blood behaves like a Newtonian fluid and achieves its minimum viscosity with erythrocytes aligning along the stream lines to decrease resistance to flow (Stuart and Kenny 1980). The experimental expression to estimate whole blood viscosity, as proposed by Weaver, accounts for the dynamic behavior of whole blood viscosity as function of hematocrit and plasma viscosity for the full physiological range of wall shear rates (Weaver et al. 1969). 
For curved arteries, accumulation of erythrocytes on the inside curvature is driven by secondary flow in combination with higher residence times (Jung et al. 2006). The higher viscosity in the central part of the curved vessel tends to block erythrocyte flow, causing them to migrate preferentially through the boundary layer of the plasma. Such behavior can also be expected from monocytes in regions prone to atherosclerotic plaque development, e.g., inner curvatures of arteries (Jung et al. 2006). Similarly, in the common carotid artery bifurcation erythrocytes and monocytes can come in close contact with the artery wall in the area of disturbed flow opposite to the flow divider. In this area, which is prone to atherosclerosis, flow deviates from the main stream and re-circulates (Reneman et al. 1985). Wall shear stress, averaged over the cardiac cycle, has been shown to be very low in this area (Dai et al. 2004).

Not only in large arteries, but also in arterioles the velocity profiles are flattened parabolas, mainly due to the dominant viscous forces in the center of these small vessels. The flattening of the profiles in large arteries and arterioles does have consequences for the determination of shear rate from velocity profiles. When assuming a parabolic velocity profile the wall shear rate values obtained will be substantially lower (up to a factor of 2 ) than those derived from a flattened velocity profile (Reneman et al. 2006). Therefore, shear rate has to be derived directly from recorded velocity profiles.

\section{Shear stress in vitro}

For flow chamber studies, used to study adhesion and detachment of leukocytes or contrast agents, the relationship between flow, wall shear rate, and wall shear stress is related to its rectangular shape (Lawrence et al. 1987; Patton et al. 1993; Takalkar et al. 2004). Since the chamber width $w$ is much larger than the height $H$, the contribution of the lateral boundaries to the shape of the velocity distribution can be neglected. Therefore, it can be assumed that for steady flow over the full width the velocity profile, as function of the position $h$, has a parabolic shape (Fig. 4) directly related to peak flow velocity $v_{\text {max }}$ :

$$
v(h)=v_{\max }\left(1-(2 h / H)^{2}\right) \text { for }|h|<H / 2
$$

By definition, the wall shear rate $\gamma_{w}$ at the chamber wall is the local derivative of the velocity distribution with respect to the position $h$ :

$$
\gamma_{w}=\left.\frac{\Delta v(h)}{\Delta h}\right|_{h=H / 2}=\left.\frac{8 v_{\max } y}{H^{2}}\right|_{h=H / 2}=\frac{4 v_{\max }}{H}=\frac{6 q}{w H^{2}}
$$


where $q$ is the volume flow rate through the flow chamber according to:

$$
q=v_{\text {mean }} w H=\left(\frac{2 v_{\max }}{3}\right) w H=\frac{2 w H v_{\max }}{3} \text { or } v_{\max }=\frac{3 q}{2 w H}
$$

where $v_{\text {mean }}$ is the mean flow velocity in the flow chamber.

The wall shear stress $\tau_{w}$, derived from the wall shear rate (Eq. 15) and medium viscosity $\eta$ in the chamber, is described as:

$$
\tau_{w}=\frac{6 \eta q}{w H^{2}}
$$

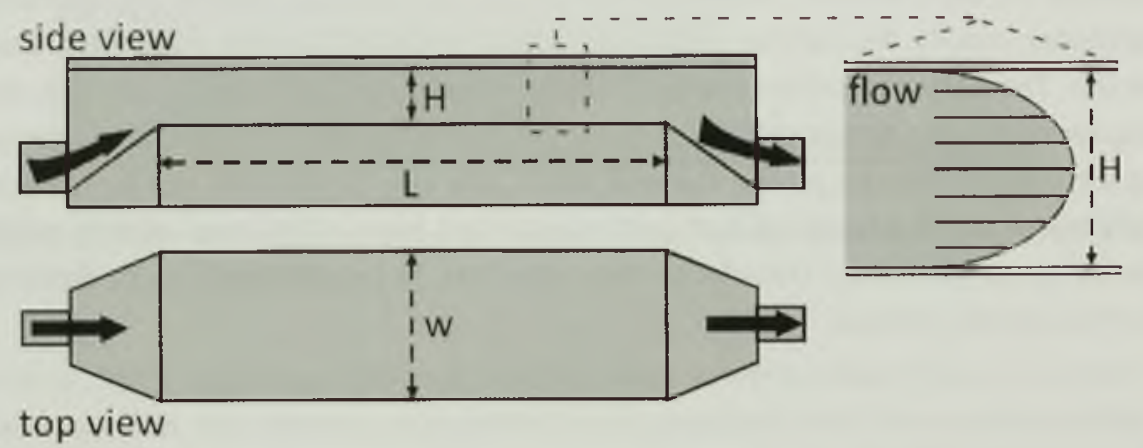

Figure 4. Example of a parallel-plate flow chamber setup to study adhesion-detachment of contrast agents or leukocytes.

\section{Biophysical aspects of particle settling}

The trajectory of a single freely circulating particle in the fluid stream is governed by the forces exerted by the fluid stream and gravitation. For dilute suspensions, Stokes' Law predicts the settling velocity $v_{s}[\mathrm{~nm} / \mathrm{s}]$ of a particle in a fluid, such as in water or blood, with viscosity $\eta$, by:

$v_{s}=\frac{g d^{2}\left(\rho_{\rho}-\rho_{f}\right)}{18 \eta}$

where $g$ is the gravitational acceleration $\left[\mathrm{m} / \mathrm{s}^{2}\right], d$ is the particle diameter, $\rho_{p}$ is the mass density of the particles $\left[\mathrm{kg} / \mathrm{m}^{3}\right]$, and $\rho_{f}$ is the mass density of the fluid $\left[\mathrm{kg} / \mathrm{m}^{3}\right]$. 
As shown in table 2 , the settling velocity for a particle in a flow chamber, filled with water $(\eta=1 \mathrm{mPa} / \mathrm{s})$, will be low for small particles or for a small difference in mass density as may be the case for blood cells suspended in blood plasma. In that case only a narrow layer along the wall may contribute to particle adhesion. The settling velocity increases sharply (quadratic relationship) for larger particles with a higher density, such as monocytes $\left(\rho=1058-1070 \mathrm{~kg} / \mathrm{m}^{3}\right.$ ) (Yang et al. 1999). On the other hand, large gas bubbles will easily converge at the top wall because they have a mass density $\left(1.3 \mathrm{~kg} / \mathrm{m}^{3}\right)$ that is almost a factor 1000 lower than that of water $(1000$ $\left.\mathrm{kg} / \mathrm{m}^{3}\right)$.

Table 2. Settling velocity $[\mathrm{nm} / \mathrm{s}]$ of a particle in stationary medium, e.g., water $\left[\rho=1000 \mathrm{~kg} / \mathrm{m}^{3}, \eta=1\right.$ $\mathrm{mPa} / \mathrm{s}$ ). Negative value is upward velocity.

\begin{tabular}{|c|c|c|c|c|c|c|c|c|c|}
\hline \multirow{2}{*}{$\begin{array}{l}\text { Particle } \\
\text { diameter } \\
{[\mu \mathrm{m}]}\end{array}$} & \multicolumn{9}{|c|}{ Particle density $\{\mathrm{kg} / \mathrm{m} 3\}$} \\
\hline & 900 & 925 & 950 & 975 & 1025 & 1050 & 1075 & 1100 & 1680 \\
\hline 0.01 & -0.0056 & -0.0042 & -0.0028 & -0.0014 & 0.0014 & 0.0028 & 0.0042 & 0.0056 & 0.0378 \\
\hline 0.02 & -0.0222 & -0.0167 & -0.0111 & -0.0056 & 0.0056 & 0.0111 & 0.0167 & 0.0222 & 0.1511 \\
\hline 0.05 & -0.1389 & -0.1042 & -0.0694 & -0.0347 & 0.0347 & 0.0694 & 0.1042 & 0.1389 & 0.9444 \\
\hline 0.1 & -0.5556 & -0.4167 & -0.2778 & -0.1389 & 0.1389 & 0.2778 & 0.4167 & 0.5556 & 3.7778 \\
\hline 0.2 & -2.2222 & -1.6667 & -1.1111 & -0.5556 & 0.5556 & 1.1111 & 1.6667 & 2.2222 & 15.1111 \\
\hline 0.5 & -13.89 & -10.42 & -6.94 & -3.47 & 3.47 & 6.94 & 10.42 & 13.89 & 94.44 \\
\hline 1 & -56 & -42 & -28 & -14 & 14 & 28 & 42 & 56 & 378 \\
\hline 2 & -222 & -167 & -111 & -56 & 56 & 111 & 167 & 222 & 1511 \\
\hline 5 & -1389 & -1042 & -694 & -347 & 347 & 694 & 1042 & 1389 & 9444 \\
\hline 6 & -2000 & -1500 & -1000 & -500 & 500 & 1000 & 1500 & 2000 & 13600 \\
\hline 7 & -2722 & -2042 & -1361 & -681 & 681 & 1361 & 2042 & 2722 & 18511 \\
\hline 8 & -3556 & -2667 & -1778 & -889 & 889 & 1778 & 2667 & 3556 & 24178 \\
\hline 9 & -4500 & -3375 & -2250 & -1125 & 1125 & 2250 & 3375 & 4500 & 30600 \\
\hline 10 & -5556 & -4167 & -2778 & -1389 & 1389 & 2778 & 4167 & 5556 & 37778 \\
\hline 12 & -8000 & -6000 & -4000 & -2000 & 2000 & 4000 & 6000 & 8000 & 54400 \\
\hline 15 & -12500 & -9375 & -6250 & -3125 & 3125 & 6250 & 9375 & 12500 & 85000 \\
\hline
\end{tabular}

A particle with diameter $d$ can approach the wall up to $d / 2$. If it is still free flowing at that position (without contact to the wall), then its velocity at that position is termed critical velocity $v_{c}$ and follows directly from the expression for a parabolic velocity distribution in a vessel with maximum velocity $v_{\max }$ and radius $R$ (Eq. 11):

$v_{c}=v_{\max }\left(1-\left(\frac{R-d / 2}{R}\right)^{2}\right)=\frac{v_{\max } d}{4 R}\left(4-\frac{d}{R}\right)$ 
Table 3 lists the critical velocity as function of particle diameter for a given vessel diameter of $0.4 \mathrm{~mm}$ and center stream velocity of $150 \mathrm{~mm} / \mathrm{s}$, which are representative of a common carotid artery of a mouse (Hartley et al. 2004).

Table 3. Critical velocity $[\mathrm{mm} / \mathrm{s}]$ of a particle in the common carotid artery $(d=0.4 \mathrm{~mm})$ of a mouse with average center stream velocity of $150 \mathrm{~mm} / \mathrm{s}$.

\begin{tabular}{ll|ll}
\hline $\begin{array}{l}\text { Particle } \\
\text { diameter }[\mu \mathrm{m}]\end{array}$ & $\begin{array}{l}\text { Critical velocity } \\
{[\mathrm{mm} / \mathrm{s}]}\end{array}$ & $\begin{array}{l}\text { Particle } \\
\text { diameter }[\mu \mathrm{m}]\end{array}$ & $\begin{array}{l}\text { Critical velocity } \\
{[\mathrm{mm} / \mathrm{s}]}\end{array}$ \\
\hline 0.01 & 0.0075 & 5 & 3.7266 \\
0.02 & 0.0150 & 6 & 4.4663 \\
0.05 & 0.0375 & 7 & 5.2041 \\
0.1 & 0.0750 & 8 & 5.9400 \\
0.2 & 0.1500 & 9 & 6.6741 \\
0.5 & 0.3748 & 10 & 7.4063 \\
1 & 0.7491 & 12 & 8.8650 \\
2 & 1.4962 & 15 & 11.0391 \\
\hline
\end{tabular}

The Stokes settling velocity, in combination with velocities close to the wall, is relevant to answer the question which particles may eventually make contact with the wall of a horizontally oriented vessel, or in other words: what region close to the wall is relevant for adhesion. To answer that question a time-varying distance of a particle to the wall (which follows from the settling velocity) is entered in the parabolic equation to find the path length $L$ of a particle along the stream lines before touches the wall. The relevant parameters are vessel radius $R$, difference in mass density $\Delta \rho$, maximum (center stream) flow velocity $v_{\max }$ viscosity $\eta$ and initial dis. tance to the wall $d_{0}$ :

$$
\begin{aligned}
& L=\frac{6 \eta v_{\text {max }}}{\Delta \rho R^{2} g d^{2}}\left(3 R^{2}\left(d_{0}-d / 2\right)-(R-d / 2)^{3}+\left(R-d_{0}\right)^{3}\right) \\
& L=\frac{6 \eta v_{\text {max }}}{\Delta \rho R^{2} g d^{2}}\left(3 R\left(d_{0}+d / 2\right)\left(d_{0}-d / 2\right)\right) \\
& L=\frac{9 \cdot \tau_{w} \cdot(n+1) \cdot n}{\Delta \rho \cdot g}
\end{aligned}
$$

The conversion from the first to the second line of the equation above results fron the assumption that the vessel radius $R$ (or flow chamber height) is much large than the particle size and the distance between particle position and the wall. Fo the conversion to the last line of the equation above, use is made of equation 1 and 13 for the wall shear stress in a vessel with a parabolic velocity profile. Scalin the free distance to the wall as a multiple $n$ of the particle diameter eliminates th diameter size from the equation. The final result indicates that the path length 
directly related to local wall shear stress and distance, and inversely related to particle size and difference in mass density. Table 4 lists the path lengths for particles as function of the initial free distance to the wall expressed in units of particle size. It follows that for the wall shear stress considered, the path lengths become excessively large as the initial distance to the wall increases from 1 diameter to 10 particle diameters. It indicates that in a straight vessel under stationary flow conditions (no mixing through whirling) only a very thin fluid layer close to the wall may contribute to adhesion.

Table 4. The path length of a particle at a distance of multiple $n$ of particle diameter from the wall in, for example, the common carotid artery $(d=0.4 \mathrm{~mm})$ of a mouse with an average center stream velocity of $150 \mathrm{~mm} / \mathrm{s}$, and a difference in mass density of $50 \mathrm{~kg} / \mathrm{m}^{3}$.

\begin{tabular}{llllll}
\hline $\begin{array}{l}\text { Wall shear } \\
\text { stress [Pa] }\end{array}$ & $\mathrm{n}=\mathbf{5}$ & $\mathrm{n}=\mathbf{2}$ & $\mathrm{n}=\mathbf{4}$ & $\mathrm{n}=\mathbf{8}$ & $\mathrm{n}=\mathbf{1 0}$ \\
\hline 0.01 & 0.4 & 1.1 & 3.6 & 13 & 19.8 \\
0.02 & 0.7 & 2.2 & 7.2 & 25.9 & 39.6 \\
0.05 & 1.8 & 5.4 & 18 & 64.8 & 99 \\
0.1 & 3.6 & 10.8 & 36 & 129.6 & 198 \\
0.2 & 7.2 & 21.6 & 72 & 259 & 396 \\
0.5 & 18 & 54 & 180 & 648 & 990 \\
1 & 36 & 108 & 360 & 1296 & 1980 \\
2 & 72 & 216 & 720 & 2592 & 3960 \\
5 & 180 & 540 & 1800 & 6480 & 9900 \\
10 & 360 & 1080 & 3600 & 12960 & 19800 \\
20 & 720 & 2160 & 7200 & 25920 & 39600
\end{tabular}

\section{Biophysical aspects of particle adhesion}

As stated in the previous section, a freely circulating particle (e.g., blood cell or contrast agent) may interact with the bottom or surface of a flow chamber or artery because of gravity in combination with prevailing flow patterns (e.g., in curves and bifurcations). At the surface, a particle undergoes free (no adhesion) rolling in the shear flow, due to hemodynamic forces and external torques acting on the particle, causing it to rotate (Zhao et al. 2001). Adhesion of a particle occurs either nonspecifically by means of van der Waals forces, electromagnetic and steric interactions, or specifically by means of ligand-receptor interactions, as shown in figure 5 (Decuzzi et al. 2005).

In case of specific adhesion, a freely rolling particle must first overcome surface protein electrostatic repulsive forces to bring the receptor and ligand pair into close 
proximity to achieve initial attachment. Secondly, the contact time between receptor and ligand must be long enough to allow at least one bond formation (Alon et al. 1995). This ligand-receptor bond exerts an adhesive force, which slows the velocity of a particle and increases the contact area, which again increases the number of receptors available for binding. This may lead to additional bond formation, resulting in an increased adhesive force (Chang and Hammer 1999; Hammer and Apte 1992; Munn et al. 1996). Due to the combination of hemodynamic forces and bonds dissociating at the back edge contact of the particle, a particle tumbles forward in the direction of the flow (Brunk and Hammer 1997). To prevent dislodging of a particle from the surface, the net adhesive force must balance the hemodynamic force and torque imposed by the shear flow (Alon et al. 1995; Brunk and Hammer 1997; Cozens-Roberts et al. 1990; Hammer and Lauffenburger 1987; Orsello et al. 2001; Saterbak and Lauffenburger 1996).

Adhesive forces are influenced by biological factors such as the receptor and ligand density on both particle and target surface, respectively, the type of ligand-receptor family, the rates of reaction between them and their affinity (multiple bond strength) and avidity (single bond strength) for each other. These biological factors determine the number of bonds formed during collision within the contact region close to the surface (Alon et al. 1995; Brunk and Hammer 1997; Cozens-Roberts et al. 1990; Decuzzi and Ferrari 2006; Hammer and Apte 1992; Hammer and Lauffenburger 1987; Orsello et al. 2001). The disruptive forces are influenced by physiological forces (e.g., wall shear stress) and particle properties (e.g., size, deformability and morphology) (Cozens-Roberts et al. 1990; Decuzzi and Ferrari 2006; Hammer and Apte 1992).

Because the force and torque exerted on the particle are proportional to the square and the cube of the particle diameter, respectively (Goldman et al. 1967), and the size of the contact area is a function of particle diameter (Cozens-Roberts et al. 1990), it appears that both disruptive and adhesive forces acting on the rolling and adhesion of particles are a function of the particle diameter (Chang and Hammer 1999; Decuzzi and Ferrari 2006; Hammer and Apte 1992; Hammer and Lauffenburger 1987; Shinde Patil et al. 2001). This is supported by an experimental model, showing that at low wall shear stress size hardly affects adhesion, but that at high shear stresses a small size favors attachment (Shinde Patil et al. 2001). With increasing diameter the shear stress required to set a particle in motion becomes lower (force equals stress times cross-section) and favors detachment. Since the moment exerted on a particle increases with diameter and the shear stress gradient across that particle, the tendency to roll and the rolling velocity also increase with greater diameter, impeding attachment. It should be kept in mind that the effective shear 
stress gradient across the particle will decrease with deformability, favoring attachment.
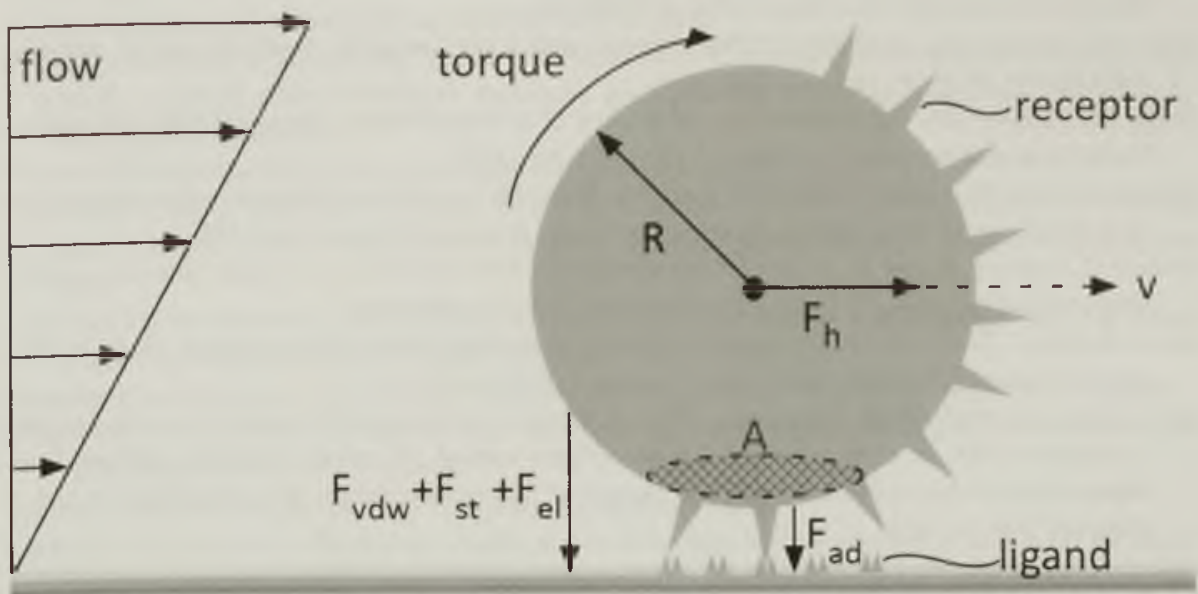

Figure 5. Schematic diagram of a particle adhering non-specifically by means of van der Waals forces ( $F v d w)$, electromagnetic ( $F e l)$ and steric (Fst) interactions, or specifically by means of ligand-receptor interactions. Shear flow induces a hemodynamic force $(F h)$ and external torque $(T)$ on a particle with a radius $\mathrm{R}$, causing it to rotate. In case of specific adhesion, a ligand-receptor bond exerts an adhesive stress, which slows the velocity $(\mathrm{V})$ of a particle and increases the contact area $(\mathrm{A})$, thereby increasing the number off receptors available for binding and promoting additional bond formation, resulting in an increased adhesive force (Fad). An adhered particle is in static equilibrium: its net adhesive force is in balance with the force and torque exerted by blood flow and gravitation.

The number of contrast agents adhering to the endothelium varies with the properties of the particles, like size, deformability, density and bioavailability. In addition, flow patterns and associated wall shear stress, density of adhesion molecules and binding strength play a role in attachment to the site of interaction. If only gravity would be involved in the migration of agents towards the wall, the relevant fluid layer would be rather thin. However, in straight arteries, large particles will migrate to areas with a low shear stress gradient, thereby pushing smaller particles towards the wall. In addition, swirling and vortices, especially in areas with recirculating flow, as in bifurcations and bends, will enhance the density of both small and larger contrast agents close to the wall. Smaller particles will more easily adhere to the wall than larger contrast agents under shear stress conditions but the echogenicity will be lower per particle, requiring a larger number of adhered particles to reach adequate echogenicity for ultrasound molecular imaging. 


\section{References}

Alon R, Hammer DA, Springer TA. Lifetime of the P-selectin-carbohydrate bond and its response to tensile force in hydrodynamic flow. Nature 1995;374:539-542.

Brunk DK, Hammer DA. Quantifying rolling adhesion with a cell-free assay: E-selectin and its carbohydrate ligands. Biophys 」 1997;72:2820-2833.

Chang KC, Hammer DA. The forward rate of binding of surface-tethered reactants: effect of relative motion between two surfaces. Biophys $\perp$ 1999;76:1280-1292

Couture O, Bevan PD, Cherin E, Cheung K, Burns PN, Foster FS. A model for reflectivity enhancement due to surface bound submicrometer particles. Ultrasound Med Biol 2006;32:1247-1255.

Couture $O$, Cherin E, Foster FS. Model for the ultrasound reflection from micro-beads and cells distributed in layers on a uniform surface. Phys Med Biol 2007;52:4189-4204.

Cozens-Roberts C, Quinn JA, Lauffenberger DA. Receptor-mediated adhesion phenomena. Model studies with the Radical-Flow Detachment Assay. Biophys J 1990;58:107-125.

Dai G, Kaazempur-Mofrad MR, Natarajan S, Zhang Y, Vaughn S, Blackman BR, Kamm RD, Garcia-Cardena G, Gimbrone MA, Jr. Distinct endothelial phenotypes evoked by arterial waveforms derived from atherosclerosis-susceptible and -resistant regions of human vasculature. Proc Natl Acad Sci U S A 2004;101:14871-14876.

Decuzzi P, Ferrari $M$. The adhesive strength of non-spherical particles mediated by specific interactions. Biomaterials 2006;27:5307-5314.

Decuzzi P, Lee S, Bhushan B, Ferrari M. A theoretical model for the margination of particles within blood vessels. Ann Biomed Eng 2005;33:179-190.

Duck FA. Physical Properties of Tissue: A Comprehensive Reference Book. London: Academic, 1990.

Goldman A, Cox RG, Brenner H. Slow viscous motion of a sphere parallel to a plane wall--Il Couette flow. Chemical Engineering Science 1967;22:653-660.

Goss SA, Johnston RL, Dunn F. Comprehensive compilation of empirical ultrasonic properties of mammalian tissues. J Acoust Soc Am 1978;64:423-457.

Hammer DA, Apte SM. Simulation of cell rolling and adhesion on surfaces in shear flow: general results and analysis of selectin-mediated neutrophil adhesion. Biophys J 1992;63:35-57.

Hammer DA, Lauffenburger DA. A dynamical model for receptor-mediated cell adhesion to surfaces. Biophys J 1987;52:475-487.

Hartley CJ, Reddy AK, Madala S, Entman ML, Michael LH, Taffet GE. Noninvasive ultrasonic measurement of arterial wall motion in mice. Am J Physiol Heart Circ Physiol 2004;287:H1426-1432.

Jung J, Lyczkowski RW, Panchal CB, Hassanein A. Multiphase hemodynamic simulation of pulsatile flow in a coronary artery. J Biomech 2006;39:2064-2073.

Lanza GM, Trousil RL, Wallace KD, Rose JH, Hall CS, Scott MJ, Miller JG, Eisenberg PR, Gaffney PJ, Wickline SA. In vitro characterization of a novel, tissue-targeted ultrasonic contrast system with acoustic microscopy. J Acoust Soc Am 1998;104:3665-3672.

Lawrence MB, McIntire LV, Eskin SG. Effect of flow on polymorphonuclear leukocyte/endothelial cell adhesion. Blood 1987; 70:1284-1290.

Marsh JN, Partlow KC, Abendschein DR, Scott MJ, Lanza GM, Wickline SA. Molecular imaging with targeted perfluorocarbon nanoparticles: quantification of the concentration dependence of contrast enhancement for binding to sparse cellular epitopes. Ultrasound Med Biol 2007;33:950-958.

Marshall BT, Long M, Piper JW, Yago T, McEver RP, Zhu C. Direct observation of catch bonds involving cell-adhesion molecules. Nature 2003;423:190-193.

Moran CM, Ross JA, Cunningham C, Butler M, Anderson T, Newby D, Fox KA, McDicken WN. Manufacture and acoustical characterisation of a high-frequency contrast agent for targeting applications. Ultrasound Med Biol 2006;32:421-428.

Munn LL, Melder RJ, Jain RK. Role of erythrocytes in leukocyte-endothelial interactions: mathematical model and experimental validation. Biophys J 1996;71:466-478. 
Nichols WM, O'Rourke MF. McDonald's blood flow in arteries. Theoretical, experimental and clinical principles. London: Hodder Arnold, 2005.

O'Brien WD, Jr. Ultrasound-biophysics mechanisms. Prog Biophys Mol Biol 2007;93:212-255.

Orsello CE, Lauffenburger DA, Hammer DA. Molecular properties in cell adhesion: a physical and engineering perspective. Trends Biotechnol 2001;19:310-316.

Patton JT, Menter DG, Benson DM, Nicolson GL, McIntire LV. Computerized analysis of tumor cells flowing in a parallel plate chamber to determine their adhesion stabilization lag time. Cell Motil Cytoskeleton 1993;26:88-98.

Pearson TC. Hemorheology in the erythrocytoses. Mt Sinai J Med 2001;68:182-191.

Reneman RS, Arts T, Hoeks AP. Wall Shear Stress - an Important Determinant of Endothelial Cell Function and Structure - in the Arterial System in vivo. Discrepancies with Theory. J Vasc Res 2006;43:251269.

Reneman RS, van Merode T, Hick P, Hoeks AP. Flow velocity patterns in and distensibility of the carotid artery bulb in subjects of various ages. Circulation 1985;71:500-509.

Saterbak A, Lauffenburger DA. Adhesion mediated by bonds in series. Biotechnol Prog 1996;12:682-699.

Shinde Patil VR, Campbell CJ, Yun YH, Slack SM, Goetz DJ. Particle diameter influences adhesion under flow. Biophys J 2001;80:1733-1743.

Stuart J, Kenny MW. Blood rheology. J Clin Pathol 1980;33:417-429.

Takalkar AM, Klibanov AL, Rychak JJ, Lindner JR, Ley K. Binding and detachment dynamics of microbubbles targeted to P-selectin under controlled shear flow. I Control Release 2004;96:473-482.

Weaver JP, Evans A, Walder DN. The effect of increased fibrinogen content on the viscosity of blood. Clin Sci 1969;36:1-10.

Yang J, Huang Y, Wang X, Wang XB, Becker FF, Gascoyne PR. Dielectric properties of human leukocyte subpopulations determined by electrorotation as a cell separation criterion. Biophys J 1999;76:33073314.

Zhao Y, Chien S, Weinbaum S. Dynamic contact forces on leukocyte microvilli and their penetration of the endothelial glycocalyx. Biophys J 2001;80:1124-1140. 


\section{CHAPTER 3}

\section{Critical appraisal of artificial targeted ultrasound contrast agents for molecular imaging in large arteries}

L.M. Kornmann ${ }^{1}$, K.D. Reesink ${ }^{1}$, R.S. Reneman ${ }^{2}$, A.P.G. Hoeks ${ }^{1}$ Departments of Biomedical Engineering ${ }^{1}$ and Physiology ${ }^{2}$, Cardiovascular Research Institute Maastricht (CARIM), Maastricht University, Maastricht, The Netherlands 


\begin{abstract}
Molecular imaging may provide new insights into the early detection and development of atherosclerosis before first symptoms occur. One of the techniques in use employs non-invasive ultrasound. In the past decade, experimental and clinical validation studies showed that for the microcirculation targeted ultrasound contrast agents, such as echogenic liposomes, microbubbles and perfluorocarbon emulsions, do improve visualization of specific structures. For large arteries, however, successful application is less obvious. In this review we will address the challenges for molecular imaging of large arteries. We will discuss the problems encountered in the use of targeted ultrasound contrast agents presently available, mainly based on data obtained in flow chambers and animal studies because clinical studies are lacking. We conclude that molecular imaging of activated endothelium in large and middle-sized arteries by site-specific accumulation of contrast material is still difficult to achieve due to wall shear stress conditions in these vessels.
\end{abstract}




\section{Introduction}

Atherosclerosis is a slowly progressing, multi-factorial inflammatory disease of large and middle-sized arteries, initiated by the activation and dysfunctioning of endothelial cells by mediators, such as hyperlipidemia and shear stress (Gimbrone et al. 2000; Lusis 2000; Ross 1999). Atherogenesis involves leukocyte recruitment, accumulation of lipids, foam cell formation in the intima, and changes in the extracellular matrix of arterial walls (Hansson 2005; Lusis 2000; Ross 1999). Atherosclerotic plaques preferentially develop in branch points or curves where blood flow is disturbed (Reneman et al. 1985), local wall shear stress is bidirectional and average wall shear stress is relatively low (Dai et al. 2004; Friedman et al. 1986; Zarins et al. 1983). One of the main biological processes in atherogenesis is related to the leukocyte adhesion cascade. Damaged or stimulated endothelial cells express proinflammatory adhesion molecules such as platelet (P)-selectin, endothelial (E)-selectin, and integrins such as vascular adhesion molecule-1 (VCAM-1) and intracellular adhesion molecule-1 (ICAM-1). The up-regulation of endothelial adhesion molecules subsequently mediates initial attachment, restrained rolling and firm adhesion of monocytes to the activated endothelium via the monocyte adhesion molecules P-selectin glycoprotein ligand-1 (PSGL-1), very late antigens-4 (VLA-4), macrophage antigen complex 1 (Mac-1) and lymphocyte function-associated antigen 1 (LFA-1) (Gerszten et al. 1998; Huo et al. 2000; Ley et al. 2007). One should realize that in the arterial system monocytes will only be able to come in close contact with the endothelial wall in areas of disturbed, recirculatory flow associated with low wall shear stress (Fig. 1). Both initial attachment and rolling, predominantly regulated by selectins and their respective carbohydrate ligands, are reversible adhesive processes: monocytes can detach and be released back into the blood stream (Springer 1994). Monocyte rolling is characterized by the speed with which selectin-ligand bonds form and dissociate (i.e., high on- and off-rates, respectively), and the rolling velocity, mediated by the shear forces present at the vessel wall (Alon et al. 1995; Marshall et al. 2003). For stable rolling of leukocytes a certain wall shear stress threshold should be reached (Lawrence et al. 1997; Ridger et al. 2008). During rolling, endothelium-bound chemokines have the opportunity to interact with specific chemokine receptors on the monocytes. The chemo-tactic activation of monocytes increases the a4-integrin affinity and avidity (clustering) for VCAM-1, resulting in monocyte arrest (Chan et al. 2001; Ley et al. 2007). During arrest, signaling via a4-integrins leads to cell spreading and increase of LFA-1 avidity. In turn, LFA-1 binding to ICAM-1 leads to down-regulation of a4-integrin mediated adhesion, which may facilitate monocyte migration through the endothelium into the subendothelial space (Chan et al. 2001; Ley et al. 2007).

In the intima, monocytes accumulate oxidized low density lipoproteines (LDL) and other lipids and transform into foam cells to form early plaques. These so-called 
fatty streaks, prevalent in young people, never cause symptoms. They may disappear or eventually progress into more advanced atherosclerotic plaques. Vulnerable plaques can rupture and induce thrombus formation, which eventually leads to symptoms like stroke, due to emboli shedding, or acute myocardial infarction, due to coronary artery occlusion (Hansson 2005).

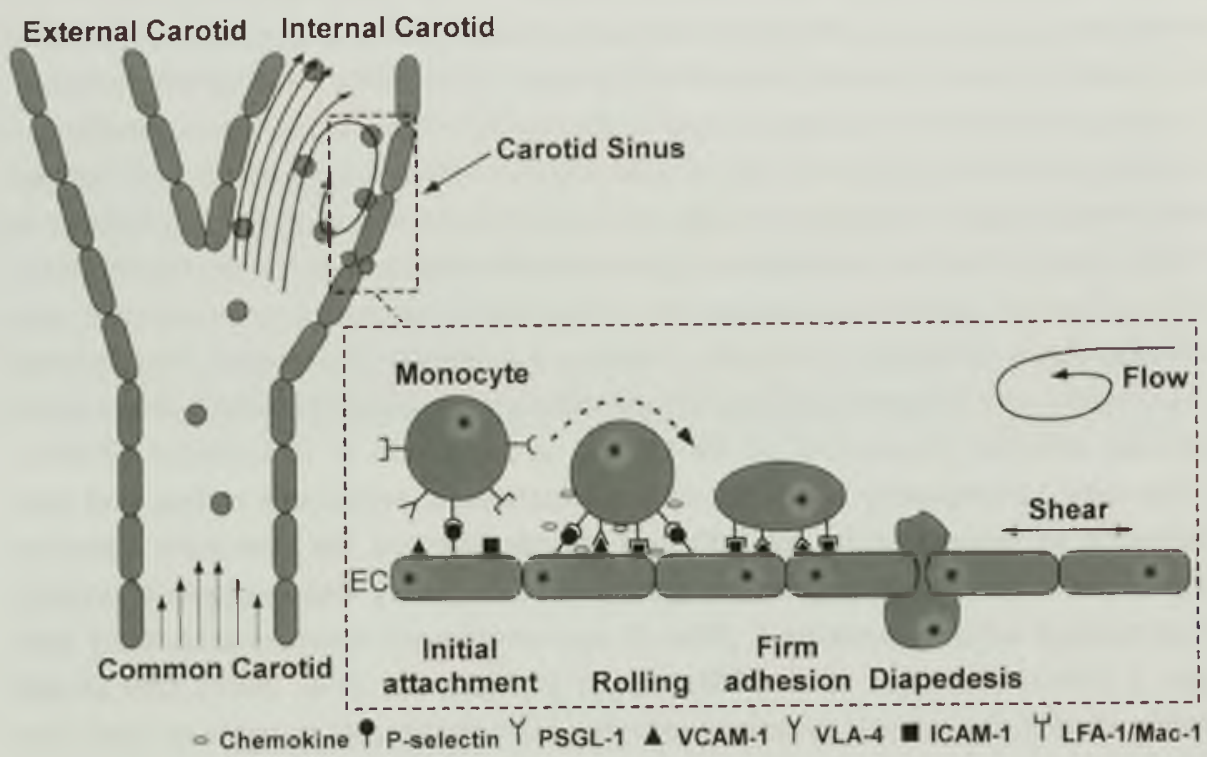

Figure 1. As an example the monocyte adhesion cascade within a low shear stress region (carotid sinus) of the carotid artery with the main steps illustrated in a separate panel. initial attachment and rolling are mainly mediated by the selectins; arrest (firm adhesion) is mediated by integrins. EC: Endothelial Cell.

Direct visualization of early atherosclerosis progression and prediction of the vulnerability of lesions is not yet possible with standard, non-invasive imaging techniques like MRI and ultrasound. Because the progression of atherosclerotic plaque development is accompanied by upregulation of adhesion molecules, the latter process may be detected by contrast agents with a high sensitivity and selectivity to atherosclerotic molecular targets. Targeted contrast agents can be tailored to make them suitable to be detected by specific imaging modalities. The selective imaging of a molecular target is known as molecular imaging, which may provide new insights into the development of atherosclerosis and facilitate early detection of the disease before the first symptoms occur.

Recent improvements in ultrasound imaging with targeted ultrasound contrast agents in the microcirculation (Barnard et al. 2008; Bruce et al. 2004; Chappell and 
Price 2006; Lindner et al. 2002; Rovai et al. 2000) have led to high expectations for molecular ultrasound imaging of activated endothelium of large and middle-sized arteries (Behm and Lindner 2006; Dayton and Rychak 2007; Lindner 2002; Lindner 2004; Rychak et al. 2007; Zhao et al. 2007). Below we will discuss the challenges this new approach is facing. We will provide an overview of the problems encountered in the use of targeted ultrasound contrast agents presently available for molecular imaging of large arteries. The evaluation is mainly based on flow chamber and animal studies, because of the lack of clinical studies in this area.

\section{Ultrasound contrast agents}

Historically, ultrasound contrast agents were conceived to assess tissue perfusion. The blood in small blood vessels, like arterioles and capillaries, cannot be visualized non-invasively, because the size of the vessels is typically below the resolution of transcutaneous ultrasound systems (in the order of 0.2-0.4 mm) (Shung et al. 1986). By injecting ultrasound contrast agents into the circulation the echo intensity level of the blood pool is increased due to the strongly deviating acoustic impedance of the contrast agent with respect to its environment. Enhancement of the signal originating from small vessels is the basis for imaging of vasa vasorum supplying atherosclerotic plaques with blood (Feinstein 2006), but also allows Doppler recordings in small vessels or at sites difficult accessible to ultrasound (Bokor 2000; Schwarz et al. 1994).
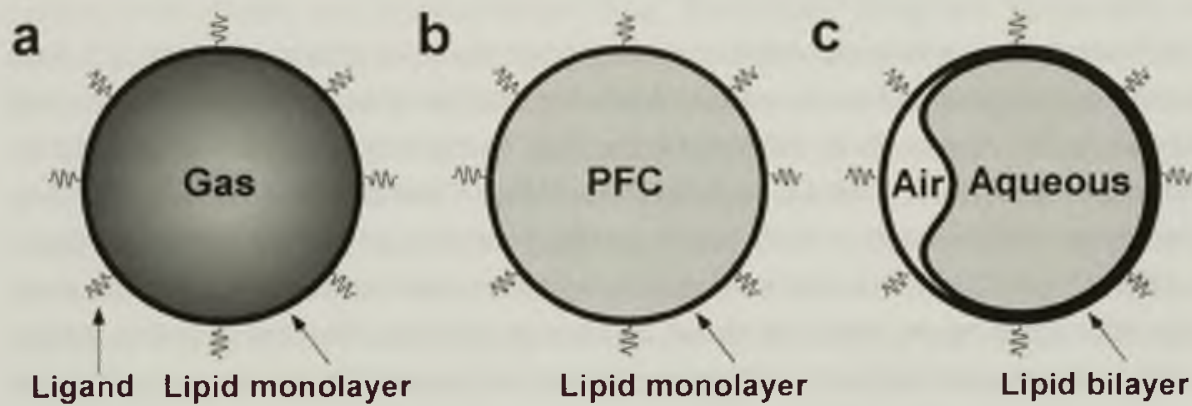

Lipid monolayer

Lipid bilayer

Figure 2. Schematic diagram of 3 different kinds of ultrasound contrast agents: (a) a gas-filled microbubble, (b) a nongaseous perfluorocarbon (PFC) emulsion, and (c) an echogenic liposome containing an aqueous medium and (possibly) air within the bilayer.

Acoustic blood-pool contrast agents were first described by Gramiak and Shah in 1968, who reported ultrasound contrast enhancement after administration of large air filled microbubbles (Gramiak and Shah 1968). Eventually, this has led to the 
design of ultrasound contrast agents targeted to specific molecular targets: perfluorocarbon nanoparticles (Alkan-Onyuksel et al. 1996; Lanza et al. 1997), echogenic liposomes (Alkan-Onyuksel et al. 1996; Demos et al. 1997) and microbubbles (Klibanov et al. 1997; Lindner et al. 2001; Villanueva et al. 1997) (Fig. 2).

\section{Microbubbles}

The first generation of microbubbles was produced by (manual) agitation of solutions, like saline, dextrose, hydrogen peroxide and even blood (Feigenbaum et al. 1970; Ophir and Parker 1989). These microbubbles lack persistence and are too large and too unstable to survive trans-pulmonary passage and. therefore, are not suitable for targeted molecular imaging (Raisinghani and DeMaria 2002). The new generations of microbubbles ( 1-8 $\mu \mathrm{m}$ in diameter) are filled with heavy-molecular weight gasses, like sulfur hexafluoride and perfluorocarbons, and are encapsulated by a layer of phospholipids, albumin or polymers, which make the shell either strong, flexible and stiff, respectively (Christiansen et al. 1994; Cohen et al. 1998; Narayan et al. 2001) (Fig. 2a). Microbubbles are highly echogenic due to their gas content, which creates a high acoustic impedance mismatch with surrounding fluids, and a resonant and highly non-linear behavior (de Jong et al. 2002). Even a single microbubble might be detectable with ultrasound, because of its size and its echogenic properties (Takalkar et al. 2004). Nowadays, several varieties of microbubbles (e.g., Levovist, Sonovue) are commercially available and are used in the clinic to assess tissue and tumor perfusion (Barnard et al. 2008; Rovai et al. 2000).

\section{Nongaseous perfluorocarbon nanoparticles}

Perfluorocarbon emulsions have originally been used as oxygen carriers and have become a main candidate for safe and reliable artificial blood substitute (Spahn and Kocian 2005). Lanza et al. developed the first ligand-targeted, lipid-encapsulated, nongaseous perfluorocarbon nanoparticles (Alkan-Onyuksel et al. 1996) (Fig. 2b). Compared to gas filled microbubbles, perfluorocarbon emulsions consist of liquid perfluorocarbon which is encapsulated by a lipid monolayer as surfactant. The average size of the nanoparticles is about $250 \mathrm{~nm}$ in diameter, thereby avoiding pulmonary entrapment. Perfluorocarbon emulsions are attractive as acoustic contrast agents, because of their favorable acoustic properties. Perfluorocarbon has a very low acoustic sound velocity $(-670 \mathrm{~m} / \mathrm{sec})$ and a high density $\left(-1700 \mathrm{~kg} / \mathrm{m}^{3}\right)$ compared to water and surrounding tissue $\left(-1540 \mathrm{~m} / \mathrm{sec}\right.$ and $1000 \mathrm{~kg} / \mathrm{m}^{3}$, respectively). The acoustic impedances of perfluorocarbon ranges from $\sim 0.9 \mathrm{MRayl}$ at $20^{\circ} \mathrm{C}$ to $\sim 0.8 \mathrm{MRayl}$ at $37^{\circ} \mathrm{C}$, which is considerably less than that of blood (1.5 MRayl) (Marsh et al. 2002b). When bound to the cell surface of tissues, these emulsions are de- 
tectable due tc accumulation and the local acoustic impedance mismatch (Lanza and Wickline 2003).

Perfluorocarbon nanoparticles are produced through emulsification techniques, like extrusion (Kornmann et al. 2008), sonication (Freire et al. 2005) and microfluidization (Alkan-Onyuksel et al. 1996; Couture et al. 2006a). These particles have a good resistance to pressure, atmospheric exposure, heat and shear forces. Therefore, they are not susceptible to destruction by incident acoustic pressure that normally cavitates or deforms microbubbles during ultrasonic imaging (Lanza and Wickline 2003). Furthermore, compared to microbubbles they have a long circulating half-live ( $\approx 1 \mathrm{~h}$ in dogs) (Lanza et al. 1997), but are less echogenic in blood (Lanza and Wickline 2003).

Generally, perfluorocarbons are biologically inert and do not pose a toxicological risk related to metabolic degradation (McGoron et al. 1994). Perfluorocarbon emulsions are cleared by phagocytosis through the reticulo-endothelial system and eventually eliminated via the lungs by expiration (Flaim 1994). The chemical inertness, high biocompatibility and excellent stability of perfluorocarbon emulsions have made them desirable agents for parenteral administration, for example, as blood substitutes (Flaim 1994).

\section{Liposomes}

Echogenic liposomes are submicron-sized vesicles (800-900 $\mathrm{nm}$ in diameter) (Pozharski et al. 2001). Compared to perfluorohexane emulsions (liquid perfluorocarbon, monolayer) and microbubbles (gas, monolayer) they are composed of aqueous fluid and a bilayer of phospholipids (Alkan-Onyuksel et al. 1996) (Fig. 2C). Their reflectivity is caused by either their multi-laminar structure (Alkan-Onyuksel et al. 1996; Hamilton et al. 2002a) or gas trapped inside the liposomes (Huang et al. 2002; Kheirolomoom et al. 2007; Smith et al. 2007; Suzuki et al. 2007). Several types of echogenic liposomes have been developed and their structure depends on the phospholipid-composition and the preparation method used, e.g., freezelyophilization, pressure freeze and reverse phase evaporation (Alkan-Onyuksel et al. 1996; Demos et al. 1999; Huang and MacDonald 2004; Kheirolomoom et al. 2007; Smith et al. 2007; Suzuki et al. 2007; Suzuki et al. 2008). Even with a diameter less than a micron, to avoid lung entrapment, echogenic liposomes encounter rapid clearance by the reticulo-endothelial system (Klegerman et al. 2007). Longevity may be increased by using polyethylene glycol coatings or by incorporating polymerized lipids (Laverman et al. 2000; Woodle et al. 1992). Echogenic liposomes are as sensitive to pressure variations and ultrasound irradiation as microbubbles (Huang and MacDonald 2004). 


\section{Targeted ultrasound contrast agents}

Targeting of a contrast agent to a specific site of interest can be either active or passive (non-specific, non-directed uptake of particles). Uptake by macrophages, where the degree of uptake might be indicative of the presence and density of macrophages in any tissue, is a way of passively targeting inflammatory sites (Lindner et al. 2000b). Active targeting needs a ligand such as antibodies (e.g., P-selectin antibody), peptides or carbohydrates (e.g., Sialyl Lewis ${ }^{x}$ ) that can be conjugated to different types of contrast agent surfaces and has a high sensitivity and specificity for its molecular target (Jaffer et al. 2007). Ligands can be attached either indirectly, via covalent (via reactive groups) (Villanueva et al. 1998) or non-covalent (via avidinbiotin interactions) binding (Lanza et al. 1996), or directly via surface absorption (Fig. 3) (Klibanov et al. 1999). Surface proteins, lipids or polymers, creating the shell, can serve as an anchor for these ligands.

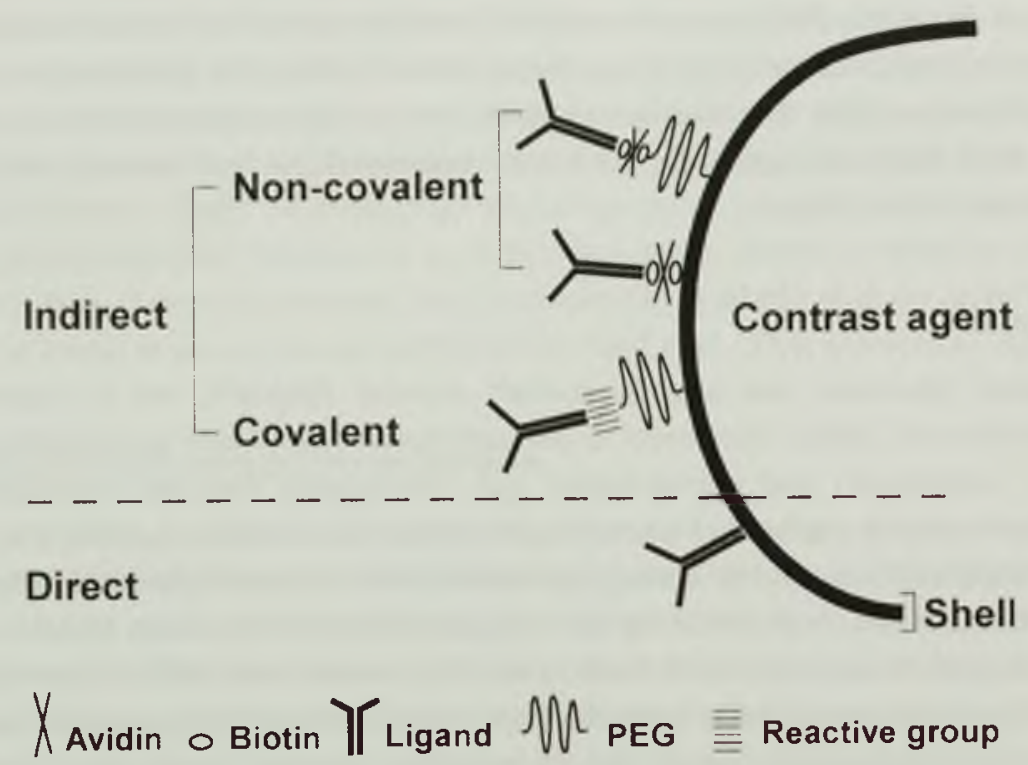

Figure 3. Methods for active targeting of ultrasound contrast agents. Shown are indirect, non-covalent (via avidin-biotin) and covalent (via reactive groups), and direct ways (via surface absorption) to attach target specific ligands (e.g., antibodies) to the contrast agent shell. A flexible polyethylene glycol spacer arm can be incorporated to extend the ligand arm and improve targetability

\section{Targeted microbubbles}

Microbubbles have been studied in vitro and in animal studies for targeting and imaging of disease markers involved in inflammation, myocardial ischemic cardiac disease and angiogenesis (Kaufmann et al. 2007; Klibanov et al. 2006; Rychak et al. 
2006b; Takalkar et al. 2004; Weller et al. 2005a; Weller et al. 2005b). The acoustic reflectivity of targeted microbubbles has extensively been studied in the microcirculation (cremaster muscle) (Lindner et al. 2001; Rychak et al. 2007; Rychak et al. $2006 \mathrm{~b}$ ) and to a lesser extent in the macrocirculation (femoral artery or thoracic aorta) of mice (Kaufmann et al. 2007; Klibanov et al. 2006).

\section{Targeted perfluorocarbon emulsions}

Perfluorocarbon emulsions have been targeted in vitro and in animals (carotid- and femoral artery of pigs and dogs) to tissue factor and fibrin (Alkan-Onyuksel et al. 1996; Lanza et al. 2000; Marsh et al. 1999). The first perfluorocarbon emulsions targeted involved a multi-step method, which is an indirect administration method consisting of first biotinylated antibodies, then avidin, and finally biotinylated perfluorocarbon emulsions (Lanza et al. 1996; Marsh et al. 1999). This indirect method revealed that, after administration of avidin, endogenous biotin competes with the injected biotinylated ligand for avidin binding sites and can only be superseded by an excess of avidin. Antibody conjugated perfluorocarbon emulsion have been used for direct site specific targeting (Lanza et al. 2000; Lanza and Wickline 2003; Marsh et al. 1999).

\section{Targeted echogenic liposomes}

Echogenic liposomes have been evaluated as imaging and drug delivery agents with conjugated antibodies to their surface (Alkan-Onyuksel et al. 1996; Demos et al. 1999; Hamilton et al. 2002b; Huang et al. 2002). Most targeting studies with echogenic liposomes were directed to molecular targets, such as fibrin, fibrinogen and tissue factor (Demos et al. 1998; Demos et al. 1997; Hamilton et al. 2002a; Hamilton et al. 2002b), and to a lesser extent to VCAM-1 and ICAM-1 (Demos et al. 1999; Hamilton et al. 2004). In animal studies, targeted echogenic liposomes were imaged in the macrocirculation (left ventricle and, femoral and, carotid artery) (Demos et al. 1999; Hamilton et al. 2002a; Hamilton et al. 2004).

\section{Targeting and imaging of ultrasound contrast agents in large arteries}

Targeted ultrasound contrast agents are designed to specifically and sensitively enhance the reflectivity of pathological tissue, which otherwise is difficult to distinguish from surrounding normal tissues with clinical imaging techniques. In vivo imaging with ultrasound contrast agents involves a complex interplay between bioavailability, sensitivity and selectivity to target sites, in relation to local wall shear stress on the one hand (Takalkar et al. 2004; Weller et al. 2005a) and the acoustic 
properties and eventual density of the contrast agent with implications for ultrasound reflectivity on the other hand (Couture et al. 2007; Dayton and Rychak 2007; Marsh et al. 2007).

\section{Ultrasound reflectivity: contrast agent density and size}

Reflectivity enhancement after binding is not only determined by the acoustical properties of their content (e.g., gas), but also by the number of adhered contrast particles (Couture et al. 2006b; Lanza et al. 1998) and by the diameter (crosssection) of the agents (de Jong et al. 1991). For particles with a diameter smaller than the wavelength of the ultrasound used, the echogenicity of an ultrasound contrast agent is proportional to the sixth power of the diameter (de Jong et al. 1991). Consequently, ultrasound is highly sensitive to large gas-filled microbubbles and less to the smaller perfluorocarbon emulsions and echogenic liposomes. Small (adherent) nanoparticles will therefore be missed by the imaging system. To gain similar reflectivity a large number of adhering particles is required. In vitro, it has been shown that with perfluorohexane emulsions the reflectivity from a surface can be enhanced by increasing the binding of these particles until saturation (at $-50 \%$ surface coverage) (Couture et al. 2006b).

\section{Bioavailability: size and shell properties}

After administration into the blood stream, the bioavailability of the contrast agents in blood is of importance for targeted imaging. To achieve a long circulation time (>30 minutes) suitable for targeted imaging, lung entrapment and uptake by the reticulo-endothelial system (e.g., monocytes and Kupfer cells) of the contrast agents have to be avoided. Longevity can be increased by adjusting the size, but also the shape and membrane components of ultrasound contrast agents. Small contrast agents with a diameter less than a micron, such as echogenic liposomes, can avoid lung entrapment, but still encounter rapid clearance by the reticulo-endothelial system (Klegerman et al. 2007). Incorporation of membrane components, such as polyethylene glycol or polymerized lipids, decreases uptake of contrast agents by the reticulo-endothelial system (Klibanov et al. 1990; Loughrey et al. 1993; Peng and Hsu 2001; Woodle et al. 1992).

\section{Shear stress}

As blood flows through an artery it induces friction of the blood cells and plasma with the endothelial cells that line the vessel wall. The force exerted on the endothelium per unit of area is defined as wall shear stress. Wall shear stress can be estimated as the product of wall shear rate and blood viscosity, wall shear rate be- 
ing defined as the radial derivative of blood flow velocity distribution at the wall (Reneman et al. 2006). Wall shear stress is sensed by the endothelial cells and has been shown to be an important determinant of endothelial cell function and intimal structure (Reneman et al. 2006).

Leukocyte adhesion occurs at sites with low average and oscillatory shear stress which are dominantly present in curvatures and at branch points, e.g., in the carotid artery opposite to the flow divider (Bharadvaj et al. 1982a; Bharadvaj et al. 1982b; Dai et al. 2004; Reneman et al. 1985; Rindt and Steenhoven 1996). In these recirculation zones, leukocytes come in contact with the vessel wall, creating conditions for interaction (Fig. 1). Shear stress also modulates leukocyte rolling speed on the endothelium: rolling speed increases with increasing shear stress (Alon et al. 1995; Marshall et al. 2003).

Similarly, shear stress modulates the transport, initial attachment, and rolling of ultrasound contrast agents. After binding to the endothelial wall, ultrasound contrast agents have to withstand the prevailing wall shear stress and should remain bound to the vessel wall sufficiently long to allow accumulation and imaging.

\section{Shear stress: contrast agent size and shell properties}

In laminar flow, large contrast agents (e.g., microbubbles) tend to migrate towards regions with relatively low shear stress gradients, i.e., the axis of the blood vessel, decreasing the concentration near the wall-Iumen interface (Ismail et al. 1996; Jayaweera et al. 1994; Lindner et al. 2002). This may be selectively counteracted by applying transcutaneously an acoustic radiation force, pushing ultrasound contrast agents towards their target (Crowder et al. 2005; Rychak et al. 2005; Rychak et al. 2007).

When contrast agents come in contact with the vessel wall, their properties, such as diameter and deformability, affect adhesion in relation to the wall shear stress level they are exposed to. At low wall shear stress, size hardly affects adhesion, but at high shear stresses a small size favors attachment. With increasing diameter the shear stress required to set a particle in motion becomes lower (force equals stress times cross-section) and favors detachment. Since the moment exerted on a particle increases with diameter and the shear stress gradient across that particle, the tendency to roll and the rolling velocity also increase, impeding attachment (Shinde Patil et al. 2001).

Ultrasound contrast agents are normally very stiff and not deformable, and therefore have a limited contact area and remain subjected to a large shear stress gradi- 
ent across the particle, impeding adhesion. One targeting study with wrinkled microbubbles demonstrated that, under low shear stress conditions (max. $0.14 \mathrm{~Pa}$ ), these microbubbles exhibited more adhesion, compared to the standard, round and stiffer microbubbles, both in vitro and in vivo (Rychak et al. 2006b).

\section{Contrast agent adhesion under shear stress}

The adhesion behavior of ultrasound contrast agents in relation to different wall shear stress conditions has been studied in vitro and in animals extensively for microbubbles (Demos et al. 1998; Kaufmann et al. 2007; Klibanov et al. 1998; Klibanov et al. 2006; Rychak et al. 2005; Rychak et al. 2006a; Rychak et al. 2006b; Takalkar et al. 2004; Villanueva et al. 1998; Weller et al. 2002), and to a lesser extent for echogenic liposomes (Demos et al. 1998; Hamilton et al. 2002b) and targeted perfluorocarbon emulsions (Hall et al. 2000; Lanza et al. 1996; Marsh et al. 1999). The latter studies were mainly focused on acoustic reflectivity enhancement rather than on the targeting mechanism itself, e.g., on wall shear stress vs. size, deformability and ligand density (Alkan-Onyuksel et al. 1996; Huang et al. 2002; Lanza et al. 1997; Marsh et al. 2002b).

The ability of a contrast agent to attach to and detach from the target of interest was studied in flow chambers (Demos et al. 1998; Hamilton et al. 2002b; Kaufmann et al. 2007; Klibanov et al. 2006; Rychak et al. 2006a; Takalkar et al. 2004) and in (occluded) arteries of animals (Hamilton et al. 2004; Kaufmann et al. 2007; Klibanov et al. 2006; Lanza et al. 1996; Lindner et al. 2001; Rychak et al. 2006b). In detachment studies, contrast agents were first statically adhered under zero flow conditions and then exposed to shear stresses. In vitro attachment studies were mainly performed under steady state (no acceleration/deceleration) flow conditions. The rate of attachment and detachment was related to different parameters, such as flow velocity (Hall et al. 2000; Klibanov et al. 1998; Marsh et al. 2002a), (critical) shear rate (Rychak et al. 2005; Villanueva et al. 1998; Villanueva et al. 1997; Weller et al. 2002; Weller et al. 2005a), and shear stress (Demos et al. 1998; Hamilton et al. 2002b; Kaufmann et al. 2007; Klibanov et al. 2006; Rychak et al. 2006a; Rychak et al. 2006b; Takalkar et al. 2004). However, of those parameters only shear stress actually reflects the stresses the microbubbles are exposed to. Flow velocity and shear rate eventually convert to shear stress if vessel diameter and fluid viscosity are known.

Detachment studies, with microbubbles in flow chambers, showed that attachment of targeted microbubbles to a receptor coated surface is firm after static incubation. Once attached to the target, microbubbles can withstand wall shear stresses up to $16 \mathrm{~Pa}$, but retention reduced already to $50 \%$ at $3.4 \mathrm{~Pa}$ (Takalkar et al. 2004). Most 
adhesion studies with microbubbles showed that targeted microbubbles are able to adhere under steady state, but low shear stress conditions and that the adhesion rate decreases with increasing shear stress (Kaufmann et al. 2007; Klibanov et al. 2006; Rychak et al. 2005; Rychak et al. 2006a; Rychak et al. 2006b; Takalkar et al. 2004; Weller et al. 2002). More specifically, these studies showed that adhesion was only achieved by a low number of microbubbles (max. $10 \%$ of total microbubble $\mathrm{flux}$ ) at shear stresses ranging from 0.02-0.5 $\mathrm{Pa}$ ( $\max$. adhesion at $-0.07 \mathrm{~Pa}$ ), which is far below the normal mean value of $1.2 \mathrm{~Pa}$ in the human common carotid artery (Reneman et al. 2006; Samijo et al. 1998). Only one of these studies showed in vitro the ability of microbubbles to adhere firmly at higher shear stresses of 0.8 and 1.2 $\mathrm{Pa}$ under pulsatile shear stress conditions (5-second pauses of $<0.05 \mathrm{~Pa}$ ), but the number of adhering particles was quite low (Kaufmann et al. 2007).

Studies with liposomes (smaller size than microbubbles) show a different picture. In one detachment study, liposomes, which were first adhered to fibrin coated disks and then placed in a flow chamber, showed detachment at wall shear stresses beyond $1.5 \mathrm{~Pa}$, with $70 \%$ retention at $1.5 \mathrm{~Pa}$. Moreover, this study also showed that pulsatile flow resulted in only a slight reduction of binding (Demos et al. 1998). A steady state adhesion study in a flow chamber, with echogenic liposomes targeted to fibrin, showed adhesion at a shear stress level of $1.5 \mathrm{~Pa}$. Targeting of these liposomes was mainly effective due to multiple passes over the target and nonspecific binding of the liposomes to each other (Hamilton et al. 2002b).

\section{Contrast agent-receptor binding kinetics}

As stated above, shear stress modulates the transport, initial attachment, and rolling of ultrasound contrast agents. In the few seconds that they do make contact with the endothelium, the receptor-ligand pair involved in initial attachment must react quickly. To realize this, they must have a high affinity for their counterreceptor and a rapid on- and a slow off-rate during rolling.

Monoclonal antibodies, such as anti-P-selectin, are often chosen as a targeting ligand on the surface of contrast agents because of their high affinity for P-selectin. Anti-P-selectin monoclonal antibody coated microbubbles show a low capture efficiency and a low (max. $5 \%$ of total microbubble flux), but firm adhesion under both static and steady state low shear conditions (Klibanov et al. 2006; Rychak et al. 2006a; Takalkar et al. 2004; Weller et al. 2002). Adhesion of these microbubbles at higher, more physiological shear stresses $(>0.5 \mathrm{~Pa})$ has not been studied so far. Compared to anti-P-selectin monoclonal antibody coated microbubbles, microbubbles coated with Sialyl Lewis ${ }^{x}$ (isolated carbohydrate structures) (Klibanov et al. 2006) and glycosulfopeptide (derived from PSGL-1) (Rychak et al. 2006a) exhibit a 
more rapid (high capture efficiency) and stronger (max. $10 \%$ of microbubble flux) adhesion to P-selectin.

In vivo, monocyte arrest is realized through chemotactic activation of monocytes, which increases integrin affinity and avidity (clustering) for VCAM-1 (Chan et al. 2001; Ley et al. 2007). This step cannot be realized with artificial contrast agents and, therefore, such agents require ligands with a high affinity for VCAM-1 and ICAM-1. Monoclonal antibodies against VCAM-1 and ICAM-1 are the only type of ligands that have been studied for in vitro and in vivo contrast agent targeting (Demos et al. 1999; Hamilton et al. 2004; Kaufmann et al. 2007; Villanueva et al. 1998; Weller et al. 2002; Weller et al. 2005a). In vitro targeting studies, with only these antibodies on the microbubble surface, demonstrate adhesion under static (Lankford et al. 2006), and low and pulsatile shear stress conditions (Kaufmann et al. 2007). However, considering the low adhesion efficiency of anti VCAM-1 coated microbubbles demonstrated in vitro, it remains unclear how these microbubbles are able to attach in sufficiently high density to the aortic arch of mice (Kaufmann et al. 2007) during considerably high mean (8.8 Pa (Greve et al. 2006)) and even higher peak shear stresses. In vitro and animal studies demonstrated that anti-P-selectin ligands or incorporation of multiple types of ligands (e.g., directed to both P-selectin and ICAM-1) is needed to achieve reduced rolling and increased firm attachment of microbubbles to the target site (Dayton and Rychak 2007; Eniola et al. 2003; Rychak et al. 2006a; Weller et al. 2005a; Wickline et al. 2007). Moreover, in vitro and animal studies showed that the adhesion rate of targeted contrast agents increases with increasing ligand surface density (Klibanov et al. 1997; Klibanov et al. 1998; Klibanov et al. 2006; Rychak et al. 2006b; Takalkar et al. 2004; Weller et al. 2002; Weller et al. 2005a) and target molecule density (Kaufmann et al. 2007; Weller et al. 2005a).

\section{Current state of the art}

In summary, various studies, both in vitro and in vivo, have shown that sufficient adhesion of ultrasound contrast agents to the endothelium in large arteries under physiological conditions is difficult to achieve. Most detachment studies with contrast agents were performed after static incubation, and those studying attachment of contrast agents were performed under low shear stress conditions. In animal models, contrast agents showed a short circulation time, because they were large, stiff and did not contain suitable shell membrane components. In vitro, stiff-shelled agents exhibited low capture and weak firm adhesion efficiency at low shear stresses. Changing to deformable agents, to multiple contrast agent surface ligands, or to pulsatile flow improved adhesion, but the improvements were still limited. 
In small rodents the adherence requirements for ultrasound contrast agents are even more demanding, since wall shear stress is substantially higher in small animals than in humans (Cheng et al. 2007; Greve et al. 2006; Reneman et al. 2006).

\section{Alternative approaches}

Considering the difficulties encountered with artificial contrast agents, a possible alternative for targeted artificial contrast agents may be provided by circulatory cells, like leukocytes. Leukocytes are naturally equipped to adhere selectively to activated endothelium and to resist physiological shear stresses in large- and middle-sized arteries. During early plaque development they roll in and adhere to inflammatory regions, especially in hemodynamically favorable areas (recirculation combined with low shear stress), where adhesion molecules like ICAM-1, P-selectin and VCAM-1 are upregulated at the endothelial cell surface. Furthermore, leukocytes are able to deform when they are exposed to high shear stress conditions, which is shown, with microbubbles, to enhance adhesion rate experimentally (Rychak et al. 2006b). Leukocytes can contribute to targeted molecular imaging by serving as a vehicle after labeling the activated cells with ultrasound contrast agents (Christiansen et al. 1994; Kornmann et al. 2008; Lindner 2001; Lindner et al. 2000a; Lindner et al. 2000b). Leukocytes are known to take up pathogens and foreign material, such as perfluorocarbon emulsions (Smith et al. 1994) and microbubbles (Lindner et al. 2000b).

Indeed, studies have confirmed enhanced echogenicity of leukocytes after uptake of echogenic material (Kornmann et al. 2008; Lindner 2001). Furthermore, in vitro perfluorohexane loaded macrophages maintain their functional adhesive properties under stationary, no shear conditions. In this light, leukocytes may have increased potential to be used as a targeted ultrasound contrast agent (Kornmann et al. 2008), but their usefulness as such an agent has still to be studied in an animal model of arterial inflammation, under physiological shear stress conditions. A complicating factor might be the larger size and loss of deformability of leukocytes loaded with echogenic material, which may have consequences for the blood flow at the microcirculatory level and may lead to increased sensitivity to shear stress. Moreover, this approach may not easily be translated into clinical routine, because ex-vivo isolation and labeling of blood leukocytes can be cumbersome and time consuming. However, for several years ex-vivo radio-labeled leukocytes are used clinically for scintigraphic imaging of inflammatory and infectious processes in humans (Basu et al. 2009; Van Hemert et al. 2009). Alternatively one might consider imaging of vasa vasorum by means of ultrasound contrast agents to identify the atherosclerotic plaque at risk (Vicenzini et al. 2007). Such studies are of importance, because it is 
still incompletely understood whether enhanced vascularization of the plaque contributes to its instability.

\section{Conclusion}

The past decade has provided many insights into targeting of ultrasound contrast agents. Despite high expectations, targeting with ultrasound contrast agents of atherosclerosis in large human arteries is still difficult to achieve. Targeting to activated endothelium at atherosclerosis prone sites (at branch points and in bends) requires ultrasound contrast agents that are able to attach, roll and finally firmly adhere to the wall during oscillating shear stress to achieve sufficient accumulation and ultrasound imaging enhancement. Notably, the adherence requirements for ultrasound contrast agents in small rodents are even more severe since wall shear stress is substantially higher in small animals than in humans (Cheng et al. 2007; Greve et al. 2006; Reneman et al. 2006).

Still, ultrasound is a promising modality for non-invasive imaging of the activated endothelium, therefore, new strategies for ultrasound molecular imaging of arterial walls under physiological shear stress conditions need to be developed.

An important aim for future studies should be the development of ultrasound contrast agents with adhesive properties similar to those of leukocytes, which naturally and selectively adhere to atherosclerosis prone sites.

\section{Acknowledgement}

This study was supported by CTMM grant BSIK03033 (SenterNovem, Ministry of Economic Affairs, the Netherlands). 


\section{References}

Alkan-Onyuksel H, Demos SM, Lanza GM, Vonesh MJ, Klegerman ME, Kane BJ, Kuszak J, McPherson DD. Development of inherently echogenic liposomes as an ultrasonic contrast agent. J Pharm Sci $1996 ; 85: 486-490$.

Alon R, Hammer DA, Springer TA. Lifetime of the P-selectin-carbohydrate bond and its response to tensile force in hydrodynamic flow. Nature 1995;374:539-542.

Barnard S, Leen E, Cooke T, Angerson W. A contrast-enhanced ultrasound study of benign and malignant breast tissue. S Afr Med J 2008;98:386-391.

Basu S, Zhuang H, Torigian DA, Rosenbaum J, Chen W, Alavi A. Functional imaging of inflammatory diseases using nuclear medicine techniques. Semin Nucl Med 2009;39:124-145

Behm CZ, Lindner JR. Cellular and molecular imaging with targeted contrast ultrasound. Ultrasound $Q$ 2006;22:67-72.

Bharadvaj BK, Mabon RF, Giddens DP. Steady flow in a model of the human carotid bifurcation. Part 1-flow visualization. J Biomech 1982a;15:349-362.

Bharadvaj BK, Mabon RF, Giddens DP. Steady flow in a model of the human carotid bifurcation. Part II-laser-Doppler anemometer measurements. J Biomech 1982b;15:363-378.

Bokor D. Diagnostic efficacy of SonoVue. Am J Cardiol 2000;86:19G-24G.

Bruce M, Averkiou M, Tiemann K, Lohmaier S, Powers J, Beach K. Vascular flow and perfusion imaging with ultrasound contrast agents. Ultrasound Med Biol 2004;30:735-743.

Chan JR, Hyduk SJ, Cybulsky MI. Chemoattractants induce a rapid and transient upregulation of monocyte alpha4 integrin affinity for vascular cell adhesion molecule 1 which mediates arrest: an early step in the process of emigration. J Exp Med 2001;193:1149-1158.

Chappell JC, Price RJ. Targeted therapeutic applications of acoustically active microspheres in the microcirculation. Microcirculation 2006;13:57-70.

Cheng C, Helderman F, Tempel D, Segers D, Hierck B, Poelmann R, van Tol A, Duncker DJ, Robbers-Visser D, Ursem NT, van Haperen R, Wentzel JJ, Gijsen F, van der Steen AF, de Crom R, Krams R. Large variations in absolute wall shear stress levels within one species and between species. Atherosclerosis 2007;195:225-235.

Christiansen C, Kryvi H, Sontum PC, Skotland T. Physical and biochemical characterization of Albunex, a new ultrasound contrast agent consisting of air-filled albumin microspheres suspended in a solution of human albumin. Biotechnol Appl Biochem 1994;19 (Pt 3):307-320.

Cohen JL, Cheirif J, Segar DS, Gillam LD, Gottdiener JS, Hausnerova E, Bruns DE. Improved left ventricular endocardial border delineation and opacification with OPTISON (FS069), a new echocardiographic contrast agent. Results of a phase III Multicenter Trial. J Am Coll Cardiol 1998;32:746-752.

Couture O, Bevan PD, Cherin E, Cheung K, Burns PN, Foster FS. Investigating perfluorohexane particles with high-frequency ultrasound. Ultrasound Med Biol 2006a;32:73-82.

Couture O, Bevan PD, Cherin E, Cheung K, Burns PN, Foster FS. A model for reflectivity enhancement due to surface bound submicrometer particles. Ultrasound Med Biol 2006b;32:1247-1255.

Couture O, Cherin E, Foster FS. Model for the ultrasound reflection from micro-beads and cells distributed in layers on a uniform surface. Phys Med Biol 2007;52:4189-4204.

Crowder KC, Hughes MS, Marsh JN, Barbieri AM, Fuhrhop RW, Lanza GM, Wickline SA. Sonic activation of molecularly-targeted nanoparticles accelerates transmembrane lipid delivery to cancer cells through contact-mediated mechanisms: implications for enhanced local drug delivery. Ultrasound Med Biol 2005;31:1693-1700.

Dai G, Kaazempur-Mofrad MR, Natarajan S, Zhang Y, Vaughn S, Blackman BR, Kamm RD, Garcia-Cardena G, Gimbrone MA, Jr. Distinct endothelial phenotypes evoked by arterial waveforms derived from atherosclerosis-susceptible and -resistant regions of human vasculature. Proc Natl Acad Sci U S A 2004;101:14871-14876.

Dayton PA, Rychak JJ. Molecular ultrasound imaging using microbubble contrast agents. Front Biosci 2007; 12:5124-5142. 
de Jong N, Bouakaz A, Frinking P. Basic acoustic properties of microbubbles. Echocardiography 2002;19:229-240.

de Jong N, Ten Cate FJ, Lancee CT, Roelandt JR, Bom N. Principles and recent developments in uitrasound contrast agents. Ultrasonics 1991;29:324-330.

Demos SM, Alkan-Onyuksel H, Kane BJ, Ramani K, Nagaraj A, Greene R, Klegerman M, McPherson DD. In vivo targeting of acoustically reflective liposomes for intravascular and transvascular ultrasonic enhancement. J Am Coll Cardiol 1999;33:867-875

Demos SM, Dagar S, Klegerman M, Nagaraj A, McPherson DD, Onyuksel H. In vitro targeting of acoustically reflective immunoliposomes to fibrin under various flow conditions. J Drug Target 1998;5:507-518.

Demos SM, Onyuksel H, Gilbert J, Roth SI, Kane B, Jungblut P, Pinto JV, McPherson DD, Klegerman ME. In vitro targeting of antibody-conjugated echogenic liposomes for site-specific ultrasonic image enhancement. J Pharm Sci 1997;86:167-171.

Eniola AO, Willcox PJ, Hammer DA. Interplay between rolling and firm adhesion elucidated with a cellfree system engineered with two distinct receptor-ligand pairs. Biophys $J$ 2003;85:2720-2731.

Feigenbaum H, Stone JM, Lee DA, Nasser WK, Chang S. Identification of ultrasound echoes from the left ventricle by use of intracardiac injections of indocyanine green. Circulation 1970;41:615-621.

Feinstein SB. Contrast ultrasound imaging of the carotid artery vasa vasorum and atherosclerotic plaque neovascularization. J Am Coll Cardiol 2006;48:236-243.

Flaim SF. Pharmacokinetics and side effects of perfluorocarbon-based blood substitutes. Artif Cells Blood Substit Immobil Biotechnol 1994;22:1043-1054.

Freire MG, Dias AM, Coelho MA, Coutinho JA, Marrucho IM. Aging mechanisms of perfluorocarbon emulsions using image analysis. J Colloid Interface Sci 2005;286:224-232.

Friedman MH, Deters OJ, Bargeron CB, Hutchins GM, Mark FF. Shear-dependent thickening of the human arterial intima. Atherosclerosis 1986;60:161-171.

Gerszten RE, Lim YC, Ding HT, Snapp K, Kansas G, Dichek DA, Cabanas C, Sanchez-Madrid F, Gimbrone MA, Jr., Rosenzweig A, Luscinskas FW. Adhesion of monocytes to vascular cell adhesion molecule-1transduced human endothelial cells: implications for atherogenesis. Circ Res 1998;82:871-878.

Gimbrone MA, Jr., Topper JN, Nagel T, Anderson KR, Garcia-Cardena G. Endothelial dysfunction, hemodynamic forces, and atherogenesis. Ann N Y Acad Sci 2000;902:230-239; discussion 239-240.

Gramiak R, Shah PM. Echocardiography of the aortic root. Invest Radiol 1968;3:356-366.

Greve JM, Les AS, Tang BT, Draney Blomme MT, Wilson NM, Dalman RL, Pelc NJ, Taylor CA. Allometric scaling of wall shear stress from mice to humans: quantification using cine phase-contrast MRI and computational fluid dynamics. Am J Physiol Heart Circ Physiol 2006;291:H1700-1708

Hall CS, Marsh JN, Scott MJ, Gaffney PJ, Wickline SA, Lanza GM. Time evolution of enhanced ultrasonic reflection using a fibrin-targeted nanoparticulate contrast agent. J Acoust Soc Am 2000;108:30493057.

Hamilton A, Huang SL, Warnick D, Stein A, Rabbat M, Madhav T, Kane B, Nagaraj A, Klegerman M, MacDonald $R$, McPherson $D$. Left ventricular thrombus enhancement after intravenous injection of echogenic immunoliposomes: studies in a new experimental model. Circulation 2002a;105:27722778.

Hamilton A, Rabbat M, Jain P, Belkind N, Huang SL, Nagaraj A, Klegerman M, Macdonald R, McPherson $D D$. A physiologic flow chamber model to define intravascular ultrasound enhancement of fibrin using echogenic liposomes. Invest Radiol 2002b;37:215-221.

Hamilton A, Huang SL, Warnick D, Rabbat M, Kane B, Nagaraj A, Klegerman M, McPherson DD. Intravascular ultrasound molecular imaging of atheroma components in vivo. J Am Coll Cardiol 2004;43:453-460.

Hansson GK. Inflammation, atherosclerosis, and coronary artery disease. N Engl I Med 2005;352:16851695. 
Huang SL, Hamilton AJ, Pozharski E, Nagaraj A, Klegerman ME, McPherson DD, MacDonald RC. Physical correlates of the ultrasonic reflectivity of lipid dispersions suitable as diagnostic contrast agents. Uitrasound Med Biol 2002;28:339-348.

Huang SL, MacDonald RC. Acoustically active liposomes for drug encapsulation and ultrasound-triggered release. Biochim Biophys Acta 2004;1665:134-141.

Huo Y, Hafezi-Moghadam A, Ley K. Role of vascular cell adhesion molecule-1 and fibronectin connecting segment-1 in monocyte rolling and adhesion on early atherosclerotic lesions. Circ Res 2000;87:153159 .

Ismail S, Jayaweera AR, Camarano G, Gimple LW, Powers ER, Kaul S. Relation between air-filled albumin microbubble and red blood cell rheology in the human myocardium. Influence of echocardiographic systems and chest wall attenuation. Circulation 1996;94:445-451.

Jaffer FA, Libby P. Weissleder R. Molecular imaging of cardiovascular disease. Circulation 2007;116:10521061.

Jayaweera AR, Edwards N, Glasheen WP, Villanueva FS, Abbott RD, Kaul S. In vivo myocardial kinetics of air-filled albumin microbubbles during myocardial contrast echocardiography. Comparison with radiolabeled red blood cells. Circ Res 1994;74:1157-1165.

Kaufmann BA, Sanders JM, Davis C, Xie A, Aldred P, Sarembock IJ, Lindner JR. Molecular imaging of inflammation in atherosclerosis with targeted ultrasound detection of vascular cell adhesion molecule-1. Circulation 2007;116:276-284.

Kheirolomoom A, Dayton PA, Lum AF, Little E, Paoli EE, Zheng H, Ferrara KW. Acoustically-active microbubbles conjugated to liposomes: characterization of a proposed drug delivery vehicle. Control Release 2007;118:275-284.

Klegerman ME, Huang S, Parikh D, Martinez J, Demos SM, Onyuksel HA, McPherson DD. Lipid contribution to the affinity of antigen association with specific antibodies conjugated to liposomes. Biochim Biophys Acta 2007;1768:1703-1716.

Klibanov AL, Hughes MS, Marsh JN, Hall CS, Miller JG, Wible JH, Brandenburger GH. Targeting of ultrasound contrast materiai. An in vitro feasibility study. Acta Radiol Suppl 1997;412:113-120

Klibanov AL, Hughes MS, Villanueva FS, Jankowski R, Wagner WR, Wojdyla JK, Wible JH, Brandenburger $\mathrm{GH}$. Targeting and ultrasound imaging of microbubble-based contrast agents. Magma 1999;8:177184.

Klibanov AL, Hughes MS, Wojdyla JK, Marsh JN, Hall CS, Miller JG, Wible JH, Jr., Brandenburger GH. Targeting of ultrasound contrast material: selective imaging of microbubbles in vitro. Acad Radiol 1998;5 Suppl 1:S243-246.

Klibanov AL, Maruyama K, Torchilin VP, Huang L. Amphipathic polyethyleneglycols effectively prolong the circulation time of liposomes. FEBS Lett 1990;268:235-237.

Klibanov AL, Rychak JJ, Yang WC, Alikhani S, Li B, Acton S, Lindner JR, Ley K, Kaul S. Targeted ultrasound contrast agent for molecular imaging of inflammation in high-shear flow. Contrast Media Mol Imaging 2006;1:259-266.

Kornmann LM, Curfs DM, Hermeling E, van der Made I, de Winther MP, Reneman RS, Reesink KD, Hoeks AP. Perfluorohexane-loaded Macrophages as a Novel Ultrasound Contrast Agent: A Feasibility Study. Mol Imaging Biol 2008;10:264-270.

Lankford M, Behm CZ, Yeh J, Klibanov AL, Robinson P, Lindner JR. Effect of microbubble ligation to cells on ultrasound signal enhancement: implications for targeted imaging. Invest Radiol 2006;41:721728.

Lanza GM, Abendschein DR, Hall CS, Marsh JN, Scott MJ, Scherrer DE, Wickline SA. Molecular imaging of stretch-induced tissue factor expression in carotid arteries with intravascular ultrasound. Invest Radiol 2000;35:227-234.

Lanza GM, Trousil RL, Wallace KD, Rose JH, Hall CS, Scott MJ, Miller JG, Eisenberg PR, Gaffney PJ, Wickline SA. In vitro characterization of a novel, tissue-targeted ultrasonic contrast system with acoustic microscopy. J Acoust Soc Am 1998;104:3665-3672. 
Lanza GM, Wallace KD, Fischer SE, Christy DH, Scott MJ, Trousil RL, Cacheris WP, Miller JG, Gaffney PJ, Wickline SA. High-frequency ultrasonic detection of thrombi with a targeted contrast system. Ultrasound Med Biol 1997;23:863-870.

Lanza GM, Wallace KD, Scott MJ, Cacheris WP, Abendschein DR, Christy DH, Sharkey AM, Miller JG, Gaffney PJ, Wickline SA. A novel site-targeted ultrasonic contrast agent with broad biomedical appication. Circulation 1996;94:3334-3340.

Lanza GM, Wickline SA. Targeted ultrasonic contrast agents for molecular imaging and therapy. Curr Probl Cardiol 2003;28:625-653

Laverman P, Zalipsky S, Oyen WJ, Dams ET, Storm G, Mullah N, Corstens FH, Boerman OC. Improved imaging of infections by avidin-induced clearance of $99 \mathrm{mTc}$-biotin-PEG liposomes. J Nucl Med 2000;41:912-918.

Lawrence MB, Kansas GS, Kunkel EJ, Ley K. Threshold levels of fluid shear promote leukocyte adhesion through selectins (CD62L,P,E). J Cell Biol 1997;136:717-727

Ley K, Laudanna C, Cybulsky MI, Nourshargh S. Getting to the site of inflammation: the leukocyte adhesion cascade updated. Nat Rev Immunol 2007;7:678-689.

Lindner JR. Assessment of inflammation with contrast ultrasound. Prog Cardiovasc Dis 2001;44:111-120

Lindner JR. Detection of inflamed plaques with contrast ultrasound. Am J Cardiol 2002;90:32L-35L.

Lindner JR. Molecular imaging with contrast ultrasound and targeted microbubbles. J Nucl Cardiol 2004;11:215-221

Lindner JR, Coggins MP, Kaul S, Klibanov AL, Brandenburger GH, Ley K. Microbubble persistence in the microcirculation during ischemia/reperfusion and inflammation is caused by integrin- and complement-mediated adherence to activated leukocytes. Circulation 2000a;101:668-675.

Lindner JR, Dayton PA, Coggins MP, Ley K, Song J, Ferrara K, Kaul S. Noninvasive imaging of inflammation by ultrasound detection of phagocytosed microbubbles. Circulation 2000b;102:531-538.

Lindner JR, Song J, Christiansen J, Klibanov AL, XU F, Ley K. Ultrasound assessment of inflammation and renal tissue injury with microbubbles targeted to P-selectin. Circulation 2001;104:2107-2112.

Lindner JR, Song J, Jayaweera AR, Sklenar J, Kaul S. Microvascular rheology of Definity microbubbles after intra-arterial and intravenous administration. J Am Soc Echocardiogr 2002;15:396-403.

Loughrey HC, Ferraretto A, Cannon AM, Acerbis G, Sudati F, Bottiroli G, Masserini M, Soria MR. Characterisation of biotinylated liposomes for in vivo targeting applications. FEBS Lett 1993;332:183188.

Lusis AJ. Atherosclerosis. Nature 2000;407:233-241.

Marsh JN, Hall CS, Scott MJ, Fuhrhop RW, Gaffney PJ, Wickline SA, Lanza GM. Improvements in the ultrasonic contrast of targeted perfluorocarbon nanoparticles using an acoustic transmission line model. IEEE Trans Ultrason Ferroelectr Freq Control 2002a;49:29-38.

Marsh IN, Hall CS, Wickline SA, Lanza GM. Temperature dependence of acoustic impedance for specific fluorocarbon liquids. J Acoust Soc Am 2002b;112:2858-2862.

Marsh JN, Partlow KC, Abendschein DR, Scott MJ, Lanza GM, Wickline SA. Molecular imaging with targeted perfluorocarbon nanoparticles: quantification of the concentration dependence of contrast enhancement for binding to sparse cellular epitopes. Ultrasound Med Biol 2007;33:950-958

Marshall BT, Long M, Piper JW, Yago T, McEver RP, Zhu C. Direct observation of catch bonds involving cell-adhesion molecules. Nature 2003;423:190-193.

McGoron AJ, Pratt R, Zhang J, Shiferaw Y, Thomas S, Millard R. Perfluorocarbon distribution to liver, lung and spleen of emulsions of perfluorotributylamine (FTBA) in pigs and rats and perfluorooctyl bromide (PFOB) in rats and dogs by 19F NMR spectroscopy. Artif Cells Blood Substit Immobil Biotechnol 1994;22:1243-1250.

Narayan P, Marchant D, Wheatley MA. Optimization of spray drying by factorial design for production of hollow microspheres for ultrasound imaging. J Biomed Mater Res 2001;56:333-341.

Ophir J, Parker KJ. Contrast agents in diagnostic ultrasound. Ultrasound Med Biol 1989;15:319-333.

Peng CA, Hsu YC. Fluoroalkylated polyethylene glycol as potential surfactant for perfluorocarbon emulsion. Artif Cells Blood Substit Immobil Biotechnol 2001;29:483-492. 
Pozharski EV, McWilliams L, MacDonald RC. Relationship between turbidity of lipid vesicle suspensions and particle size. Anal Biochem 2001;291:158-162.

Raisinghani A, DeMaria AN. Physical principles of microbubble ultrasound contrast agents. Am J Cardiol 2002;90:3J-7J.

Reneman RS, Arts T, Hoeks AP. Wall Shear Stress - an Important Determinant of Endothelial Cell Function and Structure - in the Arterial System in vivo. Discrepancies with Theory. J Vasc Res 2006;43:251269.

Reneman RS, van Merode T, Hick P, Hoeks AP. Flow velocity patterns in and distensibility of the carotid artery bulb in subjects of various ages. Circulation 1985;71:500-509.

Ridger V, Krams R, Carpi A, Evans PC. Hemodynamic parameters regulating vascular inflammation and atherosclerosis: A brief update. Biomed Pharmacother 2008;62:536-540.

Rindt CC, Steenhoven AA. Unsteady flow in a rigid 3-D model of the carotid artery bifurcation. $J$ Biomech Eng 1996;118:90-96.

Ross R. Atherosclerosis--an inflammatory disease. N Engl J Med 1999;340:115-126.

Rovai D, Morales MA, Amyot R, L'Abbate A. Clinical experience with SonoVue in myocardial perfusion imaging. Echocardiography 2000;17:S17-23.

Rychak J, Klibanov AL, Hossack JA. Acoustic radiation force enhances targeted delivery of ultrasound contrast microbubbles: in vitro verification. IEEE Trans Ultrason Ferroelectr Freq Control 2005;52:421-433.

Rychak JJ, Klibanov AL, Ley KF, Hossack JA. Enhanced Targeting of Ultrasound Contrast Agents Using Acoustic Radiation Force. Ultrasound Med Biol 2007;33:1132-1139.

Rychak JJ, Li B, Acton ST, Leppanen A, Cummings RD, Ley K, Klibanov AL. Selectin ligands promote ultrasound contrast agent adhesion under shear flow. Mol Pharm 2006a;3:516-524.

Rychak JJ, Lindner JR, Ley K, Klibanov AL. Deformable gas-filled microbubbles targeted to P-selectin. $J$ Control Release 2006b;114:288-299.

Samijo SK, Willigers JM, Barkhuysen R, Kitslaar PJ, Reneman RS, Brands PJ, Hoeks AP. Wall shear stress in the human common carotid artery as function of age and gender. Cardiovasc Res 1998;39:515-522.

Schwarz KQ, Becher H, Schimpfky C, Vorwerk D, Bogdahn U, Schlief R. Doppler enhancement with SH U 508A in multiple vascular regions. Radiology 1994;193:195-201.

Shinde Patil VR, Campbell CJ, Yun YH, Slack SM, Goetz DJ. Particle diameter influences adhesion under flow. Biophys J 2001;80:1733-1743.

Shung KK, Fei DY, Ballard JO, 3rd. Further studies on ultrasonic properties of blood clots. J Clin Ultrasound 1986;14:269-275.

Smith DA, Porter TM, Martinez J, Huang S, Macdonald RC, MCPherson DD, Holland CK. Destruction thresholds of echogenic liposomes with clinical diagnostic ultrasound. Ultrasound Med Biol 2007;33:797-809.

Smith DJ, Kornbrust ES, Lane TA. Phagocytosis of a fluorescently labeled perflubron emulsion by a human monocyte cell line. Artif Cells Blood Substit Immobil Biotechnol 1994;22:1215-1221.

Spahn DR, Kocian R. Artificial O2 carriers: status in 2005. Curr Pharm Des 2005;11:4099-4114.

Springer TA. Traffic signals for lymphocyte recirculation and leukocyte emigration: the multistep paradigm. Cell 1994;76:301-314.

Suzuki R, Takizawa T, Negishi Y, Hagisawa K, Tanaka K, Sawamura K, Utoguchi N, Nishioka T, Maruyama K. Gene delivery by combination of novel liposomal bubbles with perfluoropropane and ultrasound. J Control Release 2007;117:130-136.

Suzuki R, Takizawa T, Negishi Y, Utoguchi N, Maruyama K. Effective gene delivery with novel liposomal bubbles and ultrasonic destruction technology. Int J Pharm 2008;354:49-55.

Takalkar AM, Klibanov AL, Rychak JJ, Lindner JR, Ley K. Binding and detachment dynamics of microbubbles targeted to P-selectin under controlled shear flow. J Control Release 2004;96:473-482.

Van Hemert FJ, Voermans C, Van Eck-Smit BL, Bennink RJ. Labeling monocytes for imaging chronic inflammation. QJ Nucl Med Mol Imaging 2009;53:78-88. 
Vicenzini E, Giannoni MF, Puccinelli F, Ricciardi MC, Altieri M, Di Piero V, Gossetti B, Valentini FB, Lenzi GL. Detection of carotid adventitial vasa vasorum and plaque vascularization with ultrasound cadence contrast pulse sequencing technique and echo-contrast agent. Stroke 2007;38:2841-2843.

Villanueva FS, Jankowski RJ, Klibanov S, Pina ML, Alber SM, Watkins SC, Brandenburger GH, Wagner WR. Microbubbles targeted to intercellular adhesion molecule-1 bind to activated coronary artery endothelial cells. Circulation 1998;98:1-5.

Villanueva FS, Jankowski R, Manaugh C, Wagner WR. Albumin microbubble adherence to human coronary endothelium: implications for assessment of endothelial function using myocardial contrast echocardiography. J Am Coll Cardiol 1997;30:689-693.

Weller GE, Villanueva FS, Klibanov AL, Wagner WR. Modulating targeted adhesion of an ultrasound contrast agent to dysfunctional endothelium. Ann Biomed Eng 2002;30:1012-1019.

Weller GE, Villanueva FS, Tom EM, Wagner WR. Targeted ultrasound contrast agents: in vitro assessment of endothelial dysfunction and multi-targeting to ICAM-1 and sialyl Lewisx. Biotechnol Bioeng 2005a;92:780-788.

Weller GE, Wong MK, Modzelewski RA, Lu E, Klibanov AL, Wagner WR, Villanueva FS. Ultrasonic imaging of tumor angiogenesis using contrast microbubbles targeted via the tumor-binding peptide argininearginine-leucine. Cancer Res 2005b;65:533-539.

Wickline SA, Neubauer AM, Winter PM, Caruthers SD, Lanza GM. Molecular imaging and therapy of atherosclerosis with targeted nanoparticles. J Magn Reson Imaging 2007;25:667-680.

Woodle MC, Matthay KK, Newman MS, Hidayat JE, Collins LR, Redemann C, Martin FJ, Papahadjopoulos D. Versatility in lipid compositions showing prolonged circulation with sterically stabilized liposomes. Biochim Biophys Acta 1992;1105:193-200.

Zarins CK, Giddens DP, Bharadvaj BK, Sottiurai VS, Mabon RF, Glagov S. Carotid bifurcation atherosclerosis. Quantitative correlation of plaque localization with flow velocity profiles and wall shear stress. Circ Res 1983;53:502-514.

Zhao S, Kruse DE, Ferrara KW, Dayton PA. Selective imaging of adherent targeted ultrasound contrast agents. Phys Med Biol 2007;52:2055-2072. 


\title{
CHAPTER 4
}

\section{Monodisperse perfluorohexane}

\section{emulsions for targeted ultrasound contrast imaging}

\begin{abstract}
J.M.M. Simons ${ }^{1 *}$, L.M. Kornmann ${ }^{2}$, K.D. Reesink ${ }^{2}$, A.P.G. Hoeks ${ }^{2}$, M.F. Kemmere ${ }^{1}$, J. Meuldijk ${ }^{1}$, J.T.F. Keurentjes ${ }^{1}$

*Both authors contributed equally to this work

Department of Chemical Engineering and Chemistry ${ }^{1}$, Eindhoven University of Technology, Eindhoven, The Netherlands. Department of Biomedical Engineering ${ }^{2}$, Cardiovascular Research Institute Maastricht (CARIM), Maastricht University, Maastricht, The Netherlands.
\end{abstract}




\section{Abstract}

Quantitative targeted ultrasound contrast imaging demands for contrast agents with a small monodisperse size and a high coverage of specific ligands for effective adhesion under physiological shear stress conditions. However, the particles should also be large enough to generate sufficient ultrasound reflection. Standard perfluorocarbon emulsions do not satisfy both requirements (adhesion and echogenicity). Therefore, we decided to develop a membrane emulsification technique to produce echogenic monodisperse perfluorohexane emulsions able to carry specific ligands for adhesion to the artery wall. In this work, we demonstrate that membrane emulsification is an excellent tool to create strictly monodisperse echogenic perfluorohexane emulsions with a preset droplet size. Perfluorohexane is emulsified in water using photolithographic microsieves. An ultrasound experiment demonstrates that the perfluorohexane emulsions clearly enhance echogenicity. The acoustic enhancement varies with droplet size and surface coverage. The emulsions, with a biotinylated fluoro-surfactant, are able to bind avidine coated $\mathrm{SiO}_{2}$ particles. This proves that these emulsions show a very promising potential to act as key species in the field of selective targeting, which can provide novel insights into the development and early detection of important vascular diseases, e.g., atherosclerosis. 


\section{Introduction}

Selective imaging of a molecular target (molecular imaging) can provide novel insights into the development and early detection of important diseases, e.g., atherosclerosis. Quantitative ultrasound contrast imaging of the presence and coverage of adhesion molecules on the endothelium requires dispersed contrast agents with a precisely defined droplet size, small enough to reach and attach to the arterial wall and large enough to induce sufficient enhancement of echogenicity. Molecular ultrasound imaging requires echogenic contrast agents carrying specific targeting ligands on their surface, such as liposomes (Alkan-Onyuksel et al. 1996; Demos et al. 1997), microbubbles (Klibanov et al. 1997; Lindner et al. 2000; Villanueva et al. 1998), or perfluorocarbon nanoparticles (Lanza et al. 1997; Lanza et al. 1996). Liposomes (diameter $<1 \mu \mathrm{m}$ ) (Pozharski et al. 2001) are normally not echogenic, but for ultrasound application echogenicity can be created by either trapping air inside the lipid bilayers during lyophilization (Huang et al. 2002) or by a multilamilar structure (Alkan-Onyuksel et al. 1996; Huang et al. 2002). Microbubbles (diameter $-3 \mu \mathrm{m}$ ), albeit highly echogenic (de Jong et al. 2002), have a shorter life-time as compared to perfluorocarbon submicron particles $(-0.3 \mu \mathrm{m}$ in diameter) due to their reduced stability. In blood, perfluorocarbon emulsions are less echogenic than gas-filled microbubbles (Hughes et al. 2005) However, when bound to the surface of a tissue cell, these emulsions are detectable due to a local acoustic impedance mismatch and accumulation (Lanza et al. 1996).

Conventional methods for producing perfluorocarbon emulsions utilize techniques like sonication and high pressure homogenization. A disadvantage of these methods is that the mixture contains by-products like gas bubbles and liposomes (Cornelus et al. 1993; Couture et al. 2006a; De Vleeschauwer and Van der Meeren 1998), which can be removed with centrifugation (Couture et al. 2006a; De Vleeschauwer and Van der Meeren 1998). Standard perfluorocarbon emulsions exhibit a broad size distribution (Couture et al. 2006a; De Vleeschauwer and Van der Meeren 1998), prohibiting conversion from observed intensity distribution to adhesion site coverage. Moreover, echogenicity is limited because of the small average droplet diameter in the order of $0.3 \mu \mathrm{m}$.

In vivo quantitative imaging with ultrasound contrast agents involves a complex interplay between bioavailability and selectivity towards target sites in relation to local wall shear stress on one hand (Takalkar et al. 2004; Weller et al. 2005), and acoustic properties as well as coverage of the contrast agent with implications for ultrasound reflectivity on the other hand (Couture et al. 2007; Dayton and Rychak 2007; Marsh et al. 2007). Reflectivity enhancement after binding is not only governed by the acoustic properties of ultrasound contrast agent and its diameter (de 
Jong et al. 1991), but also by the amount of contrast agent accumulated at the site of interest (Couture et al. 2006b; Lanza et al. 1998).

This paper reports a method for the production of monodisperse perfluorohexane emulsions with a predetermined size $(4$ and $12 \mu \mathrm{m})$. At a first stage, we developed a membrane emulsification technique to produce monodisperse perfluorohexane emulsions with a standard surfactant and assessed their echogenicity. Subsequently, we exchanged the standard surfactant by a biotinylated fluoro-surfactant (BFS) and attached avidin coated silica $\left(\mathrm{SiO}_{2}\right)$ particles to demonstrate that the emulsion indeed is able to carry ligands.

\section{Materials and Methods}

\section{Materials}

Pentadecafluorooctanoyl chloride $\left(\mathrm{C}_{7} \mathrm{~F}_{15} \mathrm{COCl}\right)$, dodecyl benzene sulfonic acid sodium salt (SDBS) and avidin were supplied by Sigma-Aldrich (Steinheim, Germany), Fluorescein-conjugated biotin by Molecular Probes (Leiden, The Netherlands). $\alpha$ Biotin- $\omega$-hydroxy poly(ethylene glycol) with a molecular weight of 3000 Da was obtained from Iris Biotech (Marktredwitz, Germany). An aqueous dispersion of avidin coated $\mathrm{SiO}_{2}$ particles (average diameter of $1.5 \mu \mathrm{m}$ ) was obtained from $\mathrm{G}$. Kisker (Steinfurt, Germany). These materials were used without further purification. Perfluorohexane was obtained from Fluorochem (Derbyshire, Great Britain) and was purified over an alumina column prior to use. Photolithographic membranes were purchased from Nanomi BV (Oldenzaal, The Netherlands). The membranes used were photolithographic microsieves, consisting of silicon with a silica toplayer. These membranes show a very high uniformity in pore size and shape. In this study, membranes with pores of $1.8 \mu \mathrm{m}$ and $4 \mu \mathrm{m}$ were used. These membranes do not require shear flow for droplet formation, resulting in a constant droplet size distribution independent of the velocity of the aqueous phase.

\section{Membrane emulsification}

An aqueous phase, containing demineralized water and SDBS as surfactant, was circulated through the membrane module. After complete wetting of the membrane surface, perfluorohexane was pressed through the membrane into the aqueous phase by applying a pressure of $20 \mathrm{kPa}$ using nitrogen, see Fig. 1 . The emulsification was continued until an emulsion of $5 \mathrm{wt} \%$ perfluorohexane was obtained. 


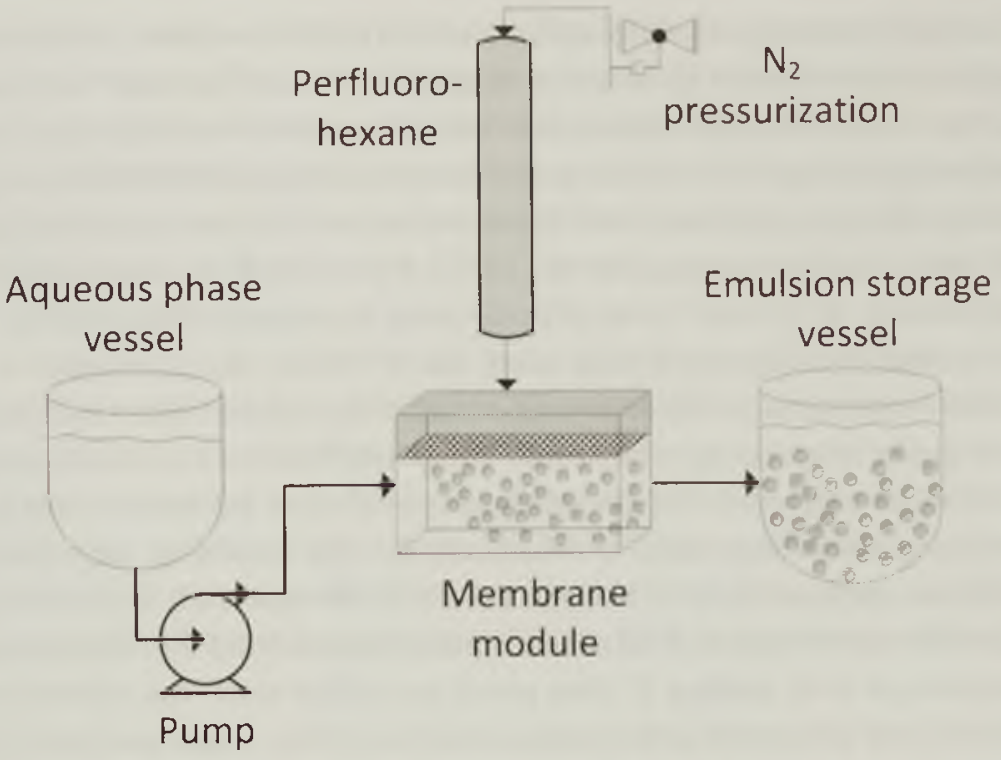

Figure 1. Schematic illustration of the membrane emulsification setup.

\section{Droplet size distribution analysis}

The evolution of the droplet size distributions was observed with an optical microscope (Axioplan 2 imaging, Carl Zeiss, Oberkochen, Germany), equipped with a digital camera (AxioCam Color, Type 412-312). Size distributions were obtained from these images by a proprietary routine written in Matlab R2006b (The Mathworks, Natick, MA, USA) and Imagel (Abramoff et al. 2004). The size distribution was measured immediately after emulsification. The image analysis procedure consisted of the following steps. First, the background was subtracted. The resulting image was binarized using a luminance threshold. The droplets were separated from the noise by filtering for a luminance maximum within the droplets. Further processing steps involved separation of connecting droplets and filtering out objects with a circularity ratio below 0.8 . From the resulting images, the droplet areas were measured. Statistical analysis of the data provided the mean and standard deviation for the droplet diameter distribution. Each distribution was based on the measurement of at least $5 \times 10^{3}$ droplets. Emulsion stability was investigated by storing a sample of $10 \mathrm{~mL}$ of emulsion and measuring droplet size distributions with intervals of 10 days over a period of 30 days. 


\section{Echogenicity}

$300 \mathrm{~mL}$ of agar solution ( $1 \% \mathrm{w} / \mathrm{v})$ were poured in a plastic container, casted into the desired form with a mould to obtain multiple circular wells (volume $-150 \mu \mathrm{L}$, bottom surface area $0.196 \mathrm{~cm}^{2}$ ) and cured at room temperature (Fig. 2). After infusing perfluorohexane droplets ( 4 and $12 \mu \mathrm{m}$ in diameter dissolved in $150 \mu \mathrm{L}$ phosphate buffer) into the agar wells, they were allowed to settle randomly on the well bottom surface with a surface coverage of $50,25,12.5$ and $6.25 \%$ as determined by the infused quantity. A $40 \mathrm{~mm} 7.5 \mathrm{MHz}$ linear array transducer (Picus, Esaote Maastricht, the Netherlands), with a focal beam size of $1.3 \mathrm{~mm}$, was suspended in phosphate buffer solution, with the focal point set at $20 \mathrm{~mm}$ positioned at the bottom of the wells (buffer solution-agar interface). The plastic head of a pin served as ultrasound reflection reference. The pin was inserted between the wells at well-bottom level, allowing paired acquisition of reflectivity. B-mode recordings were taken at 3 different cross-sections (A, B, C) through the wells. The maximum of the echo signal envelope was determined at 9 positions (equally spaced at $0.3 \mathrm{~mm}$ increments) per cross-section per well, yielding 27 data points per well in total. The reflectivity ratio was defined and calculated as the mean echo level of the respective perfluorohexane emulsion layer divided by the mean echo level of the reference reflector within the same recording. The measurement was repeated twice.

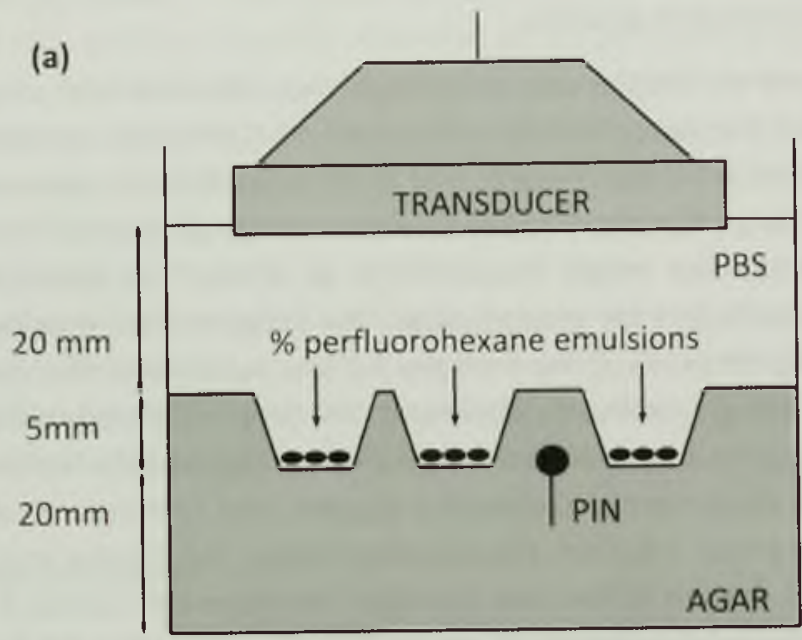

(b)

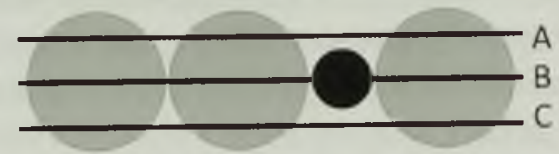

Figure 2. Schematic illustration of the ultrasound reflectivity measurement setup in (a) side view, (b) top view. Simultaneous recordings were made at three different cross-sections ( $A, B$ and $C$ ). PBS is phosphate buffer saline. 


\section{Surfactant exchange}

A biotinylated fluoro-surfactant (BFS, see Fig. 3, 3) was produced based on the method proposed by Peng et al (Peng and Hsu 2001). To allow targeting of PFH emulsions, $\alpha$-Biotin- $\omega$-hydroxy poly(ethylene glycol) ( $M W=3000 \mathrm{Da}$ ) was used in stead of poly(ethylene glycol). The effectiveness of coupling pentadecafluorooctanoyl chloride and $\alpha$-Biotin- $\omega$-hydroxy poly(ethylene glycol), see Fig. 3 ( 1 and 2 ), was verified by ${ }^{1} \mathrm{H} \mathrm{NMR}\left(300 \mathrm{MHz} \mathrm{CDCl}_{3}\right.$ ). The yield was calculated to be $83 \% .50$ $\mathrm{mg}$ of BFS was added to $4 \mathrm{~mL}$ of emulsion. The emulsion was stored at $279 \mathrm{~K}$ for 3 hours to allow exchange of surfactant at the droplet surface. Afterwards, $3 \mathrm{~mL}$ of supernatant, containing free BFS and SDBS, was removed and the emulsion was diluted again to $4 \mathrm{~mL}$ with demineralized water. Supernatant removal and dilution sequence was repeated three times. For fluorescence microscopy, perfluorohexane emulsions were incubated with avidin for 10 minutes, subsequently washed and incubated for 10 minutes with fluorescein-conjugated biotin. After washing, samples were analyzed under a microscope (Eclipse E800, Nikon) using a $60 x$ objective lens.

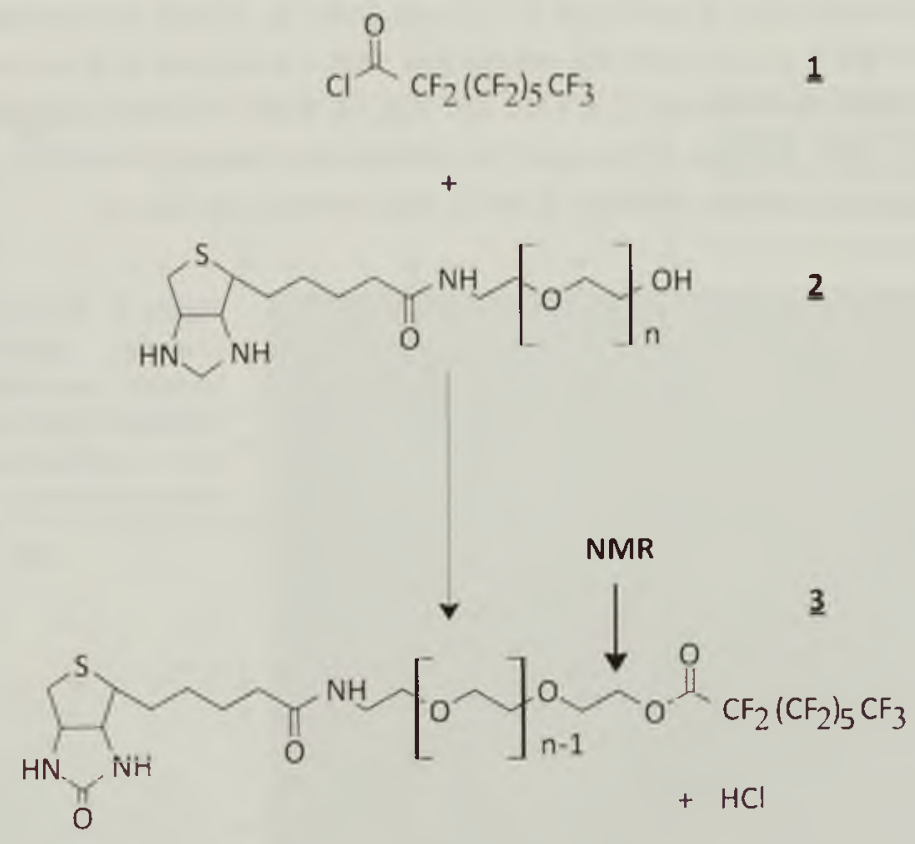

Figure 3. Reaction scheme for the synthesis of the biotinylated fluoro-surfactant (3) by coupling pentadecafluorooctanoyl chloride (1) and $\alpha$-Biotin- $\omega$-hydroxy poly(ethylene glycol) (2). 


\section{Attachment to avidin coated $\mathrm{SiO} 2$ particles}

$25 \mu \mathrm{g}$ of an aqueous dispersion $\left(156 \mu \mathrm{g} / \mathrm{mL}\right.$ ) of avidin coated $\mathrm{SiO}_{2}$ particles (average diameter of $1.5 \mu \mathrm{m}$ ) were added to $4 \mathrm{~mL}$ of the biotinylated perfluorohexane emulsion. The sample was incubated for 1 hour and analyzed under a microscope (Axioplan 2 imaging, Carl Zeiss, Oberkochen, Germany), equipped with a digital camera (AxioCam Color, Type 412-312).

\section{Results and discussion}

\section{Membrane emulsification}

To overcome the limitations of the conventional methods for perfluorohexane emulsification, we developed a membrane emulsification technique, as illustrated in Fig. 1, to produce monodisperse perfluorocarbon emulsions. The main advantage of this technique is that the size of the resulting droplets can easily be chosen by selecting the pore size of the membrane. The membranes used were photolithographic microsieves (Veldhuis et al. 2009). The diameter of the membrane pores was $1.8 \mu \mathrm{m}$ for membrane 1 and $4 \mu \mathrm{m}$ for membrane 2 . The emulsion produced with a membrane with a pore size of $1.8 \mu \mathrm{m}$ (see Fig. 4) had an average droplet diameter of $4.4 \pm 0.2 \mu \mathrm{m}$ and the membrane with a pore size of $4 \mu \mathrm{m}$ yielded an average droplet diameter of $11.9 \pm 0.4 \mu \mathrm{m}$ (Fig. 5). Both emulsions appeared to be very stable. After 30 days of storage the distribution changed slightly to $4.4 \pm 0.3$ $\mu \mathrm{m}$ and $12.0 \pm 0.5 \mu \mathrm{m}$ for emulsion 1 and 2, respectively (see Fig. 6).

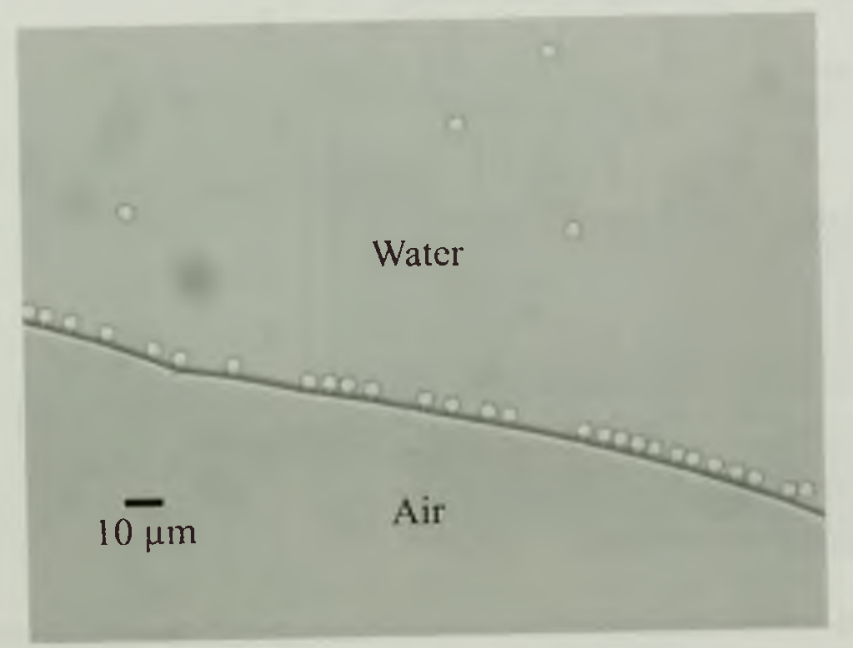

Figure 4. Microscopy image showing perfluorohexane droplets produced with a membrane with a pore size of $1.8 \mu \mathrm{m}$, moving freely near the water-air interface. 

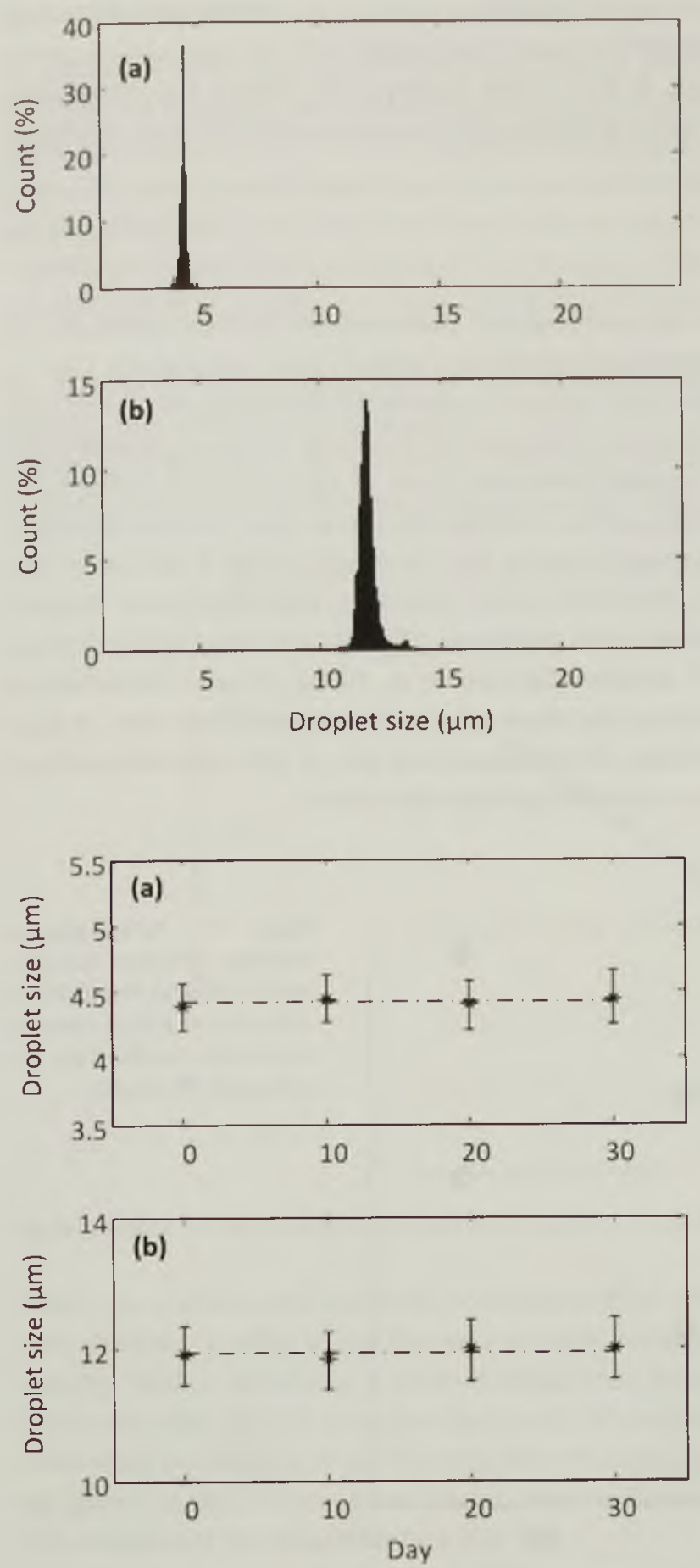

Figure 5. Droplet size distributions of emulsions produced with a membrane with a pore size of a) $1.8 \mu \mathrm{m}$ and b) $4 \mu \mathrm{m}$.

Figure 6. Emulsion size distributions as function of storage time for emulsions produced with a membrane with a pore size of a) $1.8 \mu \mathrm{m}$ and b) $4 \mu \mathrm{m}$. 
To evaluate the stability of the PFH droplets in vitro, $1 \mathrm{~mL}$ of emulsion containing $11.9 \pm 0.4 \mu \mathrm{m}$ droplets ( $20 \mathrm{wt} \%$ in water) was added to $5 \mathrm{~mL}$ fetal bovine serum (FBS). The sample was kept at $37^{\circ} \mathrm{C}$. After 21 days, the droplet size distribution changed to $11.9 \pm 0.5 \mu \mathrm{m}$, proving that the $\mathrm{PFH}$ emulsions maintain their stability in FBS.

\section{Echogenicity}

An ultrasound experiment was performed to determine the acoustic reflectivity of the emulsions. The perfluorohexane emulsions exhibited clear echogenicity (Fig. 7). The acoustic reflectivity loss (with respect to a perfectly hard reflector) varied with droplet size (diameter) and surface coverage. A monolayer of $12 \mu \mathrm{m}$ droplets with $50 \%$ coverage exhibited a similar reflectivity level as the reference (ratio 0.91). Within the range of $6.25-50 \%$, surface coverage had more impact on the reflectivity of the $12 \mu \mathrm{m}$ droplet monolayer than on the reflectivity of the $4 \mu \mathrm{m}$ layer. This might be explained by the fact that at high coverages, perfluorohexane droplets cannot be considered as independent scatterers. This was also observed by Couture et al. for polydisperse PFH samples (Couture et al. 2006a). Despite the effect of surface coverage on reflectivity, the above observations demonstrate that, at least in a phantom setting, emulsions of monodisperse 4 and $12 \mu \mathrm{m}$ sized perfluorohexane droplets can be used as a contrast agent for ultrasound.

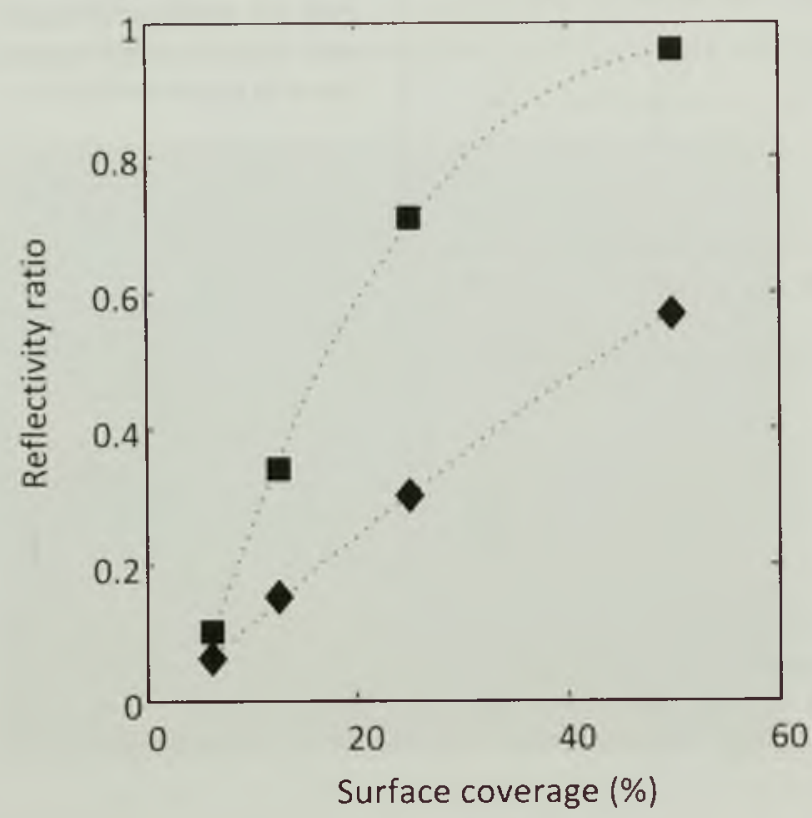

Figure 7. Perfluorohexane emulsion reflectivity (normalized to reference amplitude) as a function of surface coverage and droplet size for $4 \mu \mathrm{m}(\bullet)$ and $12 \mu \mathrm{m}$ (घ) droplets. 


\section{Exchange of surfactant}

To validate whether perfluorohexane emulsions are able to carry ligands, necessary for selective targeting, we replaced the SDBS surfactant with a biotinylated fluorosurfactant, see Fig. 3, 3. The SDBS surfactant that covers the droplet surface is necessary for proper emulsification, but is not suitable for targeting purposes. The BFS on the other hand does not have the interfacial tension properties required for membrane emulsification. Removal of free BFS after SDBS exchange is important to prevent it from occupying active sites during future targeting experiments.

To validate the interfacial activity of the synthesized BFS, the surface tension of aqueous BFS solutions was measured as a function of concentration. Fig. 8 demonstrates that the BFS is surface active. Note that no critical micelle concentration could be determined for BFS concentrations up to $10 \mathrm{mM}$.

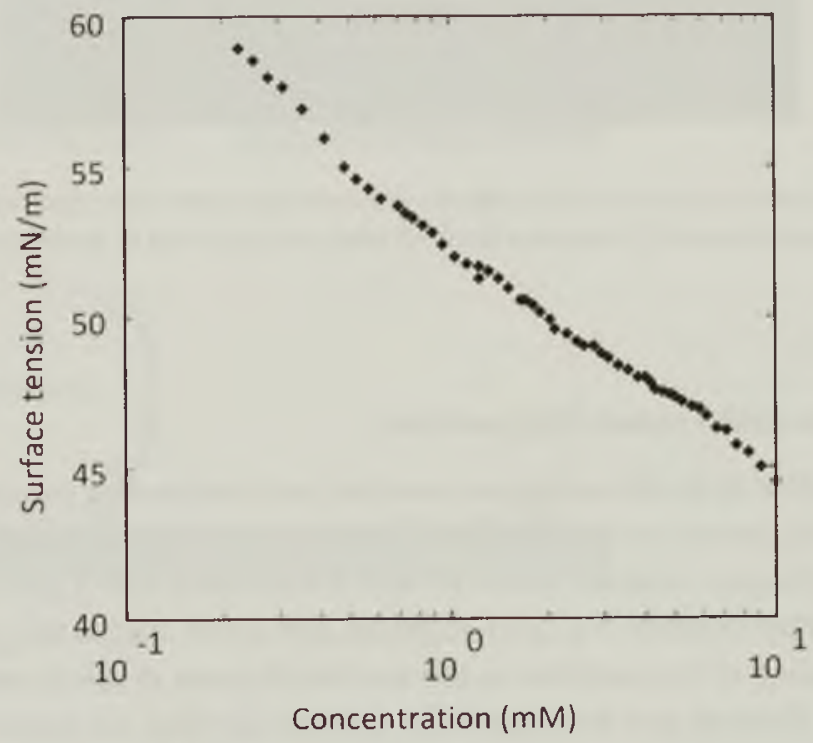

Figure 8. Surface tension titration curve for the biotinylated fluoro-surfactant (BFS) in water.

Finally, we evaluated the surfactant exchange process with fluorescent biotin molecules. Emulsion binding to the fluorescent biotin molecules was mediated by avidin bridging. Avidin, containing 4 biotin binding sites, binds to both the fluorescent biotin molecules and the selective end groups of the biotinylated fluorosurfactant. Fluorescent microscopy of perfluorohexane emulsions showed fluorescence intensity (green) at the surface of the droplet, which indicated that the BFS had successfully adsorbed at the droplet surface (Fig. 9b). 

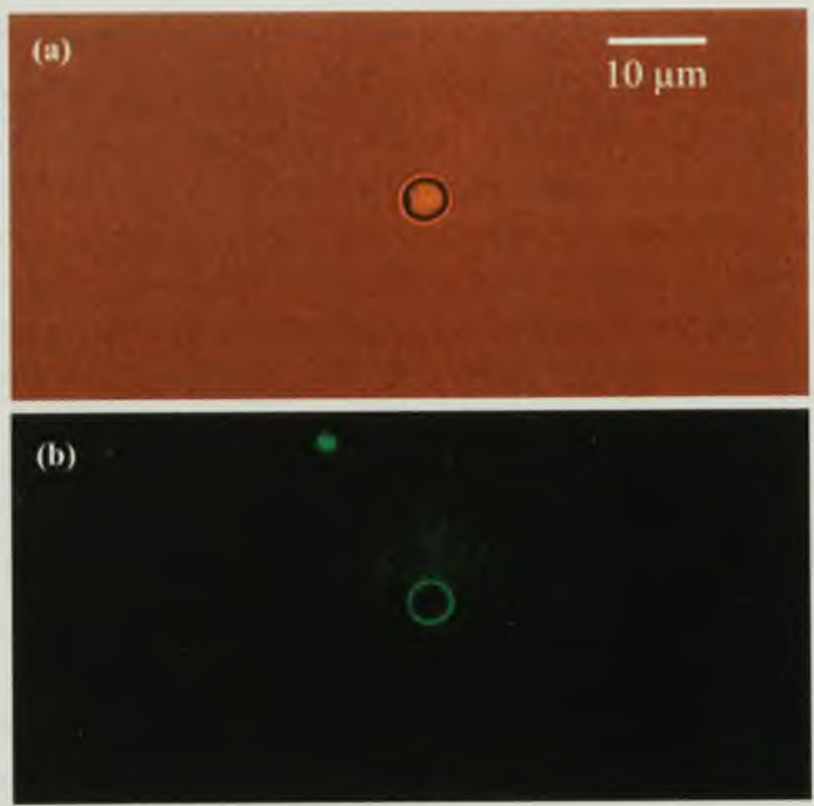

Figure 9. a) Microscopy image of a perfluorohexane emulsion coated with biotinylated fluoro-surfactant. b) Labeling of the emulsion with fluorescent biotin via avidin was confirmed by fluorescence microscopy in green.

\section{Attachment to avidin coated SiO2 particles}

The next question to be answered was whether perfluorohexane emulsions are able to carry ligands, necessary for selective targeting. Fig. 10 shows microscopy images of a perfluorohexane emulsion produced with a membrane with a pore size of $4 \mu \mathrm{m}$, resulting in $12 \mu \mathrm{m}$ droplets (Fig. 10a), together with avidin coated $\mathrm{SiO}_{2}$ particles (Fig $10 \mathrm{~b})$. The binding of the particles to the perfluorohexane droplets was successful, although Fig. 10c may give the impression that the particles are located within the droplets. The $\mathrm{SiO}_{2}$ particles were sliding over the surface towards the lower part of the droplets due to gravity (Fig. 10e). For droplets moving freely in the field of view of the microscope, movement of the particle over the outside of the surface could clearly be observed. An interesting case appeared when an avidin coated $\mathrm{SiO}_{2}$ particle was able to bind to two different droplets. Due to the opposing forces of both droplets on the $\mathrm{SiO}_{2}$ particle, the particle was trapped (Fig. 10d, 10e). 


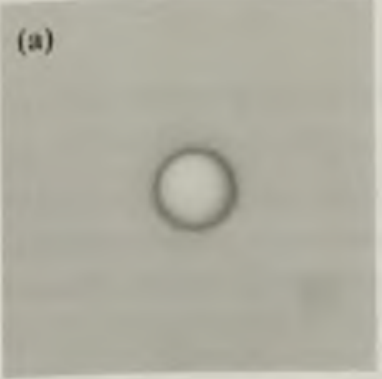

(b)

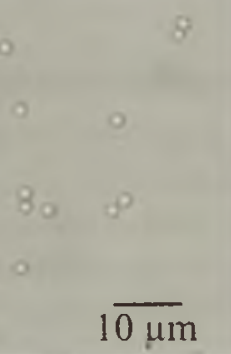

(c)

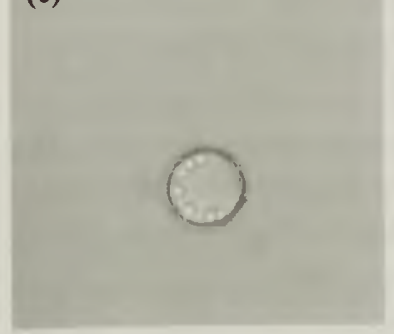

(e)

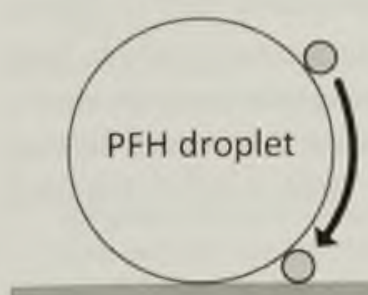

\section{(d)}
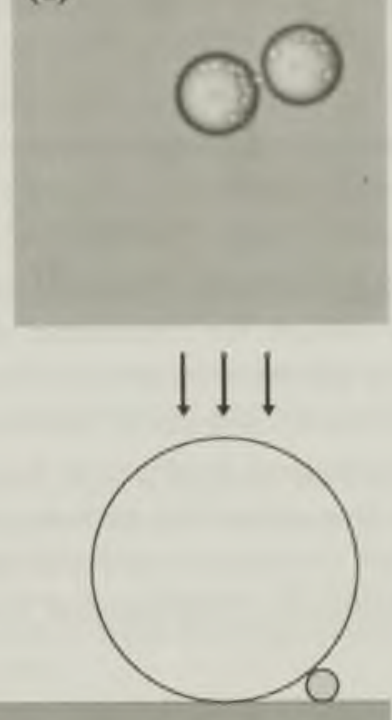

Figure 10. Microscopy images of a) perfluorohexane emulsion, b) avidin coated $\mathrm{SiO} 2$ particles, c) avidin coated $\mathrm{SiO} 2$ particles bound to a perfluorohexane emulsion d) an avidin coated $\mathrm{SiO}_{2}$ particle trapped between 2 different emulsions. e) Illustration of the optical artifacts.

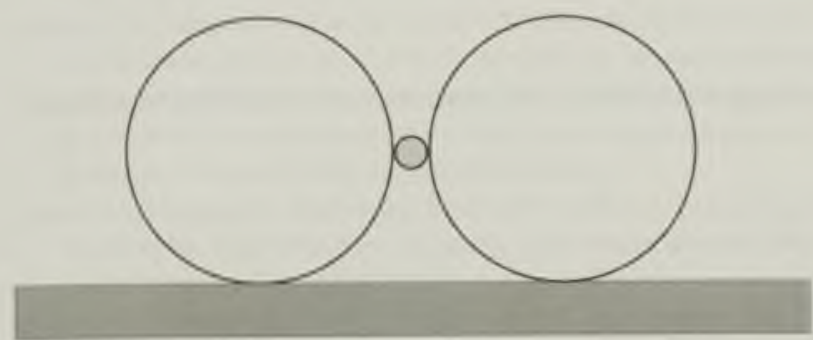

\section{Avidin coated
silica particle}

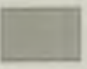

Glass surface 


\section{Conclusions and outlook}

In spite of improvements in molecular ultrasound contrast imaging in the microcirculation, imaging of activated endothelium of large and middle-sized arteries is still difficult to achieve. The work presented in this paper demonstrates that membrane emulsification is an excellent tool to create strictly monodisperse perfluorohexane emulsions with a preset size. In this study we opted for droplet diameters of 4 and 12 micrometer to illustrate the production principles. The ability to produce well defined emulsions of different sizes will make it possible to explore the optimal emulsion droplet size for quantitative imaging in relation to shear stress and echogenicity. For targeted imaging in vivo under physiological shear stress conditions PFH droplets should have a small size to avoid lung entrapment and decrease their sensitivity for shear stress. One should realize that besides size, deformability is also of importance when considering the passage through lung capillaries. However, the droplets should be large enough to attain sufficient echogenicity and they should have a high coverage of specific ligands for effective adhesion to for example the artery wall. The ultrasound experiments demonstrate that the newly developed perfluorohexane emulsions exhibit the anticipated echogenic behavior. Further investigations are required to get more insight into the relationship between echogenicity and the local concentration and size of adhered ultrasound contrast agents in vivo. Furthermore, the synthesized biotinylated fluoro-surfactant is able to bind the emulsion droplets to avidine coated $\mathrm{SiO}_{2}$ particles, proving that these emulsions are very promising in the field of selective molecular targeting. To rate our findings at their true value, experiments in a physiological shear stress model of arterial inflammation are required.

\section{Acknowledgements}

This research was supported by grant BSIK03033 (SenterNovem) and by MicroNed. 


\section{References}

Abramoff MD, Magelheas PJ, Ram SJ. Image Processing with ImageJ. Biophotonics International 2004;11:36-42.

Alkan-Onyuksel H, Demos SM, Lanza GM, Vonesh MJ, Klegerman ME, Kane BJ, Kuszak J, McPherson DD. Development of inherently echogenic liposomes as an ultrasonic contrast agent. J Pharm Sci 1996;85:486-490.

Cornelus C, Giulieri F, Riess M-PKaG. Impact of the structure of phosphofipid dispersions on the stability of fluorocarbon/phospholipid emulsions for biomedical uses. Colloids and Surfaces A: Physicochemical and Engineering Aspects 1993;70:233-238.

Couture O, Bevan PD, Cherin E, Cheung K, Burns PN, Foster FS. Investigating perfluorohexane particles with high-frequency ultrasound. Ultrasound Med Biol 2006a;32:73-82.

Couture O, Bevan PD, Cherin E, Cheung K, Burns PN, Foster FS. A model for reflectivity enhancement due to surface bound submicrometer particles. Ultrasound Med Biol 2006b;32:1247-1255.

Couture $O$, Cherin E, Foster FS. Model for the ultrasound reflection from micro-beads and cells distributed in layers on a uniform surface. Phys Med Biol 2007;52:4189-4204.

Dayton PA, Rychak JJ. Molecular ultrasound imaging using microbubble contrast agents. Front Biosci 2007;12:5124-5142.

de Jong N, Bouakaz A, Frinking P. Basic acoustic properties of microbubbles. Echocardiography 2002;19:229-240.

de Jong N, Ten Cate FJ, Lancee CT, Roelandt JR, Bom N. Principles and recent developments in ultrasound contrast agents. Ultrasonics 1991;29:324-330.

De Vleeschauwer D, Van der Meeren P. A dynamic light scattering study of the influence of the phospholipid concentration in a model perfluorocarbon emulsion. Colloids and Surfaces B: Biointerfaces 1998;11:321-329.

Demos SM, Onyuksel H, Gilbert J, Roth SI, Kane B, Jungblut P, Pinto JV, McPherson DD, Klegerman ME. In vitro targeting of antibody-conjugated echogenic liposomes for site-specific ultrasonic image enhancement. J Pharm Sci 1997;86:167-171.

Huang SL, Hamilton AJ, Pozharski E, Nagaraj A, Klegerman ME, McPherson DD, MacDonald RC. Physical correlates of the ultrasonic reflectivity of lipid dispersions suitable as diagnostic contrast agents. Ultrasound Med Biol 2002;28:339-348.

Hughes MS, Marsh JN, Hall CS, Fuhrhop RW, Lacy EK, Lanza GM, Wickline SA. Acoustic characterization in whole blood and plasma of site-targeted nanoparticle ultrasound contrast agent for molecular imaging. J Acoust Soc Am 2005;117:964-972.

Klibanov AL, Hughes MS, Marsh JN, Hall CS, Miller JG, Wible JH, Brandenburger GH. Targeting of ultrasound contrast material. An in vitro feasibility study. Acta Radiol Suppl 1997;412:113-120.

Lanza GM, Trousil RL, Wallace KD, Rose JH, Hall CS, Scott MJ, Miller JG, Eisenberg PR, Gaffney PJ, Wickline SA. In vitro characterization of a novel, tissue-targeted ultrasonic contrast system with acoustic microscopy. J Acoust Soc Am 1998;104:3665-3672.

Lanza GM, Wallace KD, Fischer SE, Christy DH, Scott MJ, Trousil RL, Cacheris WP, Miller JG, Gaffney PJ, Wickline SA. High-frequency ultrasonic detection of thrombi with a targeted contrast system. Ultrasound Med Biol 1997;23:863-870.

Lanza GM, Wallace KD, Scott MJ, Cacheris WP, Abendschein DR, Christy DH, Sharkey AM, Miller JG, Gaffney PJ, Wickline SA. A novel site-targeted ultrasonic contrast agent with broad biomedical application. Circulation 1996;94:3334-3340.

Lindner JR, Coggins MP, Kaul S, Klibanov AL, Brandenburger GH, Ley K. Microbubble persistence in the microcirculation during ischemia/reperfusion and inflammation is caused by integrin- and complement-mediated adherence to activated leukocytes. Circulation 2000;101:668-675.

Marsh JN, Partlow KC, Abendschein DR, Scott MJ, Lanza GM, Wickline SA. Molecular imaging with targeted perfluorocarbon nanoparticles: quantification of the concentration dependence of contrast enhancement for binding to sparse cellular epitopes. Ultrasound Med Biol 2007;33:950-958. 
Peng CA, Hsu YC. Fluoroalkylated polyethylene glycol as potential surfactant for perfluorocarbon emulsion. Artif Cells Blood Substit Immobil Biotechnol 2001;29:483-492.

Pozharski EV, McWilliams L, MacDonald RC. Relationship between turbidity of lipid vesicle suspensions and particle size. Anal Biochem 2001;291:158-162.

Takalkar AM, Klibanov AL, Rychak J, Lindner JR, Ley K. Binding and detachment dynamics of microbubbles targeted to P-selectin under controlled shear flow. I Control Release 2004;96:473-482.

Veldhuis G, Girones M, Bingham D. Monodisperse Microspheres for Parenteral Drug Delivery. Drug Delivery Technology 2009;9:24-30.

Villanueva FS, Jankowski RJ, Klibanov S, Pina ML, Alber SM, Watkins SC, Brandenburger GH, Wagner WR. Microbubbles targeted to intercellular adhesion molecule-1 bind to activated coronary artery endothelial cells. Circulation 1998;98:1-5.

Weller GE, Villanueva FS, Tom EM, Wagner WR. Targeted ultrasound contrast agents: in vitro assessment of endothelial dysfunction and multi-targeting to ICAM-1 and sialy Lewisx. Biotechnol Bioeng 2005;92:780-788. 


\section{Perfluorohexane-loaded} macrophages as a novel ultrasound contrast agent: a feasibility study

L.M. Kornmann*1 ${ }^{1}$ D.M.J. Curfs*2 ${ }^{2}$, E. Hermeling ${ }^{1}$, I. van der Made ${ }^{2}$, M.P.J. de Winther ${ }^{2}$, R.S. Reneman ${ }^{3}$, K.D. Reesink ${ }^{1}$, A.P.G. Hoeks ${ }^{1}$

* Both authors contributed equally to this work

Departments of Biophysics ${ }^{1}$, Molecular Genetics ${ }^{2}$, and Physiology ${ }^{3}$, Cardiovascular Research Institute Maastricht (CARIM), Maastricht University, Maastricht, The Netherlands 


\section{Abstract}

We investigated in vitro the potential of macrophages to act as targeted vehicle for ultrasound molecular imaging.

Murine bone marrow derived macrophages (BMM), incubated for $3 \mathrm{~h}$ with different concentrations of perfluorohexane (PFH) emulsions, were monitored by microscopy, flow cytometry, and ultrasound. Effects of PFH loading on BMM adhesion molecule (PSGL-1, VLA-4, Mac-1, LFA-1) expression were analyzed by flow cytometry. Static adhesion of PFH loaded BMM to unstimulated and TNF- $\alpha$ stimulated b.End 5 endothelial cells was assessed by microscopy.

Incubation of BMM with PFH emulsions resulted in dose-dependent uptake as well as increased echogenicity ( $\max .17 \mathrm{~dB}$ ). Flow cytometry analyses revealed no downregulation related to $\mathrm{PFH}$ loading of $\mathrm{BMM}$ adhesion molecule expression. Endothelial adhesion remained functional, even after 24 hours, although PFH loading dosedependently attenuated static adhesion.

PFH loaded BMM may potentially serve as ultrasound contrast agent for noninvasive detection of atherogenic hotspots in arteries. 


\section{Introduction}

Atherosclerosis is a slowly progressing, multifactorial inflammatory disease of the large and middle-sized arteries. It involves leukocyte recruitment, accumulation of lipids, foam cell formation in the intima and changes in extracellular matrix of arterial walls (Hansson 2005). One of the first steps in the development of atherosclerosis is the up-regulation of adhesion molecules as P-/E-selectin, vascular adhesion molecule-1 (VCAM-1) and intracellular adhesion molecule-1 (ICAM-1) on activated endothelial cells (EC). This up-regulation of endothelial adhesion molecules subsequently mediates initial attachment and restrained rolling of monocytes to the activated endothelium via the monocyte adhesion molecules P-selectin glycoprotein ligand-1 (PSGL-1), very late antigens-4 (VLA-4), macrophage antigen complex-1 (Mac-1) and lymphocyte function-associated antigen-1 (LFA-1) (Gerszten et al. 1998; Huo et al. 2000; Ley et al. 2007). Rolling monocytes are exposed to and activated by chemoattractants released by activated EC and this results in firm adherence and ultimately diapedesis of monocytes through the endothelium into the vessel wall (Chan et al. 2001; Ley et al. 2007).

Non-invasive monitoring of atherogenic hotspots on the arterial wall can be performed by molecular imaging. Currently, molecular imaging utilizes artificial contrast agents carrying specific adhesion molecules (e.g., antibodies) on their surface, facilitating binding to activated endothelium. Successful targeting requires accumulation of the contrast agent at the targeted site. Therefore, contrast agents require specific properties, such as a long circulating half-life, a sensitive and selective binding capacity to the target site of interest, a resistance to shear stress after binding and a long residence time at the target site. Several targeted ultrasound contrast agents have been described in literature, such as echogenic liposomes (AlkanOnyuksel et al. 1996; Huang et al. 2002), microbubbles (Klibanov 2006; Klibanov et al. 1997), and perfluorocarbon nanoparticles (Lanza et al. 1996; Wickline et al. 2002). Until now, most of these targeted ultrasound contrast agents encounter problems in half-life time, sensitivity and binding selectivity to the target site. Moreover, in vivo adherence in large and middle-sized arteries under physiological shear stress circumstances is low.

An alternative to the use of artificial contrast agents is provided by monocytes. Monocytes/macrophages are naturally equipped to adhere selectively to the activated endothelium and to resist physiological shear stresses in large and middlesized arteries. Furthermore, macrophages are known to take up pathogens and foreign material, such as perfluorocarbon emulsions (Smith et al. 1994). Perfluorocarbon emulsions are attractive as acoustic contrast agents because of their favorable properties. Perfluorohexane (PFH) emulsions, for example, have an acoustic 
impedance ranging from $\sim 0.9 \mathrm{MRayl}\left(\right.$ at $20^{\circ} \mathrm{C}$ ) to $\sim 0.8 \mathrm{MRayl}$ (at $37^{\circ} \mathrm{C}$ ), which is considerably less than that of blood (1.5 MRayl) (Marsh et al. 2002). A higher relative difference in acoustic impedances favors a higher reflectivity at acoustic interfaces. Perfluorocarbon emulsions have no known toxic side effects, and are eventually removed from the system, mainly by expiration (Flaim 1994). In the present study the beneficial properties of PFH emulsions and macrophages were combined to generate an ultrasound contrast agent for molecular imaging of early atherosclerosis. We studied the feasibility of generating PFH emulsion loaded macrophages and investigated whether these cells show sufficient echogenicity to be detected by ultrasound and maintain their adhesive properties. Specifically, we considered the relations between (1) PFH uptake and echogenicity, (2) PFH uptake and effects on BMM adhesion molecules PSGL-1, VLA-4, Mac-1, and LFA-1, and (3) PFH uptake and static adhesion properties of macrophages to EC, directly after PFH loading and after 24 hours.

\section{Materials and Methods}

\section{Materials}

Perfluorohexane $\left(C_{6} F_{14}\right)$, cholesterol, Dulbecco's Modified Eagle Medium (DMEM), 2-mercaptoethanol and phosphate buffer saline (PBS) were supplied by SigmaAldrich (Steinheim, Germany). L- $\alpha$-Phosphatidylcholine, 1,2-Dipalmitoyl-sn-Glycero3-Phosphoethanolamine and Lissamine Rhodamine PE were purchased from Avanti Polar Lipids (Alabaster, Al, USA). Phycoerythrin (PE)-labeled PSGL-1, PE-labeled Mac1, Fluorescein isothiocynatae (FITC)-labeled LFA-1, and FITC-labeled F4/80 were obtained from BD Biosciences (Erembodegem, Belgium) and PE-labeled VLA-4 from Cedarlane (Burlington, Ontario, Canada). RPMI-1640, Glutamine, sodium pyruvate, Penicillin, Streptomycin, L-glutamine, Hepes, Trypsin, and EDTA, were obtained from Gibco Invitrogen (Breda, The Netherlands), heat inactivated fetal calf serum from Bodinco B.V. (Alkmaar, The Netherlands), culture dishes and well plates from Greiner Bio-one B.V. (Alphen aan de Rijn, The Netherlands) and tumor necrosis factor- $\alpha$ (TNF- $\alpha$ ) from PeproTech EC (London, United Kingdom).

\section{Preparation of PFH emulsions}

PFH emulsions were composed of PFH $(40 \% \mathrm{v} / \mathrm{v})$ and a surfactant co-mixture $10.5 \%$, $w / v)$. This mixture contained $68 \mathrm{~mol} \% \mathrm{~L}-\alpha$-Phosphatidylcholine, $30 \mathrm{~mol} \%$ cholesterol and 2 mol\% 1,2-Dipalmitoyl-sn-Glycero-3-Phosphoethanolamine. To check the concentration dependent uptake, the PFH emulsion was fluorescently labeled with 0.1 mol\% of Lissamine Rhodamine PE. The surfactant co-mixture was dried by evapora- 
tion at $60^{\circ} \mathrm{C}$ under nitrogen. The lipid film was dispersed into deionized water. Perfluorohexane was added to the lipid suspension and the resulting solution was preemulsified for approximately 1 minute on a vortex and then repetitively (25 times) extruded with an extruder device (Avanti Polar Lipids, Alabaster, Al, USA) through a polycarbonate membrane filter $(\varnothing$ filter $18 \mathrm{~mm}$, Whatman, 's-Hertogenbosch, the Netherlands) with a pore diameter of $1.0 \mu \mathrm{m}$, at $60^{\circ} \mathrm{C}$. To remove liposomes and non-incorporated lipids the samples were washed and centrifugated at 3100 RPM for 30 minutes. PFH emulsions were resuspended in $2 \mathrm{~mL}$ phosphate buffer saline (PBS) and kept under nitrogen at $4^{\circ} \mathrm{C}$ until use.

\section{Cell culture}

Bone marrow derived macrophages (BMM) were obtained from C57B/6 mice according to standard procedures (Peiser et al. 2000). Cells were cultured in R10 (RPMI-1640 supplemented with $10 \%$ heat-inactivated fetal calf serum, $100 \mathrm{U} / \mathrm{ml}$ penicillin, 100] $\mathrm{g} / \mathrm{mL}$ streptomycin, $2 \mathrm{mM}$ L-glutamine, $10 \mathrm{mM}$ Hepes with the addition of 15\% L929-cell-conditioned medium (LCM) (Hume and Gordon 1983).

Mouse brain endothelioma (b.End5) cells (courtesy of Angiogenesis Laboratory, department of Pathology, University Maastricht, the Netherlands) were cultured in Dulbecco's Modified Eagle Medium (DMEM) containing 10\% heat-inactivated fetal calf serum, $1 \%$ glutamine, $5 \mu \mathrm{mol} / / 2$-mercaptoethanol, $1 \mathrm{mmol} / \mathrm{l}$ sodium pyruvate and penicillin streptomycin at $37^{\circ} \mathrm{C}$ in a $5 \% \mathrm{CO}_{2}$ incubator. All b. End5 cells were harvested using Trypsin EDTA and PBS solution (Dirkx et al. 2006).

\section{Loading of BMM with PFH emulsions}

BMM (seeded in 6 -well plates), $2 \times 10^{6}$, were incubated with $0.5,1,2$, or $4 \% \mathrm{v} / \mathrm{v}$ (rhodamine-labeled) $\mathrm{PFH}$ emulsions for 3 hours at $37^{\circ} \mathrm{C}$ in a $5 \% \mathrm{CO}_{2}$ incubator. After PFH loading, BMM were washed with $\mathrm{R} 10$ to remove non-incorporated $\mathrm{PFH}$ emulsions and either processed immediately, hereafter referred to as Oh BMM, or placed on normal R10 medium for another 24 hours (24h BMM). Finally cells were washed, collected, and centrifuged at 1200 RPM for 5 min at $4^{\circ} \mathrm{C}$. The supernatants, containing any residual PFH emulsions and cell debris, were removed. Cell viability was monitored microscopically and by counting the numbers of viable cells upon harvesting. Control $(0 \% \mathrm{v} / \mathrm{v})$ and loaded BMM were resuspended in R10 or PBS and kept on ice $\left(4^{\circ} \mathrm{C}\right)$ until further experiments. 


\section{PFH emulsion uptake by BMM}

The uptake of rhodamine-labeled PFH emulsions $(0.5,1,2$, or $4 \% \mathrm{v} / \mathrm{v})$ by BMM was determined directly after incubation by flow cytometry using a FACSCalibur (BD Bioscience, Erembodegem, Belgium).

\section{Ultrasound study}

Three hundred $\mathrm{mL}$ of agar solution $(1 \% \mathrm{w} / \mathrm{v}$ ) was poured (height $-25 \mathrm{~mm}$ ) in a plastic container, casted into the desired form with a mould to obtain multiple circular wells (volume $-1 \mathrm{~mL}$, bottom surface area $\sim 1.3 \mathrm{~cm}^{2}$ ) and cured at room temperature (Fig. 1). After infusing control and PFH loaded (1, 2 and $4 \% \mathrm{v} / \mathrm{v}$ ) BMM into the agar wells, the cells were allowed to settle for 30 minutes on the well bottom surface, forming an approximate monolayer. Based on previous microscopic evaluation of control and loaded BMM in a 6-well plate (surface area $-9.6 \mathrm{~cm}^{2}$ ) the minimal number of cells required to obtain a monolayer on the surface of the agar well is approximately 270,000 cells. A 7.5 MHz linear array transducer (Picus, Esaote Maastricht, the Netherlands) was placed above the agar, suspended in PBS, with the focal point set at the PBS-agar interface $(25 \mathrm{~mm})$ at the bottom of the wells. B-mode recordings were taken at three different cross-sections through both wells (Fig. 1), containing control BMM and PFH loaded (1,2 and 4\% v/v) BMM. Radiofrequency (RF) signals were captured and analyzed off-line with a proprietary Matlab routine to determine the echo amplitude of the control and loaded BMM monolayers. The maximum of the RF signal envelope was determined at 10 positions (equally spaced at $1.3 \mathrm{~mm}$ ) per cross-section per well, yielding 30 data points per well in total. For each well, the mean RF amplitude per well was calculated and used to compare echo levels between loaded and control BMM. Acoustic reflectivity ratio was expressed in $\mathrm{dB}$ and defined as the mean echo level of the loaded BMM divided by that of the control BMM within the same registration.

\section{Adhesion molecule expression}

Control and loaded $(1,2$, and $4 \% \mathrm{v} / \mathrm{v})$ and BMM were stained for adhesion molecules PSGL-1, VLA-4, Mac-1, LFA-1 and macrophage marker F4/80, to study the effect of PFH emulsion loading on the surface marker expression. BMM were subsequently washed and analyzed by flow cytometry using a FACSCalibur (BD Biosciences, Erembodegem, Belgium). 


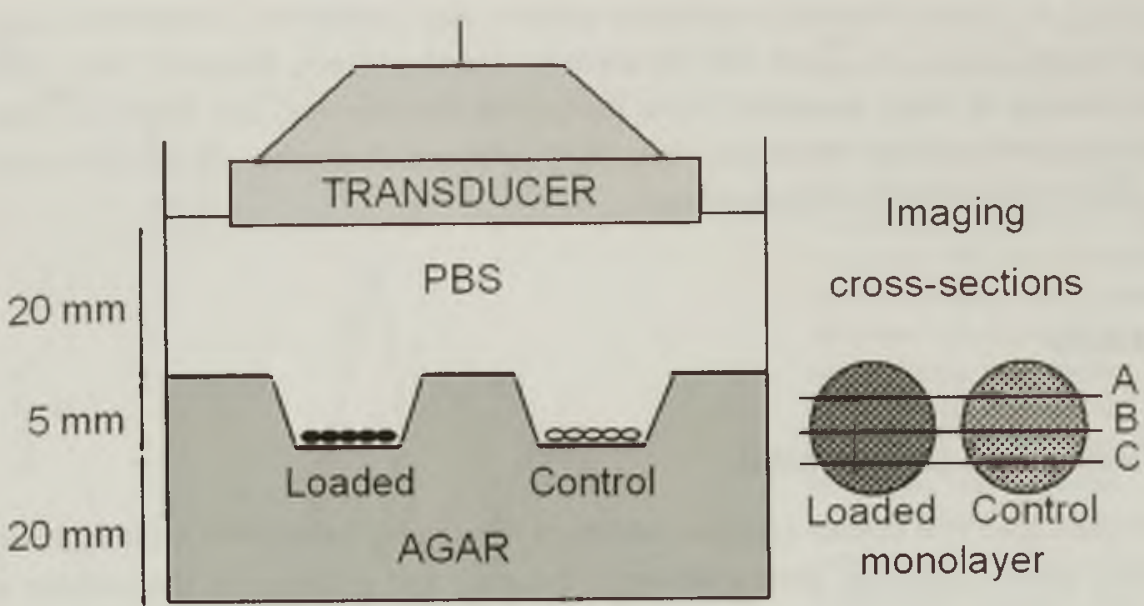

Figure 1. Experimental ultrasound setup. Monolayers of control $(0 \% \mathrm{v} / \mathrm{v})$ and loaded $(1,2$ and $4 \% \mathrm{v} / \mathrm{v})$ BMM (indicated by different hatching) were deposited in wells on $1 \% \mathrm{w} / \mathrm{v}$ agar. A $7.5 \mathrm{MHz}$ linear array ultrasound transducer, suspended in PBS, was positioned above a pair of wells, allowing paired comparison of reflectivity between loaded and their control cells. For each pair of wells simultaneous recordings were made at three different cross-sections (A-C).

\section{Static adhesion assay}

The b.End5 cells were seeded in 6 -well plates $(750,000$ cells per well) and cultured for 2 days until they reached confluency. For activation, $b$. End 5 cells were incubated with $40 \mathrm{ng} / \mathrm{ml}$ TNF- $\alpha$ for 4 hours. Subsequently, the b.End5 cell monolayers were washed and incubated for 30 minutes with control or loaded $(1,2$ and $4 \% v / v)$ BMM (250,000 cells per well). After 30 minutes, the medium was removed and the wells were washed twice with DMEM to remove non-adhering BMM. In each well, adhering BMM were counted in three fields, along a vertical cross-section (top, middle, and bottom), using an inverted microscope (Eclipse E800, Nikon) using a 20x objective lens. Two observers (D.C. and I.M.) performed the cell counts ( 3 counts per well per observer) independently. The mean count per well, based on the total of 6 counts, was used for further analysis.

\section{Statistical analyses}

All experiments were performed in triplicate and repeated. Data are presented as mean \pm standard deviation (SD), unless stated otherwise. Two-sample Student ttests were performed on ultrasound, FACS and adhesion data to detect statistical differences in acoustic reflectivity, in adhesive molecule expression, and in cell adhesion, respectively. Adhesion data were expressed as percentages of the adhesion of control BMM to unstimulated endothelial cells. To quantify the effect of PFH 
loading on static adhesion, regression analysis was performed. Calculations were performed using Cell Quest (BD Biosciences, Erembodegem, Belgium), SPSS (SPSS Inc Chicago, II, USA), GraphPad Prism (GraphPad Software Inc, San Diego, CA, USA) and Excel (Microsoft, Redmond, WA, USA) software. A p-value $<0.05$ (two-sided) was considered statistically significant.

\section{Results}

\section{PFH emulsion uptake by BMM}

We evaluated PFH uptake and the viability of PFH loaded BMM. PFH loading did not affect BMM viability as monitored by microscopy and counting of the number of viable cells harvested (data not shown). Fluorescent microscopy of control (Fig. 2A) and PFH loaded BMM (Fig. 2B) showed uptake of PFH emulsions with clear presence of intracellular fluorescence (Fig. 2C) after loading. Additionally, PFH emulsion uptake was measured by flow cytometry. Analysis was performed on gated cell populations to exclude small cell debris. The gate was based on the control BMM scatter and applied to all other populations. FACS analysis of BMM revealed a dosedependent PFH emulsion (0.5, 1, 2, and $4 \%$ v/v) uptake by BMM after 3 hours of loading (Fig. 3A and B).

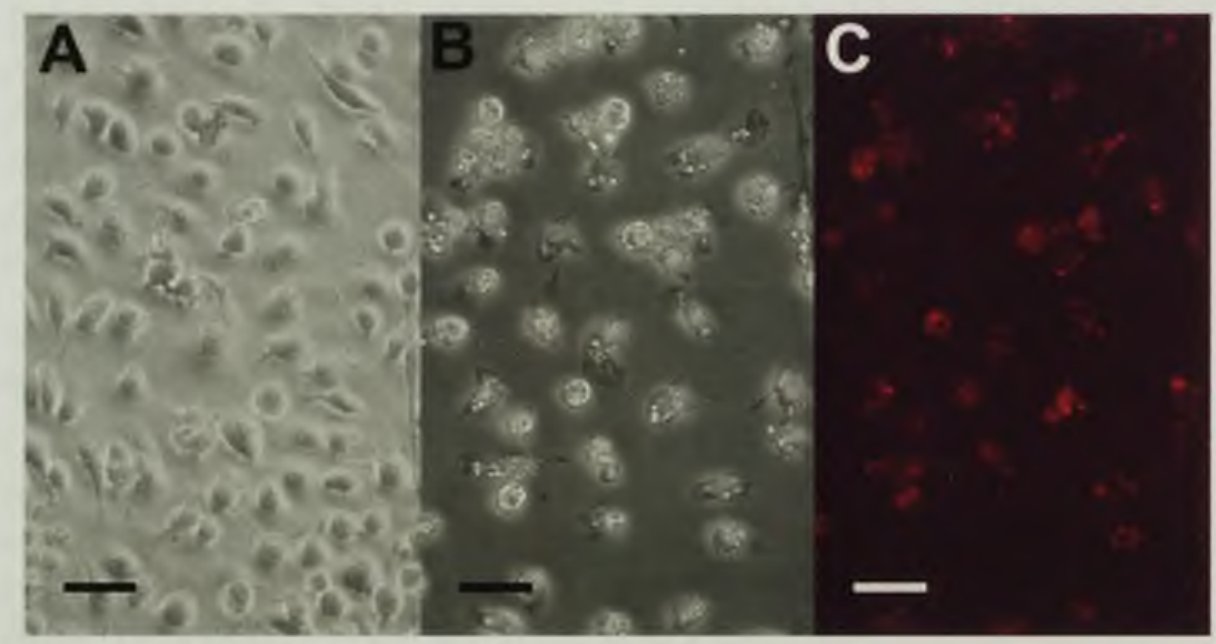

Figure 2. Microscopy images of (A) control $B M M$ and (B) BMM incubated with $1 \% \mathrm{v} / \mathrm{v}$ rhodaminelabeled PFH emulsions for three hours. PFH emulsions are visible as a speckle pattern within the cells. (C) Uptake was confirmed by fluorescence microscopy. Bar represents $40 \mu \mathrm{m}$. 
A

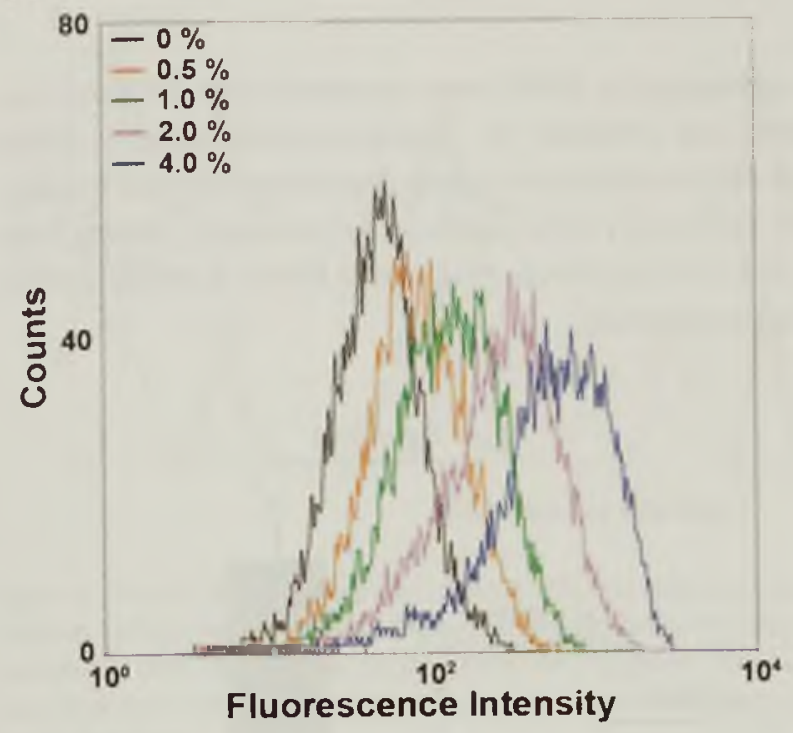

B

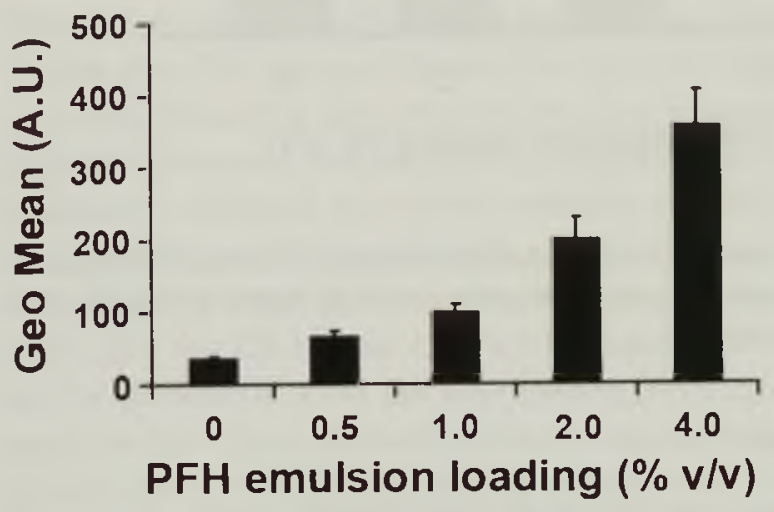

Figure 3. Dose dependent uptake of PFH by BMM after three hours of incubation as measured by flow cytometry. (A) Histograms show a shift in fluorescence intensity with increasing PFH concentrations ( $0 \%$ control black; $0.5 \%$ purple; $1 \%$ green; $2 \%$ red, and $4 \% \mathrm{v} / \mathrm{v}$ blue). Gating was applied to exclude small cell debris. (B) Quantitative analysis of the histograms $(n=3)$ shows an increase in geo mean which is consistently with PFH concentration. Bars represent mean \pm SD. 


\section{Ultrasound study}

To investigate the effect on echogenicity, BMM were incubated with different concentrations of PFH emulsions and analyzed by B-mode ultrasonography. BMM loaded with PFH $(0,1,2$, and $4 \% \mathrm{v} / \mathrm{v})$ exhibited a dose-dependent increase in echogenicity (Fig. 4). The acoustic reflectivity ratio significantly increased, ranging from $5.6 \pm 1.5 \mathrm{~dB}$ for $1 \% \mathrm{v} / \mathrm{v}$ to $17.7 \pm 1.7 \mathrm{~dB}$ for $4 \% \mathrm{v} / \mathrm{v}$ PFH loaded BMM. A similar pattern was found after 24 hours (data not shown).

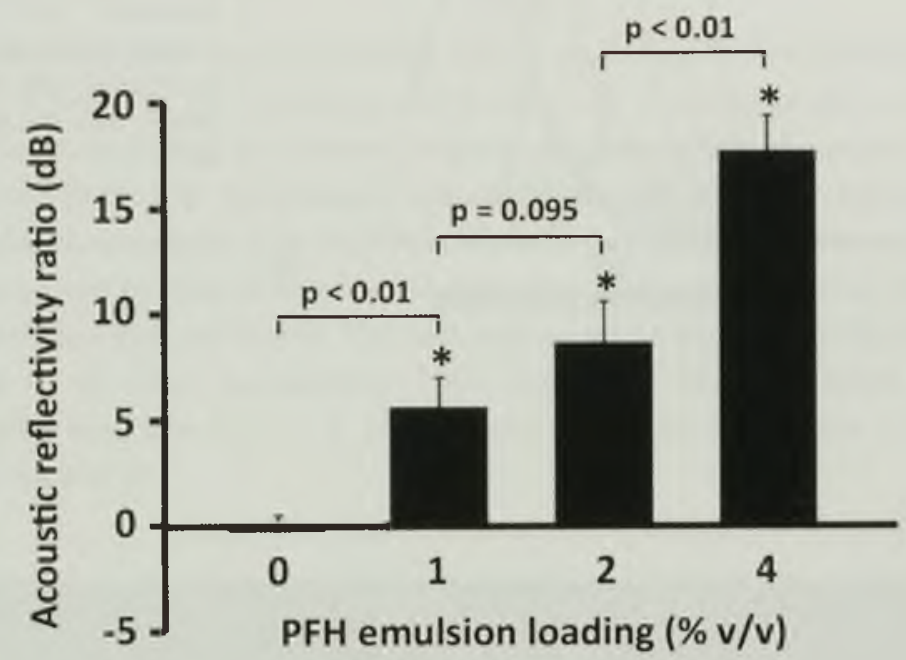

Figure 4. Acoustic reflectivity ratio of control vs loaded BMM (paired wells) as function of PFH loading $(1,2$ and $4 \% \mathrm{v} / \mathrm{v})$ indicates a dose dependent gain in echogenicity. ${ }^{*} p<0.05$, loaded BMM versus their own controls $(n=3)$. Bars represent mean \pm SD.

\section{Adhesion molecule expression}

The interaction of macrophages with the vessel wall depends on the presence of adhesion molecules on the surface of the macrophages. Therefore, the effects of PFH loading on the expression of several adhesion molecules were measured by flow cytometry directly (Oh) after PFH incubation and 24 hours later (24h). Analysis was performed on gated cell populations to exclude small cell debris (see previous). Results revealed no significant changes in BMM cell morphology and composition due to PFH loading. More importantly, PFH loading had also no effect on the expression levels of the BMM adhesion molecules PSGL-1, VLA-4, Mac-1 and LFA-1 (Fig. 5) and the general macrophage marker F4/80 (data not shown). 

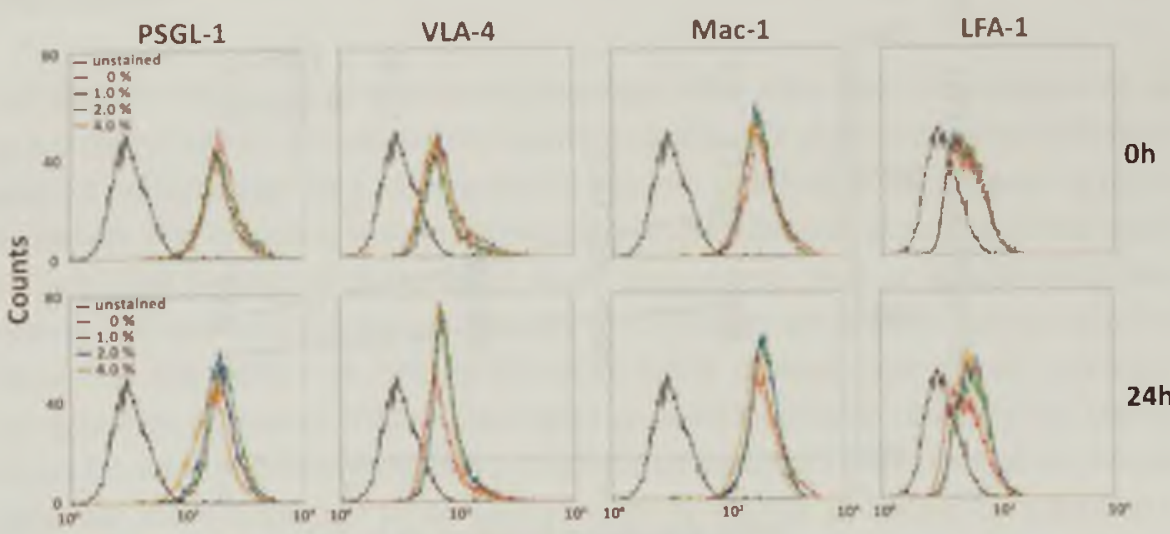

Fluorescence Intensity

Figure 5. Flow cytometry histograms of BMM adhesion molecule expression, directly after PFH loading (0h) and 24 hours after loading (24h). Gating was applied to exclude small cell debris. Histograms show comparable shifts for both control $(0 \%$, black) and $1 \%$ (green), $2 \%$ (red), and $4 \%$ v/v (blue) loaded BMM. Unstained control BMM are indicated by grey shading. Control BMM of the Oh study acted as reference for the $24 \mathrm{~h}$ study.

\section{Static adhesion assay}

Adhesion of control and PFH loaded BMM to endothelial b.End5 cells was measured directly after PFH loading (Oh) and after 24 hours (24h) (Fig. 6A and B). The b.End5 cells were stimulated with TNF- $\alpha$ to enhance expression of VCAM-1, P-selectin and E-selectin. Averaged over all loading concentrations $(0-4 \% \mathrm{v} / \mathrm{v})$, TNF- $\alpha$ stimulation significantly enhanced the relative adhesion of BMM both directly $(26 \% ; p<0.001)$, and $24 \mathrm{~h}(17 \% ; \mathrm{p}<0.001)$ after loading. In the Oh assay, TNF- $\alpha$ stimulation increased the number of adhering BMM from $135 \pm 8$ to $182 \pm 39$ for control $(0 \% \mathrm{v} / \mathrm{v})$, and from $115 \pm 3$ to $155 \pm 47$ for $4 \% \mathrm{v} / \mathrm{v}$ PFH loaded BMM. The same trend was observed for the adhesion of BMM 24h after loading (from $220 \pm 15$ to $278 \pm 11$ for control, and from $219 \pm 26$ to $236 \pm 47$ for $4 \%$ PFH loaded BMM). As shown in Figure 6 , relative adhesion of PFH loaded BMM to unstimulated EC was not affected ( $p=0.07$ for $0 \mathrm{~h}$, and $\mathrm{p}=0.97$ for $24 \mathrm{~h}$ ). Relative adhesion to stimulated EC dose-dependently decreased with increased PFH loading for the Oh BMM $(p=0.03)$, but not for the $24 \mathrm{~h}$ $B M M(p=0.09)$. Overall, the adhesion trends between unstimulated and stimulated EC were not statistically different for both $0 h(p=0.25)$ and $24 h(p=0.14) B M M$. 

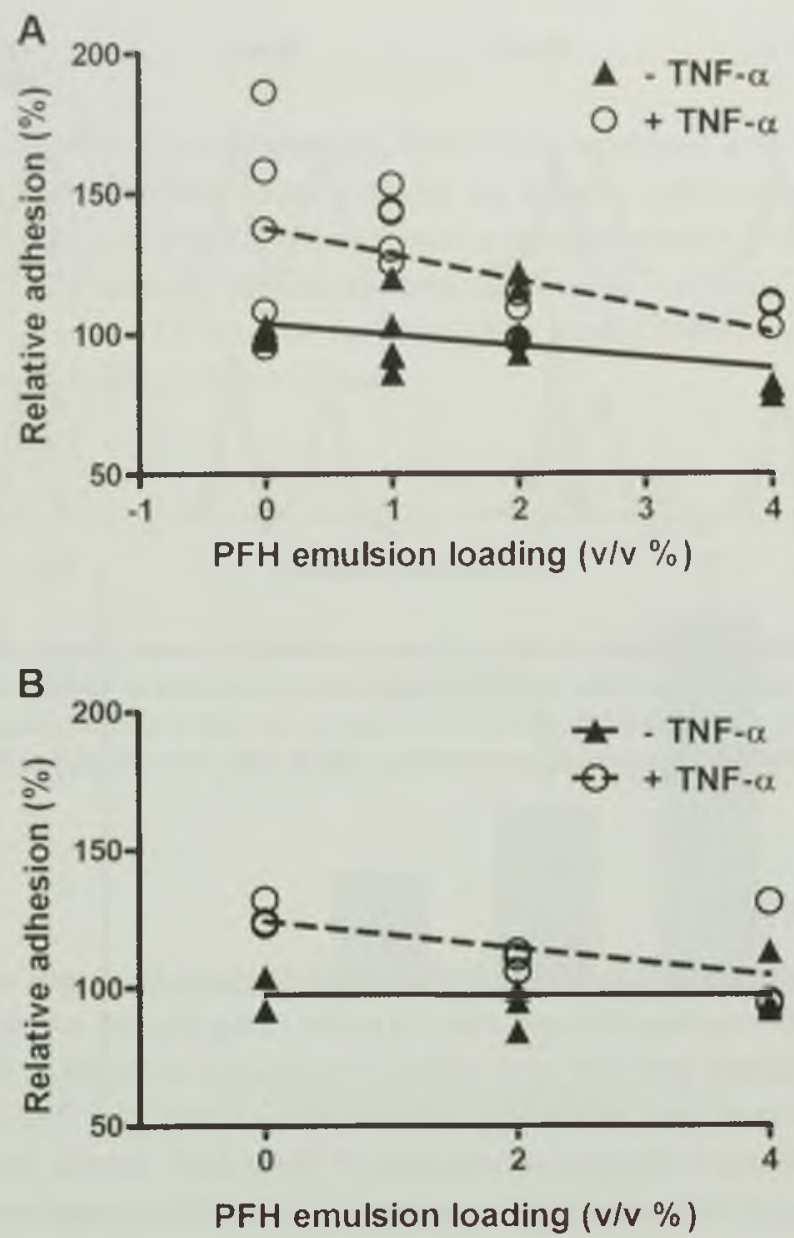

Figure 6. Relative adhesion of BMM to bEnd5 cells. (A) Directly after PFH loading BMM exhibited adhesion to unstimulated $b$.End5 celis. TNF- $\alpha$ stimulation of the endothelial cells enhanced adhesion by $26 \%$ ( $p<0.001$, averaged over $0-4 \% v / v$ ). PFH loading did not affect BMM adhesion to unstimulated $b$. End5 cells (solid line; $p=0.07$ for trend), while adhesion to stimulated $b$. End 5 celis significantly decreased with increased loading (dotted line; $p=0.03$ for trend). Slopes of both trends were not significantly different $(p=0.25)$. (B) After 24 hours, PFH loaded $(0 \%, 2 \%$ and $4 \% \mathrm{v} / \mathrm{v}$ ) BMM exhibited adhesion to unstimulated $b$. End5 cells. TNF- $a$ stimulation enhanced adhesion by $17 \%(p<0.001)$. PFH loading did not affect BMM adhesion to unstimulated (solid line; $p=0.09$ for trend) and stimulated b. End5 cells (dashed line; $p=0.97$ for trend). Slopes of both trends were not significantly different $(p=0.14)$. Triangles $(\Delta)$ represent the mean count of adhering BMM per well to unstimulated (-TNF- $a$ ) b. End5 cells. Circles (O) represent the mean count of adhering BMM per well to stimulated (+TNF- $\alpha$ ) b.End5 cells. All data are presented relative to the adhesion of control $(0 \% \mathrm{v} / \mathrm{v}) \mathrm{BMM}$ to unstimulated $b$. End 5 cells. 


\section{Discussion}

The present study was performed to investigate the potential of monocytes to act as a targeted vehicle for ultrasound contrast agents. We used primary bone marrow derived macrophages and an endothelial cell line as a first in vitro model to mimic monocyte PFH emulsion uptake, echogenicity, and adhesion potential to the endothelium. The findings of the present study demonstrate that at least in an in vitro setting PFH loaded macrophages can be used as a contrast agent for ultrasound. We show that the uptake of PFH emulsions by BMM is dose-dependently related to echogenicity. Moreover, PFH loaded BMM showed functional adherence to (stimulated) EC, which was still effective 24 hours after loading. To the best of our knowledge, our study is the first to demonstrate the echogenic and adhesion potential of PFH loaded macrophages.

Ultrasound imaging requires a high reflectivity that depends on the acoustic properties of the contrast agent relative to that of its surroundings. The PFH emulsions used in this study have a low acoustic impedance $\left(\sim 0.8 \mathrm{MRayl}\right.$ at $\left.37^{\circ} \mathrm{C}\right)$ relative to that of blood (1.5 MRayl). Compared to other types of perfluorocarbon emulsions they exhibit the lowest acoustic impedance. The higher the relative difference in acoustic impedance is, the better the reflectivity will be (Marsh et al. 2002). The observation that BMM can be effectively loaded with PFH emulsions corroborates previous studies that observed uptake of perfluorocarbon based emulsions by monocytes and macrophages (Hsu et al. 2003; Hsu and Peng 2001; Peng and Hsu 2001; Smith et al. 1994). New is that the reflectivity of BMM is dose dependently related to the volume of PFH emulsions taken up by these cells, and that the loaded cells can be readily detected with a commercially available ultrasound system. The finding that the echogenicity of the loaded BMM is still sufficient to be detected 24 hours after incubation illustrates the feasibility of this approach in vivo, where a longer circulation time favors accumulation of the contrast agent at the target site.

One aim of our study was to investigate the effect of PFH loading on the adhesion properties of BMM. We observed that loaded BMM show a similar surface expression of PSGL-1, VLA-4, Mac-1 and LFA-1 as control BMM. Furthermore, under stationary no shear conditions, PFH loaded BMM adhere to unstimulated EC while TNFa stimulation enhances the adhesion (Dirkx et al. 2003; Gunzer et al. 2005; Reiss and Engelhardt 1999; Reiss et al. 1998; Rohnelt et al. 1997). Our findings illustrate that adhesion to EC remains functional, even though we observed a PFH dose dependent attenuation in static adhesion. Imaging in vivo involves the complex interplay between bioavailability, sensitivity and selectivity to target sites in relation to shear stress on the one hand (Flaim 1994; Patil et al. 2001; Rychak et al. 2006a; Rychak et al. 2006b), and the acoustic properties and eventual density of the con- 
trast agent with implications for ultrasound reflectivity on the other (Couture et al. 2007; Dayton and Rychak 2007; de Jong et al. 2002; Marsh et al. 2007). Therefore, the results of our static adhesion assay cannot be used to derive an optimal PFH dose for in vivo applications.

The aim of the present study was to establish a proof of principle for the use of PFH loaded monocytes. Our findings demonstrate that PFH loaded BMM maintain their functional adhesive properties for at least 24 hours and have a good potential to be used as a targeted ultrasound contrast agent. To rate our findings at their true value, experiments in a high shear stress model of arterial inflammation are required.

\section{Acknowledgement}

This study was supported by Senter (Ministry of Economic Affairs), grant BSIK03033. 


\section{References}

Alkan-Onyuksel H, Demos SM, Lanza GM, Vonesh MJ, Klegerman ME, Kane BJ, Kuszak J, McPherson DD. Development of inherently echogenic liposomes as an ultrasonic contrast agent. J Pharm Sci 1996;85:486-490.

Chan JR, Hyduk SJ, Cybulsky MI. Chemoattractants induce a rapid and transient upregulation of monocyte alpha4 integrin affinity for vascular cell adhesion molecule 1 which mediates arrest: an early step in the process of emigration. J Exp Med 2001;193:1149-1158.

Couture $O$, Cherin E, Foster FS. Model for the ultrasound reflection from micro-beads and cells distributed in layers on a uniform surface. Phys Med Biol 2007;52:4189-4204.

Dayton PA, Rychak JJ. Molecular ultrasound imaging using microbubble contrast agents. Front Biosci 2007;12:5124-5142

de Jong N, Bouakaz A, Frinking P. Basic acoustic properties of microbubbles. Echocardiography 2002;19:229-240.

Dirkx AE, oude Egbrink MG, Castermans K, van der Schaft DW, Thijssen VL, Dings RP, Kwee L, Mayo KH, Wagstaff J, Bouma-ter Steege JC, Griffioen AW. Anti-angiogenesis therapy can overcome endothelial cell anergy and promote leukocyte-endothelium interactions and infiltration in tumors. Faseb J 2006;20:621-630.

Dirkx AE, Oude Egbrink MG, Kuijpers MJ, van der Niet ST, Heijnen VV, Bouma-ter Steege JC, Wagstaff J, Griffioen AW. Tumor angiogenesis modulates leukocyte-vessel wall interactions in vivo by reducing endothelial adhesion molecule expression. Cancer Res 2003;63:2322-2329.

Flaim SF. Pharmacokinetics and side effects of perfluorocarbon-based blood substitutes. Artif Cells Blood Substit Immobil Biotechnol 1994;22:1043-1054.

Gerszten RE, Lim YC, Ding HT, Snapp K, Kansas G, Dichek DA, Cabanas C, Sanchez-Madrid F, Gimbrone MA, Jr., Rosenzweig A, Luscinskas FW. Adhesion of monocytes to vascular cell adhesion molecule-1transduced human endothelial cells: implications for atherogenesis. Circ Res 1998;82:871-878.

Gunzer M, Riemann H, Basoglu Y, Hillmer A, Weishaupt C, Balkow S, Benninghoff B, Ernst B, Steinert M, Scholzen T, Sunderkotter C, Grabbe S. Systemic administration of a TLR7 ligand leads to transient immune incompetence due to peripheral-blood leukocyte depletion. Blood 2005;106:2424-2432.

Hansson GK. Inflammation, atherosclerosis, and coronary artery disease. N Engl J Med 2005;352:16851695.

Hsu YC, Acuna M, Tahara SM, Peng CA. Reduced phagocytosis of colloidal carriers using soluble CD47. Pharm Res 2003;20:1539-1542.

Hsu YC, Peng CA. Diminution of phagocytosed perfluorocarbon emulsions using perfluoroalkylated polyethylene glycol surfactant. Biochem Biophys Res Commun 2001;283:776-781

Huang SL, Hamilton AJ, Pozharski E, Nagaraj A, Klegerman ME, MCPherson DD, MacDonald RC. Physica! correlates of the ultrasonic reflectivity of lipid dispersions suitable as diagnostic contrast agents. UItrasound Med Biol 2002;28:339-348.

Hume DA, Gordon S. Optimal conditions for proliferation of bone marrow-derived mouse macrophages in culture: the roles of CSF-1, serum, Ca2t, and adherence. J Cell Physiol 1983;117:189-194.

Huo Y, Hafezi-Moghadam A, Ley K. Role of vascular cell adhesion molecule-1 and fibronectin connecting segment-1 in monocyte rolling and adhesion on early atherosclerotic lesions. Circ Res 2000;87:153159.

Klibanov AL. Microbubble contrast agents: targeted ultrasound imaging and ultrasound-assisted drugdelivery applications. Invest Radiol 2006;41:354-362.

Klibanov AL, Hughes MS, Marsh JN, Hall CS, Miller JG, Wible JH, Brandenburger GH. Targeting of ultrasound contrast material. An in vitro feasibility study. Acta Radiol Suppl 1997;412:113-120.

Lanza GM, Wallace KD, Scott MJ, Cacheris WP, Abendschein DR, Christy DH, Sharkey AM, Miller JG, Gaffney PJ, Wickline SA. A novel site-targeted ultrasonic contrast agent with broad biomedical application. Circulation 1996;94:3334-3340. 
Ley K, Laudanna C, Cybulsky MI, Nourshargh S. Getting to the site of inflammation: the leukocyte adhesion cascade updated. Nat Rev Immunol 2007;7:678-689.

Marsh JN, Hall CS, Wickline SA, Lanza GM. Temperature dependence of acoustic impedance for specific fluorocarbon liquids. J Acoust Soc Am 2002;112:2858-2862.

Marsh JN, Partlow KC, Abendschein DR, Scott MJ, Lanza GM, Wickline SA. Molecular imaging with targeted perfluorocarbon nanoparticles: quantification of the concentration dependence of contrast enhancement for binding to sparse cellular epitopes. Ultrasound Med Biol 2007;33:950-958.

Patil VRS, Campbell Cl, Yun YH, Slack SM, Goetz DJ. Particle Diameter Influences Adhesion under Flow. Biophys J 2001;80:1733-1743.

Peiser L, Gough PJ, Kodama T, Gordon S. Macrophage class A scavenger receptor-mediated phagocytosis of Escherichia coli: role of cell heterogeneity, microbial strain, and culture conditions in vitro. Infect Immun 2000;68:1953-1963.

Peng CA, Hsu YC. Fluoroalkylated polyethylene glycol as potential surfactant for perfluorocarbon emulsion. Artif Cells Blood Substit Immobil Biotechnol 2001;29:483-492.

Reiss $Y$, Engelhardt B. T cell interaction with ICAM-1-deficient endothelium in vitro: transendothelial migration of different T cell populations is mediated by endothelial ICAM-1 and ICAM-2. Int Immunol 1999;11:1527-1539.

Reiss $Y$, Hoch $G$, Deutsch U, Engelhardt B. T cell interaction with ICAM-1-deficient endothelium in vitro: essential role for ICAM-1 and ICAM-2 in transendothelial migration of $T$ cells. Eur J Immunol 1998;28:3086-3099.

Rohnelt RK, Hoch G, Reiss Y, Engelhardt B. Immunosurveillance modelled in vitro: naive and memory $T$ cells spontaneously migrate across unstimulated microvascular endothelium. Int Immunol 1997;9:435-450.

Rychak JJ, Li B, Acton ST, Leppanen A, Cummings RD, Ley K, Klibanov AL. Selectin ligands promote ultrasound contrast agent adhesion under shear flow. Mol Pharm 2006a;3:516-524.

Rychak JJ, Lindner JR, Ley K, Klibanov AL. Deformable gas-filled microbubbles targeted to P-selectin. J Control Release 2006b;114:288-299.

Smith DJ, Kornbrust ES, Lane TA. Phagocytosis of a fluorescently labeled perflubron emulsion by a human monocyte cell line. Artif Cells Blood Substit Immobil Biotechnol 1994;22:1215-1221.

Wickline SA, Hughes M, Ngo FC, Hall CS, Marsh JN, Brown PA, Allen JS, McLean MD, Scott MJ, Fuhrhop RW, Lanza GM. Blood contrast enhancement with a novel, non-gaseous nanoparticle contrast agent. Acad Radiol 2002;9 Suppl 2:5290-293. 


\section{The in vivo potential of echogenic} perfluorohexane-loaded macrophages to detect activation of vascular adhesion

L.M. Kornmann ${ }^{1}$, A. Zernecke ${ }^{2}$, D.M.J. Curfs ${ }^{3}$, B.J.A. Janssen ${ }^{4}$, C. Weber ${ }^{2}$, M.P.J. de Winther ${ }^{3}$, R.S. Reneman ${ }^{5}$, K.D. Reesink ${ }^{1}$, A.P.G. Hoeks ${ }^{1}$

Departments of Biomedical Engineering ${ }^{1}$, Molecular Genetics ${ }^{3}$, Pharmacology ${ }^{4}$, and Physiology ${ }^{5}$, Cardiovascular Research Institute Maastricht, Maastricht University, Maastricht, the Netherlands.

Institute for Molecular Cardiovascular Research ${ }^{2}$, University Hospital Aachen, RWTH Aachen University, Aachen, Germany.

Submitted to Molecular Imaging and Biology 


\section{Abstract}

In this study we investigated in mice the potential of perfluorohexane (PFH) loaded monocytes to act as ultrasound contrast agent, focusing on echo signal enhancement and selective adhesion to activated endothelium.

Enhancement of blood echogenicity was evaluated with a mouse echo scanner after jugular vein injection of PFH loaded ( 2 and $4 \% \mathrm{v} / \mathrm{v}$ ) and unloaded $(0 \%)$ bone marrow macrophages (BMM). The interaction of PFH loaded (2\%) and unloaded BMM with TNF- $\alpha$ stimulated carotid artery endothelium after tail vein injection was assessed by means of intravital microscopy. The diameter of the loaded and unloaded BMM was determined in vitro and compared to that of native leukocytes.

PFH loaded and unloaded BMM had a similar diameter, but a larger one than native leukocytes. After intravenous injection, PFH loaded BMM enhanced the echo level of arterial blood in mice. Bolus injection via the tail vein of 2.5 million $2 \% \mathrm{v} / \mathrm{v}$ loaded BMM was well tolerated by the animals. The injected BMM exhibited rolling and adhesion behavior at the TNF- $\alpha$ stimulated carotid artery endothelium, similar to native blood leukocytes. Rolling behavior was not different $(p=0.33$ ) between PFH loaded and unloaded BMM. Similarly, there was no difference in the number of adhering loaded and unloaded BMM ( $p=0.25)$.

Our findings demonstrate that, in vivo, perfluorohexane loaded macrophages enhance blood echogenicity, are able to pass the pulmonary circulation and become visible on the arterial side. Moreover, they are able to roll and adhere selectively to activated carotid artery endothelium under physiological flow conditions. 


\section{Introduction}

Atherosclerosis starts with lipid accumulation in so-called hotspots at sites of endothelial activation. Early detection of these athero-prone sites might help to identify people at risk for cardiovascular events like stroke and myocardial infarction. Ultrasound molecular imaging utilizes ultrasound contrast agents that carry specific adhesion molecules (e.g., antibodies) on their surface, facilitating binding to such specific targets as atherogenic areas on the arterial wall (Demos et al. 1999; Kaufmann et al. 2007; Klibanov et al. 1998; Klibanov et al. 2006; Lanza et al. 1996; Villanueva et al. 1998; Weller et al. 2002; Wickline et al. 2007). In the past decade, experimental and clinical validation studies have shown that for the microcirculation targeted ultrasound contrast agents, such as echogenic liposomes, microbubbles and perfluorocarbon emulsions, do improve visualization of specific structures (Barnard et al. 2008; Bruce et al. 2004; Chappell and Price 2006; Lindner 2002; Rovai et al. 2000). These results have led to high expectations for molecular ultrasound imaging of activated endothelium of large and middle-sized arteries (Behm and Lindner 2006; Dayton and Rychak 2007; Lindner 2002; Lindner 2004; Rychak et al. 2007; Zhao et al. 2007). The optimistic view emanating from many of the studies on adhesion properties of ultrasound contrast agents in larger arteries (Behm and Lindner 2006; Dayton and Rychak 2007; Lindner 2002; Lindner 2004; Rychak et al. 2007; Zhao et al. 2007), however, should be interpreted with care. They were usually performed in flow chambers studies after static incubation or under low shear stress (0.02-0.5 Pa) conditions (Klibanov et al. 2006; Rychak et al. 2005; Rychak et al. 2006a; Takalkar et al. 2004; Weller et al. 2002). Moreover, the contrast agents used exhibited low capture and weak adhesion efficiency even at those low shear stresses. The application of deformable agents, multiple contrast agent surface ligands, or intermittent flow conditions enhanced vascular adhesion in vitro and in animals, but the magnitude of these improvements is still limited (Demos et al. 1998; Hamilton et al. 2002; Kaufmann et al. 2007; Klibanov et al. 1997; Klibanov et al. 1998; Klibanov et al. 2006; Marsh et al. 2007; Rychak et al. 2006a; Rychak et al. 2006b; Weller et al. 2002; Weller et al. 2005). Especially in small rodents, the adherence requirements for ultrasound contrast agents are even more demanding than in in vitro studies. In small animals, the mean wall shear stress in the common carotid artery is about $8 \mathrm{~Pa}$ (Cheng et al. 2007; Greve et al. 2006), which is substantially higher than the $1.2 \mathrm{~Pa}$ reported for humans (Reneman et al. 2006; Samijo et al. 1998).

Considering the difficulties related to adhesion encountered with artificial contrast agents in vivo, circulatory cells like leukocytes may serve as a potential alternative. Leukocytes, such as monocytes, are naturally equipped to adhere selectively to activated endothelium and can resist physiological shear stresses in large- and mid- 
dle-sized arteries, while adhering. Studies with noninvasive techniques like PET/CT have demonstrated the possibility to use monocytes as a contrast agent vehicle for in vivo imaging (Basu et al. 2009; Kircher et al. 2008; van Hemert et al. 2007). We previously reported on the in vitro potential of monocytes to act as a targeted vehicle for ultrasound contrast agents (Kornmann et al. 2008). Using primary murine bone marrow derived macrophages ( $B M M)$ ), we demonstrated that the echogenicity of these cells is dose-dependently related to their perfluorohexane uptake. Moreover, we showed that loaded BMM maintain their functional adhesive properties under static conditions.

In the present pilot series of animal experiments, we aim to obtain proof of principle for the applicability of perfluorohexane loaded BMM as an ultrasound contrast agent in vivo. In vitro we study whether loaded BMM are different in diameter compared to blood leukocytes. We further investigate whether in mice in vivo loaded BMMs (1) are able to pass the pulmonary circulation, (2) show sufficient ultrasound echogenicity to allow detection in flowing blood and (3) interact with cytokine stimulated endothelial cells of the carotid artery.

\section{Materials}

Perfluorohexane (PFH, C6F14), cholesterol, Dulbecco's Modified Eagle Medium (DMEM), 2-mercaptoethanol and PBS were obtained from Sigma-Aldrich (Steinheim, Germany). L-a-Phosphatidylcholine and 1,2-Dipalmitoyl-sn-Glycero-3Phosphoethanolamine were purchased from Avanti Polar Lipids (Alabaster, Al, USA). RPMI-1640, Glutamine, sodium pyruvate, Penicillin, Streptomycin, L-glutamine, Hepes, Trypsin and EDTA were obtained from Gibco Invitrogen (Breda, The Netherlands), heat inactivated fetal calf serum from Bodinco B.V. (Alkmaar, The Netherlands), culture dishes and well plates from Greiner Bio-one B.V. (Alphen aan de Rijn, The Netherlands). Fluorescent dye rhodamine $G$ was purchased from Molecular Probes (Karlsruhe, Germany) and tumor necrosis factor- $\alpha$ (TNF- $\alpha$ ) from PeproTec (London, UK).

\section{Preparation of PFH emulsions}

The PFH emulsions were composed of PFH ( $40 \% \mathrm{v} / \mathrm{v})$ and a surfactant co-mixture $(0.5 \% \mathrm{w} / \mathrm{v})$ as previously described (Kornmann et al. 2008). This mixture contained 68 mol\% L-a-Phosphatidylcholine, 30 mol\% cholesterol and 2 mol\% 1,2-Dipalmitoylsn-Glycero-3-Phosphoethanol-amine. The surfactant co-mixture was dried by evaporation at $60^{\circ} \mathrm{C}$ under nitrogen. The lipid film was dispersed into de-ionized water. Perfluorohexane was added to the lipid suspension and the resulting solution was pre-emulsified for approximately 1 minute on a vortex and then repetitively $(25$ 
times) run through an extrusion device (Avanti Polar Lipids, Alabaster, Al, USA) with a polycarbonate membrane filter (filter size $18 \mathrm{~mm}$, Whatman, 's-Hertogenbosch, the Netherlands) with a pore diameter of $1.0 \mu \mathrm{m}$, at $60^{\circ} \mathrm{C}$. To remove liposomes and non-incorporated lipids the samples were washed and centrifuged at 3100 RPM for 30 minutes. PFH emulsions were resuspended in $2 \mathrm{~mL}$ phosphate buffer saline (PBS) and kept under nitrogen at $4^{\circ} \mathrm{C}$ until use.

\section{Cell culture}

BMM were obtained from C57BI6 mice according to standard procedures (Peiser et al. 2000). Cells were cultured in R10 (RPMI-1640 supplemented with $10 \%$ heatinactivated fetal calf serum, $100 \mathrm{U} / \mathrm{ml}$ penicillin, $100 \mu \mathrm{g} / \mathrm{mL}$ streptomycin, $2 \mathrm{mM} \mathrm{L}$ glutamine and $10 \mathrm{mM}$ Hepes buffer with the addition of $15 \%$ L929-cell-conditioned medium (LCM) (Hume and Gordon 1983).

\section{Loading of BMM with PFH emulsions}

BMMs (seeded in 6 -well plates, $2 \times 10^{6} /$ well) were incubated with $2 \%$ or $4 \% \mathrm{v} / \mathrm{v} \mathrm{PFH}$ emulsions for 3 hours at $37^{\circ} \mathrm{C}$ in a $5 \% \mathrm{CO}_{2}$ incubator. After PFH loading, BMM were washed with $\mathrm{R} 10$ to remove non-incorporated PFH emulsions, collected, and centrifuged at $1200 \mathrm{RPM}$ for $5 \mathrm{~min}$ at $4^{\circ} \mathrm{C}$. The supernatants, containing any residual PFH emulsions and cell debris, were removed. Cell viability was monitored microscopically and by counting the number of viable cells upon harvesting.

\section{Diameter distribution}

Loaded ( $2 \% \mathrm{v} / \mathrm{v}$ PFH) and unloaded (0\% v/v PFH) BMM, were dissolved in phosphate buffer solution (PBS) and fixated in a solution of $3 \%$ paraformaldehyde (Merck VWR, Amsterdam, The Netherlands) for 15 minutes. Fixated BMM were centrifuged at 1200 RPM for $5 \mathrm{~min}$ at $4^{\circ} \mathrm{C}$, dissolved in PBS and added to a Petri dish well for diameter distribution measurements. Images were taken along a vertical line of each Petri-dish (BMM), using a microscope (Nikon Eclipse E800, Japan) with a 20x objective. Murine blood smears, stained with May-Grunwald solution and Giemsa solution, were used as reference in leukocyte typing (neutrophils $(N)$, lymphocytes $(L)$ and monocytes $(\mathrm{M})$ ) and in the determination of the diameter distributions. For each of the above conditions, 200 cells were evaluated and measured using Image Pro Plus (Media Cybernetics Inc., Silver Spring, MD, USA). 
Animals

Male and female C57BL/6J mice (16 to 20-week old, 20 to 30 grams) were obtained from Charles River Laboratories (Maastricht, the Netherlands, and Sulzfeld Germany). Mice were fed a normal diet and were allowed to drink water ad libitum. The experiments were approved by the institutional animal care and use committee of Maastricht University, Maastricht, the Netherlands and the Landesamt für Natur, Umwelt und Verbraucherschutz Nordrhein Westfalen, Germany. Mice were anesthetized by subcutaneous administration of a mixture of xylazine (15 mg Xylazin $/ \mathrm{kg}$ body weight; Ceva Sante Animale, Naaldwijk, The Netherlands) and ketamine (75 mg Nimatek/kg body weight; Eurovet, Cuijk, The Netherlands) unless stated otherwise.

\section{Echo enhancement in blood}

Pilot studies were conducted to assess BMM echo enhancement in vivo. For this purpose, 17 mice were anesthetized, the chest was shaved, and a venous line (PE10) was inserted into the right jugular vein. Through this catheter, 2 to 15 million of unloaded ( $0 \% \mathrm{v} / \mathrm{v}$ ) or loaded ( 2 or $4 \% \mathrm{v} / \mathrm{v}$ ) BMM were administered either as a bolus (1s) injection or by slow infusion either, manually (30s) or via a pump (300s, NE1000 , ProSense BV, The Netherlands). Ultrasound imaging was performed with an ultra-high frequency (30 $\mathrm{MHz}$ ) mechanical sector imaging system (Vevo 770, Visual Sonics, Toronto, Ontario, Canada). Ultrasound was transmitted in single cycle pulses offering an axial resolution of $55 \mu \mathrm{m}$. The probe was placed on the chest (transmission gel applied) to provide a simultaneous view of the aorta, pulmonary artery and left ventricle. Echo gains of the system were held constant during imaging. Recordings were made before, during and after injection of loaded and unloaded $\mathrm{BMM}$. The total recording time was 15 minutes. Ultrasound movies were processed off-line using ImagePro software (Media Cybernetics, Silverspring, MD, USA) to evaluate relative blood enhancement.

\section{BMM-endothelium interactions in vivo}

Six hours before intravital fluorescence imaging, TNF- $\alpha(1 \mu \mathrm{g} / \mathrm{mL})$ or PBS was injected intraperitoneally. After induction of anesthesia the left carotid artery bifurcation was surgically exposed and the exposed tissue was kept moist with PBS throughout the experiment.

Before assessment of rolling and adhesion of the BMM, we verified the necessity of TNF- $\alpha$ stimulation for leukocyte interaction with the endothelium in 12 mice, 6 mice without TNF- $\alpha$ and 6 mice with TNF- $\alpha$ stimulation. As described by others, in arteries leukocyte-endothelium interactions are virtually absent without cytokine 
stimulation (Abbassi et al. 1993; Bevilacqua et al. 1987; Carvalho-Tavares et al. 2000; Eriksson et al. 2000; Hickey et al. 1998; Jung and Ley 1999). Blood leukocytes were visualized in vivo by injecting Rhodamine $6 \mathrm{G}$ via the lateral tail vein. After 20 minutes to allow binding of Rhodamine to leukocytes, the interaction between leukocytes and the carotid artery endothelium was visualized in situ by means of a Zeiss Axiotech microscope (20x water-immersion objective, Carl Zeiss, Oberkochen, Germany) with a 100W HBO mercury lamp (Osram, Eichstätt, Germany), using epiillumination. Excitation wavelength for fluorescence imaging was $526 \mathrm{~nm}$. Video images were obtained from the anterior wall of the common and the external carotid artery and at the level of the carotid bifurcation. At each location two video recordings of 5 seconds were acquired at a frame rate of $25 \mathrm{~Hz}$ and saved on hard disk.

In a subsequent series of experiments without native leukocyte labeling, both $2 \%$ loaded and unloaded BMM were labeled ex-vivo with a fluorescent dye (Rhodamine $6 \mathrm{G}, 1 \mu \mathrm{L}, 0.02 \%$ ) and washed three times with PBS. In 2 mice 2.5 million loaded (2\% $\mathrm{v} / \mathrm{v})$ and in another 2 mice unloaded BMM were injected into the lateral tail vein as a bolus. Two minutes after injection, interactions of the BMM with the carotid artery endothelium were visualized in situ by fluorescence microscopy and recorded on video, as described above.

Video images of leukocyte and BMM interactions with the artery wall were evaluated off-line, using ImagePro software. The number of BMM rolling over or adhering to the endothelium was determined per recording by two independent observers ( $L K$ and KR). Rolling distance was defined as the distance a rolling cell covered within the 5 -second duration of the video recording and within the field of view, before leaving the field of view or before detaching from the endothelium. Rolling velocity was defined as the rolling distance divided by the transit time (number of frames divided by the frame rate). Firm adhesion was defined as a cell remaining stationary during the 5 -second recording time. Cells attaching or rolling only very briefly $(<2$ sec) were not taken into account in the number of rolling or firmly adhering cells. Neither were they included in the assessment of rolling distance and velocity.

\section{Statistical analysis}

Data are presented as mean $\pm S D$, unless stated otherwise. Differences in distribution variance were tested by F-test. Two-sample, two-sided Student t-tests, assuming unequal variance, were performed on the data to detect statistical differences, if any, in cell diameter distributions, and BMM rolling and adhesion behavior. For rolling and adhesion behavior, the events seen for an individual cell were considered independent of those of other cells. Calculations were performed using Graph- 
Pad Prism (GraphPad Software Inc, San Diego, CA, USA) and Excel (Microsoft, Redmond, WA, USA) software. A p-value $<0.05$ was considered statistically significant.

\section{Results}

\section{Cell diameter}

BMM diameter was significantly larger $(p<0.001)$ and more disperse $(p<0.001)$ than that of blood leukocytes (Fig. 1). There was a borderline significance difference in average diameter $(p=0.049)$ between $2 \%$ PFH loaded $(N=200,17.7 \pm 2.8 \mu m$, median $17.4 \mu \mathrm{m})$ and unloaded BMM ( $\mathrm{N}=200,17.1 \pm 3.8 \mu \mathrm{m}$, median $16.6 \mu \mathrm{m})$, but the distribution width of the loaded cells was smaller than that of the unloaded ones $(p<0.001)$. Overall, both loaded and unloaded BMM were larger than blood monocytes $(\mathrm{N}=200,14.0 \pm 1.0 \mu \mathrm{m})$, but distributions were overlapping in the $12-16 \mu \mathrm{m}$ range.

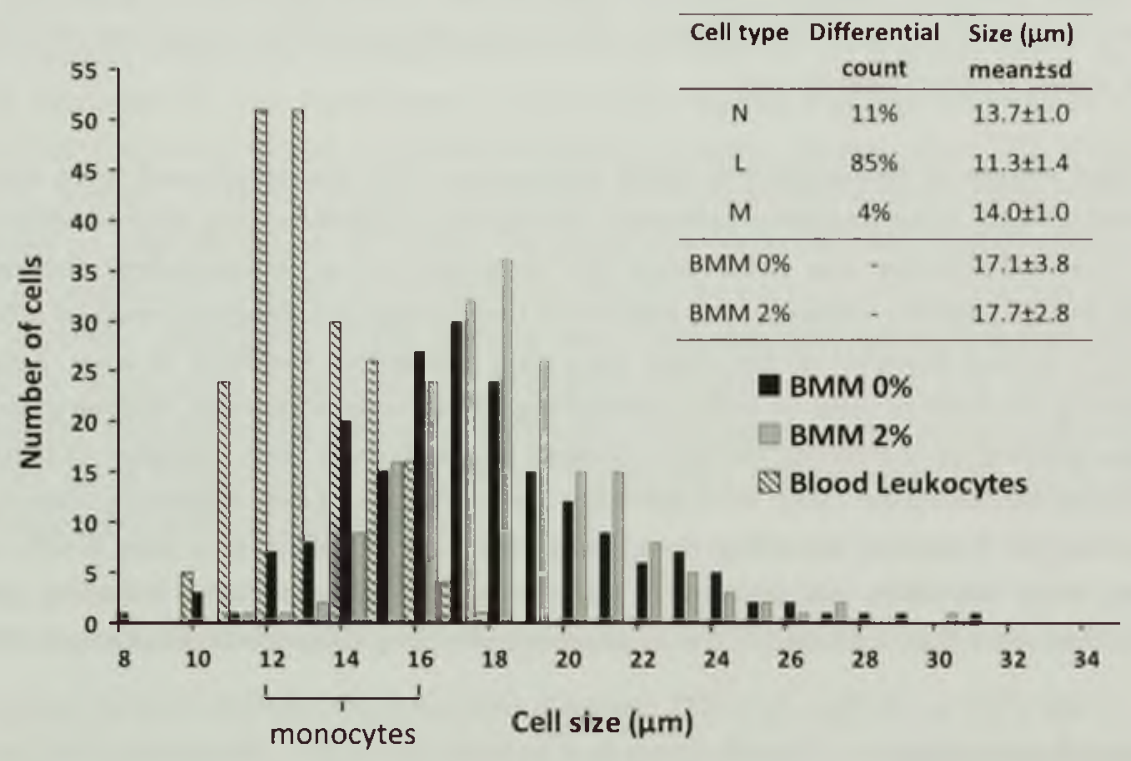

Figure 1. Diameter distribution of mouse blood leukocytes ( $N$, neutrophil; L, lymphocyte; $M$, monocyte) and cultured bone marrow macrophages (BMM). Histograms show a broad diameter distribution for both PFH loaded ( $2 \%$ ) and unloaded (0\%) BMM compared to blood leukocytes. The bracket on the $x$-axis indicates the approximate diameter range of blood monocytes. $\mathrm{N}=200$ cells, for each group. 


\section{Echo enhancement in blood}

Ultrasound B-mode images showed no blood echo enhancement in the pulmonary artery after injection of unloaded BMM into the jugular vein ( $n=8)$. A notable enhancement was observed in the pulmonary artery directly after injection of 7 million $2 \%$ (Fig. 2 ) and $4 \%$ PFH loaded BMM ( $n=3$ and $n=4$, respectively).
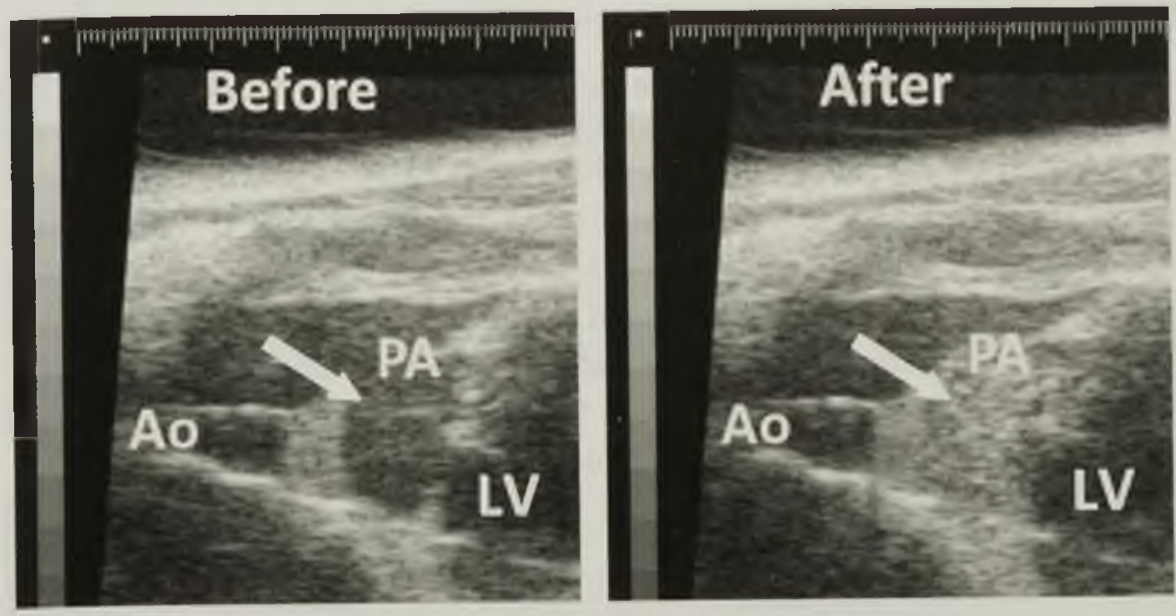

Figure 2. Ultrasound images of a mouse heart before (left) and after (right) manual injection of 7 million PFH $(2 \% \mathrm{v} / \mathrm{v})$ loaded BMM into the jugular vein. Right panel shows a clear enhancement (indicated with an arrow) in the pulmonary artery (PA) compared with the aorta (AO) and the left ventricle (LV). Data from single observations.
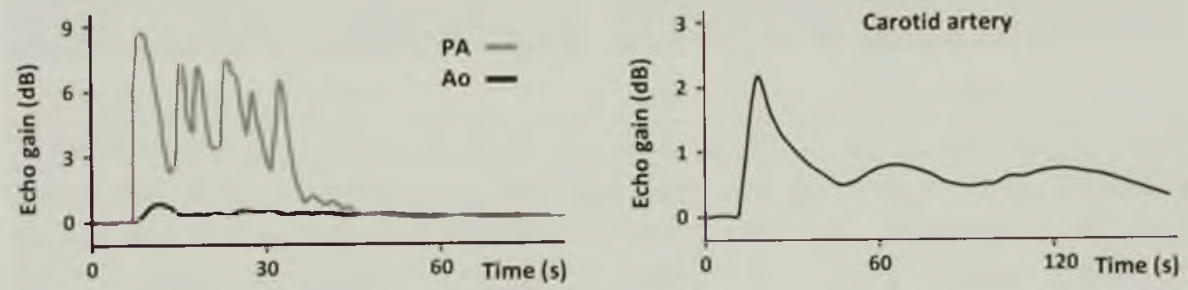

Figure 3. Left: blood enhancement in PA lumen over time (relative to blood enhancement in Ao). Right: transient increase of blood echogenicity enhancement in a carotid artery just after manual injection of 15 million of PFH ( $4 \% \mathrm{v} / \mathrm{v}$ ) loaded $\mathrm{BMM}$ into the jugular vein. Data from single observations.

Figure 3 (left panel) shows the increase over time (initial increase of $9 \mathrm{~dB}$ ) in blood echogenicity enhancement in the pulmonary artery and a small, but detectable aortic blood enhancement in the aorta ( $1 \mathrm{~dB}$ peak). Injection of a large number of $4 \%$ loaded BMM caused a substantial, but transient, blood echogenicity enhancement of $2 \mathrm{~dB}$ in the common carotid artery (Fig. 3, right panel), indicating that at 
least a part of the injected BMM did pass the pulmonary circulation and arrived on the arterial side. For this evaluation we used fast injection (1 s) of a large number (715 million) of loaded BMM via the jugular vein to achieve blood echo enhancement. However, bolus injections or fast infusion of the loaded BMM into the jugular vein, especially large numbers of the $4 \%$ PFH loaded ones, were not tolerated well.

\section{BMM injection and survival}

In this part of the ultrasound study, we varied the number of injected cells $(2,5,7$ or 15 million BMM), way of injection (manual or pump), infusion rate (1, 30 or 300 sec), and PFH loading percentage (0, 2 or $4 \%$ PFH). Jugular vein injection of loaded and unloaded BMM was poorly tolerated by some animals (Table 1). Acute cardiac and/or respiratory problems are likely to be the cause of death in the non-surviving mice (10 out of 17). In some mice ECG was clearly abnormal within 10 seconds after injection and undetectable 1-2 min later, probably due to massive pulmonary embolism and the development of right heart failure. The data suggest that survival is related to the number of cells that were injected and the PFH loading percentage.

Table 1. Ultrasound study parameters and survival.

\begin{tabular}{|c|c|c|c|c|c|c|c|c|}
\hline Mouse & $\begin{array}{l}\text { BMM } \\
{[\%)}\end{array}$ & $\begin{array}{l}\text { Injection } \\
\text { method }\end{array}$ & $\begin{array}{l}\text { Infusion } \\
\text { duration } \\
\text { [sec] }\end{array}$ & $\begin{array}{l}\text { Dose } \\
{\left[\times 10^{6}\right]}\end{array}$ & $\begin{array}{l}\text { Rate } \\
{\left[\# \times 10^{4} / \mathrm{sec}\right]}\end{array}$ & $\begin{array}{l}\text { Survival } \\
\text { time [min] }\end{array}$ & $\begin{array}{l}\text { Cause of } \\
\text { Death }\end{array}$ & Anesthesia \\
\hline A & 0 & Pump & 300 & 7 & 2,3 & 10 & Sudden & Ketamin/Xylazin \\
\hline B & 0 & Pump & 300 & 7 & 2,3 & 14 & Sudden & Ketamin/Xylazin \\
\hline C & 0 & Pump & 300 & 7 & 2,3 & $24 h$ & Sacrifice & Ketamin/Xylazin \\
\hline D & 0 & Pump & 300 & 15 & 5,0 & 3 & Sudden & Ketamin/Xylazin \\
\hline$E$ & 0 & Pump & 300 & 15 & 5,0 & 5 & Sudden & Ketamin/Xylazin \\
\hline $\mathrm{F}$ & 2 & Pump & 300 & 5 & 1,7 & 10 & Sudden & Ketamin/Xylazin \\
\hline G & 2 & Pump & 300 & 5 & 1,7 & $2 \mathrm{~h}$ & Sacrifice & Ketamin/Xylazin \\
\hline $\mathrm{H}$ & 0 & Manual & 1 & 2 & 200 & 35 & Sudden & Urethane \\
\hline 1 & 0 & Manual & 1 & 2 & 200 & 36 & Sudden & Urethane \\
\hline J & 0 & Manual & 1 & 2 & 200 & $2 \mathrm{~h} 42$ & Sacrifice & Urethane \\
\hline K & 4 & Manual & 1 & 2 & 200 & 36 & Sudden & Urethane \\
\hline L & 4 & Manual & 1 & 2 & 200 & $2 \mathrm{~h} 36$ & Sacrifice & Urethane \\
\hline$M$ & 4 & Manual & 1 & 2 & 200 & 1 & Sacrifice & Urethane \\
\hline $\mathbf{N}$ & 4 & Manual & 30 & 7 & 23,3 & $1 \mathrm{~h} 22$ & Sacrifice & Urethane \\
\hline 0 & 4 & Manual & 30 & 7 & 23,3 & $1 \mathrm{~h} 37$ & Sacrifice & Urethane \\
\hline$P$ & 4 & Manual & 1 & 15 & 1500 & 1 & Sudden & Urethane \\
\hline$Q$ & 4 & Manual & 30 & 15 & 50 & 12 & Sudden & Urethane \\
\hline
\end{tabular}

Injections of bone marrow macrophages were given via the right jugular vein 


\section{BMM-endothelium interactions in vivo}

To avoid problems associated with jugular vein injection, we switched to the lateral tail vein as site of injection. To visualize BMM-interactions with the endothelium, 2.5 million unloaded and $2 \% \mathrm{v} / \mathrm{v}$ loaded $\mathrm{BMM}$ were injected via the tail vein. The tail vein is not only easier accessible, but also its larger distance to the lungs provides a better dilution of the injected BMM, reducing the likelihood of lung congestion. In all these experiments the BMM were injected as a bolus.

Intravital microscopy of carotid arteries showed that in unstimulated mice $(N=6)$, an average count of $1 \pm 2$ adhering leukocytes (mean \pm SD, range $0-5$ ) was observed ( 36 recordings in total, Figure 4). The low number confirms the necessity of cytokine stimulation to enhance the incidence of rolling on and adhesion of native leukocytes to the carotid artery wall. Indeed, in TNF- $\alpha$ stimulated mice ( $N=6 ; 36$ recordings) significantly more leukocytes $(6 \pm 8$, range $0-45)$ were found to adhere to the endothelium (Fig. 4).
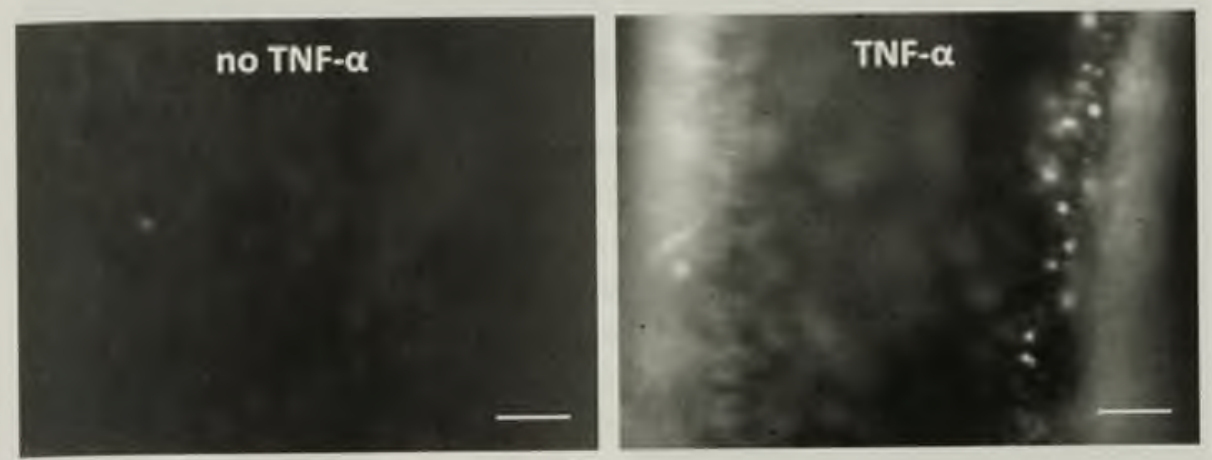

Figure 4. Intravital fluorescence microscopy images of the mouse carotid artery. Interactions of leukocytes are virtually absent in unstimulated mice (left). TNF- $\alpha$ stimulation effectively increases the number of leukocytes interacting with the endothelium (right). In the right picture the left wall of the artery is out of focus. Leukocytes are Rhodamine labeled. Scale bar $=50 \mu \mathrm{m}$.

Interactions of BMM with the TNF- $\alpha$ stimulated endothelium are illustrated in Figure 5 ( $A$ and $B$ : unloaded BMM; C: PFH loaded BMM). The trajectory could be identified over the image for 21 PFH loaded and 7 unloaded BMM. There was no significant difference in the observed number of rolling cells between PFH loaded and unloaded BMM (27 and 12, respectively; $\mathrm{p}=0.11$ ). PFH loading had no significant effect on the rolling velocity of BMM on the endothelium (Fig. 5D). Rolling velocity of loaded BMM was $39 \pm 14 \mu \mathrm{m} / \mathrm{s}$ and for unloaded BMM $33 \pm 14 \mu \mathrm{m} / \mathrm{s}$ ( $p=0.33$ for difference). Rolling distance was $130 \pm 55 \mu \mathrm{m}$ and $114 \pm 16 \mu \mathrm{m}$ for loaded and unloaded BMM, respectively $(p=0.33)$. In addition, there was no difference in the 
number of adhering cells ( 8 loaded and 5 unloaded BMM, $p=0.25$ ). The total number of cells attaching or only very briefly rolling during the 5-second recording was 11 for PFH loaded BMM and 13 for unloaded BMM. The observed numbers were too low to differentiate for carotid artery region (common carotid, bifurcation, and external carotid artery)

All animals survived and were sacrificed after imaging, indicating that the applied dose ( 2.5 million for unloaded and $2 \% \mathrm{v} / \mathrm{v}$ loaded BMM) was tolerated by the animals.
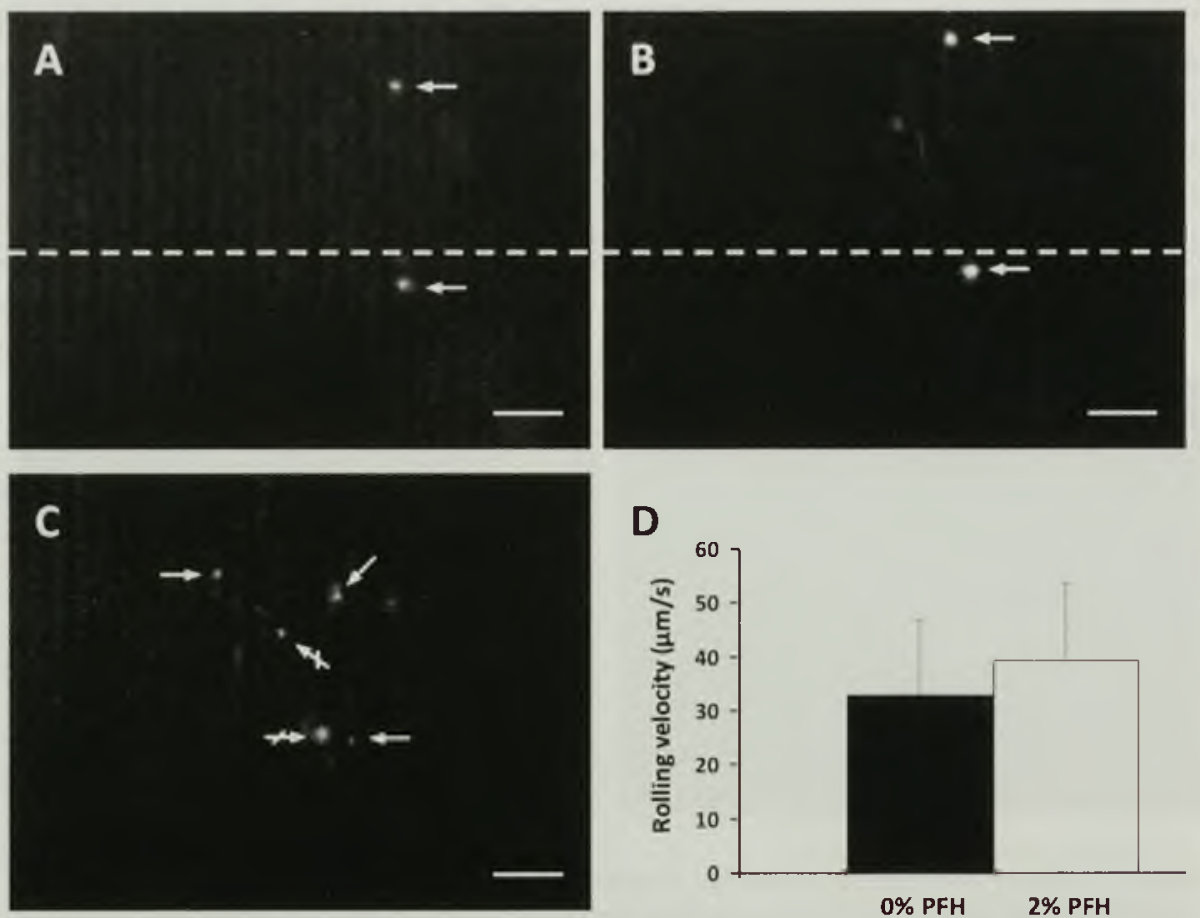

Figure 5. Intravital fluorescence microscopy images (A through $\mathrm{C}$ ) showing in situ interactions of injected BMM in mouse carotid artery. Blood flow is from bottom to top. Image focus is limited due to continuous movement of the artery wall. Scale bar $=50 \mu \mathrm{m}$. Rolling unloaded BMM (indicated by arrow) can be traced in image $\mathbf{A}$ and $\mathbf{B}$ with the lower cell exhibiting the lowest velocity. Image $\mathbf{C}$ illustrates both roiling and adhering (marked by a slash on the arrow) 2\% PFH loaded BMM. Panel D shows that there was no significant difference in rolling velocity between loaded and unloaded BMM $(p=0.33)$. Similarly, rolling distance was also not different (not shown). Bars represent mean $\pm 5 D$; number of cells tracked: $n=7$ for $0 \% \mathrm{PFH}$ and $n=21$ for $2 \% \mathrm{PFH} ; 2$ mice per group. 


\section{Discussion}

The present pilot study was performed to investigate in vivo in mice the potential of monocytes to act as ultrasound contrast agent, focusing on echo signal enhancement and selective adhesion to the endothelium. We were able to show that intravenously administrated perfluorohexane loaded bone marrow macrophages were able to pass the lung circulation and enhanced arterial blood echogenicity in mice. Most importantly, we observed that loaded macrophages exhibited rolling and adhesion behavior at the TNF- $\alpha$ stimulated endothelium of the carotid artery wall, similar to native blood leukocytes and unloaded macrophages.

Leukocytes are naturally equipped to roll and adhere selectively to activated endothelium and to resist physiological shear stresses in large- and middle-sized arteries. Rolling and adhesion specifically may occur in hemodynamically favorable areas (recirculation zones combined with low shear stress) (Bharadvaj et al. 1982a; Bharadvaj et al. 1982b; Dai et al. 2004; Friedman et al. 1986; Reneman et al. 1985; Rindt and Steenhoven 1996; Zarins et al. 1983), where endothelial P-selectin, ICAM1 (intracellular adhesion molecule-1), and VCAM-1 (vascular adhesion molecule-1) are upregulated by atherogenic processes (Brooks et al. 2002; Dai et al. 2004; Malek et al. 1999; Reneman et al. 2006; Topper et al. 1996). During early plaque development, monocytes in these recirculation zones come in contact with the vessel wall, creating conditions for interaction. Bonds formed between endothelial selectins and integrins, and monocyte ligands, such as platelet glycoprotein ligand-1 (PSGL-1), very late antigens-4 (VLA-4), macrophage antigen complex-1 (Mac-1) and lymphocyte function-associated antigen-1 (LFA-1) may result in rolling and eventually adhesion (Chan et al. 2001; Ley et al. 2007). Rolling of these monocytes on the endothelial surface is characterized by the speed with which selectin-ligand bonds form and dissociate (i.e., high on- and off-rates, respectively), and the rolling velocity, mediated by the shear forces at the vessel wall (Alon et al. 1995; Marshall et al. 2003). At a certain threshold of wall shear stress stable rolling is achieved (Lawrence et al. 1997; Ridger et al. 2008). These observations corroborate the findings in the present study. We observed that in the mouse carotid artery both PFH loaded and unloaded bone marrow macrophages roll on and adhere to the artery wall, supposedly through interaction with selectins and integrins, which are expressed after TNF- $\alpha$ stimulation. In a previous study, we showed that PFH labeling of bone marrow macrophages did not affect the presence of PSGL-1 and of the integrins, VLA-4, Mac- 1 and LFA- 1 on the cell surface, nor their ability to adhere to TNF- $\alpha$ stimulated endothelium under stationary (no shear) conditions (Kornmann et al. 2008). The present study extends our previous findings to in vivo conditions. 
The low number of adhering and rolling BMM observed in the present study is likely a consequence of the protocol followed and results from the relatively large amount of native blood cells already adhering to the stimulated wall before the BMM are injected, occupying available adhesion sites.

Loading of macrophages with echogenic material may result in an increase in diameter and loss of deformability, which may have consequences for the blood flow at the microcirculatory level and may lead to increased sensitivity to shear stress at the wall of large arteries. A good alternative for the BMM might be isolated blood monocytes, because they are smaller than cultured macrophages, which lowers the chance of being captured in the lungs and may decrease the sensitivity to shear stress. A limitation of using isolated monocytes, however, would be the number of donor mice needed to perform an ultrasound molecular imaging study in mouse models of atherosclerosis. Bone marrow isolation allows retrieval of a far higher number of BMM from a single mouse. In humans, ex-vivo radio-labeled leukocytes are in use clinically for scintigraphic imaging of inflammatory and infectious processes for several years (Basu et al. 2009; van Hemert et al. 2007), where leukocytes are obtained from the (same) patient.

The current proof of principle study clearly demonstrates that, in vivo, PFH loaded macrophages enhance the echogenicity of circulating blood and are able to roll and adhere selectively to stimulated carotid endothelium under physiological shear stress conditions. Therefore, we conclude that PFH loaded monocytes may have a potential to be used as a targeted ultrasound contrast agent. Further investigations are required to gain more insight into the relationship between local expression of molecular markers on endothelial surfaces and the local concentration and diameter of adhered ultrasound contrast agents (i.e., loaded monocytes).

\section{Acknowledgement}

The animal studies were performed at the Department of Pharmacology and Toxicology, Maastricht University, Maastricht, The Netherlands, and at the Institute for Molecular Cardiovascular Research (IMCAR), RWTH Aachen University, Aachen, Germany. We gratefully acknowledge Agnieszka Brouns-Strzelecka, Jacques Debets and Peter Leenders from Maastricht University, Department of Pharmacology and Toxicology, for excellent technical assistance. This study was supported by Senter (Ministry of Economic Affairs), grant BSIK03033. 


\section{References}

Abbassi O, Kishimoto TK, McIntire LV, Anderson DC, Smith CW. E-selectin supports neutrophil rolling in vitro under conditions of flow. I Clin Invest 1993;92:2719-2730.

Alon R, Hammer DA, Springer TA. Lifetime of the P-selectin-carbohydrate bond and its response to tensile force in hydrodynamic flow. Nature 1995;374:539-542.

Barnard S, Leen E, Cooke T, Angerson W. A contrast-enhanced ultrasound study of benign and malignant breast tissue. S Afr Med J 2008;98:386-391.

Basu S, Zhuang H, Torigian DA, Rosenbaum J, Chen W, Alavi A. Functional imaging of inflammatory diseases using nuclear medicine techniques. Semin Nucl Med 2009;39:124-145.

Behm CZ, Lindner JR. Cellular and molecular imaging with targeted contrast ultrasound. Ultrasound Q 2006;22:67-72.

Bevilacqua MP, Pober JS, Mendrick DL, Cotran RS, Gimbrone MA, Jr. Identification of an inducible endothelial-leukocyte adhesion molecule. Proc Natl Acad Sci U S A 1987;84:9238-9242.

Bharadvaj BK, Mabon RF, Giddens DP. Steady flow in a model of the human carotid bifurcation. Part I.. flow visualization. J Biomech 1982a;15:349-362.

Bharadvaj BK, Mabon RF, Giddens DP. Steady flow in a model of the human carotid bifurcation. Part II-laser-Doppler anemometer measurements. J Biomech 1982b;15:363-378.

Brooks AR, Lelkes PI, Rubanyi GM. Gene expression profiling of human aortic endothelial cells exposed to disturbed flow and steady laminar flow. Physiol Genomics 2002;9:27-41.

Bruce M, Averkiou M, Tiemann K, Lohmaier S, Powers J, Beach K. Vascular flow and perfusion imaging with ultrasound contrast agents. Ultrasound Med Biol 2004;30:735-743.

Carvalho-Tavares J, Hickey MJ, Hutchison J, Michaud J, Sutcliffe IT, Kubes P. A role for platelets and endothelial selectins in tumor necrosis factor-alpha-induced leukocyte recruitment in the brain microvasculature. Circ Res 2000;87:1141-1148.

Chan JR, Hyduk SJ, Cybulsky MI. Chemoattractants induce a rapid and transient upregulation of monocyte alpha4 integrin affinity for vascular cell adhesion molecule 1 which mediates arrest: an early step in the process of emigration. J Exp Med 2001;193:1149-1158.

Chappell JC, Price RJ. Targeted therapeutic applications of acoustically active microspheres in the microcirculation. Microcirculation 2006;13:57-70.

Cheng C, Helderman F, Tempel D, Segers D, Hierck 8, Poelmann R, van Tol A, Duncker DJ, Robbers-Visser D, Ursem NT, van Haperen R, Wentzel JJ, Gijsen F, van der Steen AF, de Crom R, Krams R. Large variations in absolute wall shear stress levels within one species and between species. Atherosclerosis 2007;195:225-235.

Dai G, Kaazempur-Mofrad MR, Natarajan S, Zhang Y, Vaughn S, Blackman BR, Kamm RD, Garcia-Cardena G, Gimbrone MA, Jr. Distinct endothelial phenotypes evoked by arterial waveforms derived from atherosclerosis-susceptible and-resistant regions of human vasculature. Proc Natl Acad Sci U S A 2004;101:14871-14876.

Dayton PA, Rychak נJ. Molecular ultrasound imaging using microbubble contrast agents. Front Biosci 2007;12:5124-5142.

Demos SM, Alkan-Onyuksel H, Kane BJ, Ramani K, Nagaraj A, Greene R, Klegerman M, McPherson DD. In vivo targeting of acoustically reflective liposomes for intravascular and transvascular ultrasonic enhancement. J Am Coll Cardiol 1999;33:867-875.

Demos SM, Dagar S, Klegerman M, Nagaraj A, McPherson DD, Onyuksel H. In vitro targeting of acoustically reflective immunoliposomes to fibrin under various flow conditions. I Drug Target 1998;5:507518.

Eriksson EE, Werr J, Guo Y, Thoren P, Lindbom L. Direct observations in vivo on the role of endothelial selectins and alpha(4) integrin in cytokine-induced leukocyte-endothelium interactions in the mouse aorta. Circ Res 2000;86:526-533.

Friedman $\mathrm{MH}$, Deters OJ, Bargeron CB, Hutchins GM, Mark FF. Shear-dependent thickening of the human arterial intima. Atherosclerosis 1986;60:161-171. 
Greve JM, Les AS, Tang BT, Draney Blomme MT, Wilson NM, Dalman RL, Pelc NJ, Taylor CA. Allometric scaling of wall shear stress from mice to humans: quantification using cine phase-contrast MRI and computational fluid dynamics. Am J Physiol Heart Circ Physioi 2006;291:H1700-1708.

Hamilton A, Rabbat M, Jain P, Belkind N, Huang SL, Nagaraj A, Klegerman M, Macdonald R, McPherson DD. A physiologic flow chamber model to define intravascular ultrasound enhancement of fibrin using echogenic liposomes. Invest Radiol 2002;37:215-221.

Hickey MJ, Issekutz AC, Reinhardt PH, Fedorak RN, Kubes P. Endogenous interleukin-10 regulates hemodynamic parameters, leukocyte-endothelial cell interactions, and microvascular permeability during endotoxemia. Circ Res 1998;83:1124-1131.

Hume DA, Gordon S. Optimal conditions for proliferation of bone marrow-derived mouse macrophages in culture: the roles of CSF-1, serum, Ca2t, and adherence. J Cell Physiol 1983;117:189-194.

Jung $\mathrm{U}$, Ley $\mathrm{K}$. Mice lacking two or all three selectins demonstrate overlapping and distinct functions for each selectin. I Immunol 1999;162:6755-6762.

Kaufmann BA, Sanders JM, Davis C, Xie A, Aldred P, Sarembock IJ, Lindner JR. Molecular imaging of inflammation in atherosclerosis with targeted ultrasound detection of vascular cell adhesion molecule1. Circulation 2007;116:276-284.

Kircher MF, Grimm J, Swirski FK, Libby P, Gerszten RE, Allport JR, Weissleder R. Noninvasive in vivo imag ing of monocyte trafficking to atherosclerotic lesions. Circulation 2008;117:388-395.

Klibanov AL, Hughes MS, Marsh IN, Hall CS, Miller JG, Wible JH, Brandenburger GH. Targeting of ultrasound contrast material. An in vitro feasibility study. Acta Radiol Suppl 1997;412:113-120.

Klibanov AL, Hughes MS, Wojdyla JK, Marsh JN, Hall CS, Miller JG, Wible JH, Jr., Brandenburger GH. Targeting of ultrasound contrast material: selective imaging of microbubbles in vitro. Acad Radiol 1998;5 Suppl 1:S243-246.

Klibanov AL, Rychak JJ, Yang WC, Alikhani S, Li B, Acton S, Lindner JR, Ley K, Kaul S. Targeted ultrasound contrast agent for molecular imaging of inflammation in high-shear flow. Contrast Media Mol Imaging 2006;1:259-266.

Kornmann LM, Curfs DM, Hermeling E, van der Made I, de Winther MP, Reneman RS, Reesink KD, Hoeks AP. Perfluorohexane-loaded Macrophages as a Novel Ultrasound Contrast Agent: A Feasibility Study Mol Imaging Biol 2008;10:264-270.

Lanza GM, Wallace KD, Scott MJ, Cacheris WP, Abendschein DR, Christy DH, Sharkey AM, Miller JG, Gaffney PJ, Wickline SA. A novel site-targeted ultrasonic contrast agent with broad biomedical application. Circulation 1996;94:3334-3340.

Lawrence MB, Kansas GS, Kunkel EJ, Ley K. Threshold levels of fluid shear promote leukocyte adhesion through selectins (CD62L,P,E). I Cell Biol 1997;136:717-727.

Ley K, Laudanna C, Cybulsky MI, Nourshargh S. Getting to the site of inflammation: the leukocyte adhesion cascade updated. Nat Rev Immunol 2007;7:678-689.

Lindner JR. Detection of inflamed plaques with contrast ultrasound. Am J Cardiol 2002;90:32L-35L.

Lindner JR. Molecular imaging with contrast ultrasound and targeted microbubbles. J Nucl Cardiol 2004;11:215-221.

Malek AM, Alper SL, Izumo S. Hemodynamic shear stress and its role in atherosclerosis. Jama 1999;282:2035-2042.

Marsh JN, Partlow KC, Abendschein DR, Scott MJ, Lanza GM, Wickline SA. Molecular imaging with targeted perfluorocarbon nanoparticles: quantification of the concentration dependence of contrast enhancement for binding to sparse cellular epitopes. Ultrasound Med Biol 2007;33:950-958.

Marshall BT, Long M, Piper JW, Yago T, McEver RP, Zhu C. Direct observation of catch bonds involving cell-adhesion molecules. Nature 2003;423:190-193.

Peiser L, Gough PJ, Kodama T, Gordon S. Macrophage class A scavenger receptor-mediated phagocytosis of Escherichia coli: role of cell heterogeneity, microbial strain, and culture conditions in vitro. Infect Immun 2000;68:1953-1963. 
Reneman RS, Arts T, Hoeks AP. Wall Shear Stress - an Important Determinant of Endothelial Cell Function and Structure - in the Arterial System in vivo. Discrepancies with Theory. J Vasc Res 2006;43:251269.

Reneman RS, van Merode T, Hick P, Hoeks AP. Flow velocity patterns in and distensibility of the carotid artery bulb in subjects of various ages. Circulation 1985;71:500-509.

Ridger V, Krams R, Carpi A, Evans PC. Hemodynamic parameters regulating vascular inflammation and atherosclerosis: A brief update. Biomed Pharmacother 2008;62:536-540.

Rindt CC, Steenhoven AA. Unsteady flow in a rigid 3-D model of the carotid artery bifurcation. J Biomech Eng 1996;118:90-96.

Rovai D, Morales MA, Amyot R, L'Abbate A. Clinical experience with SonoVue in myocardial perfusion imaging. Echocardiography 2000;17:517-23.

Rychak JJ, Klibanov AL, Hossack JA. Acoustic radiation force enhances targeted delivery of ultrasound contrast microbubbles: in vitro verification. IEEE Trans Uitrason Ferroelectr Freq Control 2005;52:421-433.

Rychak JJ, Klibanov AL, Ley KF, Hossack JA. Enhanced Targeting of Uitrasound Contrast Agents Using Acoustic Radiation Force. Ultrasound Med Biol 2007;33:1132-1139.

Rychak JJ, Li B, Acton ST, Leppanen A, Cummings RD, Ley K, Klibanov AL. Selectin ligands promote ultrasound contrast agent adhesion under shear flow. Mol Pharm 2006a;3:516-524.

Rychak JJ, Lindner JR, Ley K, Klibanov AL. Deformable gas-filled microbubbles targeted to P-selectin. J Control Release 2006b;114:288-299.

Samijo SK, Willigers JM, Barkhuysen R, Kitslaar PJ, Reneman RS, Brands PJ, Hoeks AP. Wall shear stress in the human common carotid artery as function of age and gender. Cardiovasc Res 1998,39.515-522.

Takalkar AM, Klibanov AL, Rychak JJ, Lindner JR, Ley K. Binding and detachment dynamics of microbubbles targeted to P-selectin under controlled shear flow. J Control Release 2004;96:473-482.

Topper JN, Cai J, Falb D, Gimbrone MA, Jr. Identification of vascular endothelial genes differentially responsive to fluid mechanical stimuli: cyclooxygenase-2, manganese superoxide dismutase, and endothelial cell nitric oxide synthase are selectively up-regulated by steady laminar shear stress. Proc Natl Acad Sci U S A 1996;93:10417-10422.

van Hemert FJ, Thurlings R, Dohmen SE, Voermans C, Tak PP, van Eck-Smit BL, Bennink RJ. Labeling of autologous monocytes with $99 \mathrm{mTC}-\mathrm{HMPAO}$ at very high specific radioactivity. Nucl Med Biol 2007;34:933-938.

Villanueva FS, Jankowski RJ, Klibanov S, Pina ML, Alber SM, Watkins SC, Brandenburger GH, Wagner WR. Microbubbles targeted to intercellular adhesion molecule-1 bind to activated coronary artery endothelial cells. Circulation 1998;98:1-5.

Weller GE, Villanueva FS, Klibanov AL, Wagner WR. Modulating targeted adhesion of an ultrasound contrast agent to dysfunctional endothelium. Ann Biomed Eng 2002;30:1012-1019.

Weller GE, Villanueva FS, Tom EM, Wagner WR. Targeted ultrasound contrast agents: in vitro assessment of endothelial dysfunction and multi-targeting to ICAM-1 and sialyl Lewisx. Biotechnol Bioeng 2005;92:780-788.

Wickline SA, Neubauer AM, Winter PM, Caruthers SD, Lanza GM. Molecular imaging and therapy of atherosclerosis with targeted nanoparticles. J Magn Reson Imaging 2007;25:667-680.

Zarins CK, Giddens DP, Bharadvaj BK, Sottiurai VS, Mabon RF, Glagov S. Carotid bifurcation atherosclerosis. Quantitative correlation of plaque localization with flow velocity profiles and wall shear stress. Circ Res 1983;53:502-514.

Zhao S, Kruse DE, Ferrara KW, Dayton PA. Selective imaging of adherent targeted ultrasound contrast agents. Phys Med Biol 2007;52:2055-2072. 
CHAPTER 7

\section{General discussion}


Molecular imaging of atherosclerotic processes in the carotid artery with ultrasound involves several critical steps. In relation to the stage of the atherosclerotic process specific adhesion molecules should be released to ensure selectivity and specificity. The presence of the adhesion molecules is sensed by (a combination of multiple) ligands attached to an ultrasound contrast agent. Accumulation over time will only occur if the bond between adhesion molecules and ligands is stable and can resist the stress exerted by the flowing blood (shear stress). Because selective accumulation might require some time (from hours to days), the ultrasound contrast agent should degrade or disappear slowly. Moreover, it should not have toxic side effects. Finally, to allow visualization the contrast agent material should exhibit a high acoustic mismatch with its environment, i.e., blood or the endothelium.

Imaging of gradual processes at a specific location should provide an indication of the release of specific molecules by a plaque (yes/no decision), and of the stage of the process, grading it from early plaque development to vulnerable plaques. Ideally, a quantitative molecular imaging protocol should be able to identify the presence and local density of released molecules as a measure of the process stage. In addition, those molecules should act as potential binding sites. To allow conversion from observed increase in echogenicity to the number of binding sites (quantitative imaging), contrast agents bound to the plaque should have similar echogenicity, i.e., similar size and composition.

The objective of this thesis was to increase our insight into molecular imaging by means of ultrasound contrast agents targeted to endothelial markers in large arteries. We concentrated on ultrasound echo enhancement in relation to size and surface density of the ultrasound contrast agents. With a membrane emulsification technique we were able to produce echogenic perfluorohexane emulsions with a preset droplet size (Chapter 4). In addition, we confirmed that the acoustic enhancement by these perfluorohexane emulsions varied with droplet size and surface coverage (Chapter 4). A possible limitation of artificial contrast agents is their poor specificity in regions exposed to physiological shear stresses. As an alternative, we considered circulating blood cells as macrophages/monocytes loaded with an ultrasound contrast agent, employing the inherent attraction of monocytes to atherogenic sites. Perfluorohexane loaded bone marrow derived macrophages were imaged both in vitro and in vivo with ultrasound and fluorescence microscopy and applied to a mouse model of arterial wall inflammation. We demonstrated that perfluorohexane loaded bone marrow derived macrophages are echogenic and have the potential to adhere to activated endothelium under physiological shear stress conditions as present in the carotid artery bifurcation (Chapter 5 and 6). 


\section{Quantitative imaging}

To be able to relate observed densities of adhered contrast agents to the stage of the atherosclerotic process, the contrast agents should selectively adhere to atherogenic regions despite prevailing shear stress. Moreover, the gradual accumulation of contrast agents should result in a notable increase in signal level (echogenicity), while the signal increase can be related to the number of particles adhered, and, hence, to the density of binding sites involved.

Shear stress (Chapter 2 ) is defined as the local viscosity times the local shear rate, being the radial derivative of blood velocity (Reneman, 2006; Reneman, 2008; Reneman, 2009). In straight vessels shear rate and, hence, shear stress will be maximal at the lumen-wall interface. In the human common carotid artery wall shear stress reaches peak values of 3-4 Pa, while the time average (mean) will be $1.2 \mathrm{~Pa}$ (Samijo, 1998; Dammers, 2003). However, in the atherogenic regions, e.g., at the outer curve of the internal carotid artery bulb (opposite to the flow divider), the time average is considerably lower and may even be close to zero (Dai, 2004). It is still impossible to get at these locations reliable non-invasive estimates of the wall shear stress distributions. Detailed computer simulations, however, indicate that despite a low mean shear stress value, the shear stress at peak systole may reach values of $1.5 \mathrm{~Pa}$ (Zhao, 2002).

In the carotid artery bifurcation, flow deviates from the main stream and recirculates in the bulb opposite to the flow divider (Reneman, 1985). In this area monocytes can come in close contact with the artery wall. Here, a particle is subjected to shear flow creating hemodynamic forces and external torques acting on the particle hampering free (no adhesion) rolling (Zhao, 2001). Especially larger particles will be exposed to higher radial gradients in shear stress, particularly close to the wall, causing rotation and detachment. Once a particle is in contact with the wall, the local shear stress, directed along the streamlines, is fully exerted on the particle. Consequently, larger particles will be exposed to larger stress gradients along the wall, especially when they are non-deformable. The effective shear stress gradient across the particle will decrease with deformability, favoring attachment. Therefore, it is not recommendable to utilize non-deformable contrast agents with a large diameter.

The echogenicity of a particle increases with the mismatch in acoustic impedance between the particle and its environment (Chapter 2). Air bubbles exhibit a great acoustic mismatch and are therefore attractive as contrast agent. Inherent to the process of microbubble generation (agitation), air bubble size is difficult to control. In addition to the impedance mismatch, echogenicity of a contrast agent highly 
depends on its diameter (Chapter 2), as the backscattered signal power strongly increases for either a larger sphere size (to the sixth power) or by increasing the ultrasound frequency (to the fourth power). Because of this dependency, the echo signal of a single large bubble might dominate the sum signal of a large number of small particles. This implies that the received signal loses its significance with respect to the assessment of the number of binding sites if a wide size distribution is involved. For quantitative imaging, it is essential that the contrast agents have a relatively large size with a narrow size distribution. The first requirement, however, is in conflict with the small size evolving from the shear stress conditions.

A final point to consider is the number of available binding sites in relation to the stage of the atherosclerotic process. In in vitro experiments, the binding site density can be manipulated by the application of adhesion molecules (Weller, 2005; Kaufmann, 2007). If the interspacing between binding sites is small, the diameter of the contrast agent will be the limiting factor. At the very moment there is no convincing indication that this limit is reached in in vivo conditions.

\section{Standard ultrasound contrast agents}

Small air filled microbubbles within the blood pool exhibit a high echogenicity (extremely high mismatch in acoustic impedance) and are therefore very attractive as contrast agent. However, it remains difficult to control their size, resulting in a wide size distribution ranging from 1-10 micrometer. Once injected, larger stiff microbubbles will be trapped in the microcirculation and removed from the circulation. Moreover, microbubbles have a limited life span and, hence, the time allowed for local accumulation is restricted. That is why these microbubbles are very attractive for perfusion imaging based on repetitive sequences of bubble destruction and replenishment (Rovai, 2000; Bruce, 2004; Barnard, 2008), but less suitable to image the follow-up of processes in the artery wall.

Perfluorohexane emulsions, on the other hand, are attractive as acoustic contrast agents. They do not exhibit toxic properties, are slowly removed from the circulation and have favorable acoustic properties. When bound to the cell surface of tissues, these emulsions are detectable, because of a high reflectivity coefficient of 0.3 due to a substantial acoustic impedance mismatch with the environment. A disadvantage is that they also exhibit a wide size distribution, prohibiting conversion from observed echogenicity enhancement to the number and density of particles involved. Hence, they do not provide information about the density of binding sites as a quantitative indication of the stage of the atherosclerotic process, leaving only a yes/no decision. The width of the size distribution can be restricted by appropriate 
filtering, but then the yield will be low, while filters will clog inherently. Moreover, after filtering echogenicity is limited, because of the small average droplet diameter in the order of $0.3 \mu \mathrm{m}$. In Chapter 4 , a technique is described to produce monodisperse perfluorohexane emulsions with a preset larger size. The membrane emulsification technique produced particles with preselected sizes of $4 \mu \mathrm{m}$ and $12 \mu \mathrm{m}$ and a diameter variation of only $4 \%$. The larger size of $12 \mu \mathrm{m}$ is unsuited for in vivo applications, but was only selected to demonstrate the versatility of the technique. The ability to produce well defined emulsions of different sizes will make it possible to explore the optimal droplet size for quantitative imaging in relation to echogenicity and the adhesion opposing effects of shear stress.

For in vivo targeting, the standard ultrasound contrast agents need further optimization to improve their success rate of adhesion. The poor adhesion properties can be attributed to the prevailing wall shear stress at the lumen-wall boundary, the large particle size and their poor deformability, and/or low binding affinity (Chapter 3). Future (in vivo) experiments have to show whether the perfluorohexane droplets are suitable for ultrasound molecular imaging of plaques under physiological shear stress conditions, i.e., a wall shear stress higher than $0.5 \mathrm{~Pa}$. To increase the adhesion success rate, the PFH droplets should be deformable and have a small size to avoid lung entrapment and to decrease their sensitivity to shear stress. Moreover, a cocktail of multiple ligands should be conjugated to their surface to increase their affinity, specificity and sensitivity for the target (Chapter 3 ).

\section{Monocytes as contrast agents vehicle}

Because of the low adhesion success rate of current standard ultrasound contrast agents, we evaluated as an alternative the use of circulating blood cells. Activated monocytes and macrophages exhibit a natural high and selective affinity to atherosclerotic sites. Moreover, adhered cells withstand local wall shear stresses as occur in atherosclerosis prone regions. It has been shown that leukocytes do take up ultrasound contrast agents, such as perfluorocarbon emulsions (Smith, 1994) and microbubbles (Lindner, 2000). Furthermore, for several years ex-vivo radio-labeled leukocytes have been used clinically for scintigraphic imaging of inflammatory and infectious processes (van Hemert, 2007; Basu, 2009), where the leukocytes are obtained from the same patient. These findings prompted us to adopt monocytes as a vehicle for ultrasound contrast agents (Chapter 5). A possible limitation of using isolated blood monocytes is the number of donors needed to perform a molecular imaging study, e.g., in mice. Bone marrow isolation, on the other hand, allows retrieval of a far higher number of bone marrow macrophages from a single donor. 
As observed in this thesis, the uptake of contrast agents (e.g., perfluorohexane) by bone marrow monocytes is easily controlled by the concentration of the contrast agent and the duration of exposure (Chapter 5 ). Three hour incubation with $2 \% \mathrm{v} / \mathrm{v}$ perfluorohexane emulsions slightly increases the macrophage diameter (Chapter 6), whereas the lower $50 \%$ part of the size distribution overlaps with the size distribution of native murine leukocytes. Because native leukocytes do not clog the pulmonary circulation and loaded macrophages have a similar size, the latter might be suited for in vivo use, provided that the deformability remains within physiological ranges. However, we questioned whether loaded macrophages still have the same binding properties and are still suitable for targeting after the uptake of contrast agents. In this thesis it was shown that the uptake of various concentrations of perfluorohexane emulsions did not modify the expression of adhesion molecules (VLA4, PSGL-1 and LFA-1) by the macrophages, indicating that it does not affect binding potential (Chapter 5 ). In a static adhesion assay, under no shear stress conditions, both 2 and $4 \% \mathrm{v} / \mathrm{v}$ loaded macrophages were able to adhere to tumor necrosis factor- $\alpha$ (TNF- $\alpha$ ) stimulated endothelium (Chapter 5 ). However, the exact binding mechanism, i.e., which ligand bonds were formed, was not studied. The b.End5 endothelial cells, used in our study, are known to express VCAM-1, P-selectin and Eselectin after TNF- $\alpha$ stimulation, and express ICAM-1 already under non-stimulated conditions (Rohnelt, 1997; Reiss, 1998; Reiss, 1999; Dirkx, 2003; Gunzer, 2005).

The binding mechanism between the ligands on the (perfluorohexane loaded) macrophages and those on the endothelial cells should be studied under realistic wall shear conditions. Flow chambers have been an important tool to study contrast agents or cell rolling and adhesion under clearly defined flow conditions. Furthermore, endothelial cells, but also specific ligands (e.g., P-selectins) can be applied onto the chamber glass, while the density of these ligands can be manipulated to quantify binding (Lawrence, 1991; Reinhardt, 1998; Bacabac, 2005). However, insufficient stimulation of the ligands by, e.g., an insufficient dose of TNF- $\alpha$, may contribute to limited or no adhesion. In preliminary flow chamber experiments (not shown in this thesis), performed with (un-lloaded macrophages, we did not observe differences in adhesion between both stimulated and non-stimulated b. End5 cells. Despite these results, future flow chambers experiments with loaded macrophages remain interesting to understand how these potential contrast agents are able to roll and adhere under various shear conditions.

The remaining question pertains to the in vivo applicability of loaded macrophages. Of course, injection of loaded macrophages has only potential if those macrophages are able to circulate and eventually accumulate at atherosclerotic sites. The average total blood mass of a mouse is $6-8 \%$ of total body mass, which converts to a blood volume of $1.5 \mathrm{ml}$ for a mouse with a body weight of $25 \mathrm{gram}$. It may quite well be 
that injection of $150 \mathrm{ml}$ bone marrow macrophages, even without loading, at a fast rate temporarily increases blood volume and leads to volume overload and sudden death (Chapter 6). Besides, respiratory problems due to loaded macrophage entrapment in the lungs have to be considered. For jugular vein injection, the choice of injection dose and rate as well as the perfluorohexane loading percentage affects murine survival rate (Chapter 6). However, injection via the tail vein and reducing the load to 2.5 million unloaded cells and $2 \% \mathrm{v} / \mathrm{V}$ PFH loaded cells circumvented respiratory problems and sudden death (Chapter 6 ). The relatively long distance from the tail to the lungs apparently allows for sufficiently dilution of the bone marrow macrophages.

Systemic TNF- $\alpha$ stimulation in vivo, for 6 hours, results in a clear increase in adhesion of native leukocytes to the endothelium (Chapter 6). However, compared to the high number of native leukocyte-endothelium interactions, the number of bone marrow macrophages interacting with the vessel wall is moderate. Normal mouse blood contains about $5 \mathrm{M}$ leukocytes per $\mathrm{ml}$. The addition of $2.5 \times 10^{6}$ bone marrow macrophages to a blood volume of $1.5 \mathrm{ml}$ implies that almost $1 / 3$ of the leukocytes in the blood are injected ones, presuming that no bone marrow macrophages are trapped by the microcirculation. The difference between the number of injected and native leukocytes is largely reflected by the incidence of adhering leukocytes to stimulated endothelium within a recording time of 5 seconds, being $6 \pm 8$ for native leukocytes and about 1 for injected bone marrow macrophages (Chapter 6 ). The latter observation corroborates the conclusion that lung entrapment is moderate, i.e., for the same adherence property the eventual number of circulating bone marrow macrophages is about $1 / 6$ of the number of native leukocytes versus an initial ratio of $1 / 3$. The assumed low entrapment in the lung has not been verified by histology.

The TNF- $a$, used in this study to stimulate the endothelium, is involved in a large variety of inflammatory disorders, including arterial injury and atherosclerosis (Kishikawa, 1993; Lei, 1996). TNF- $\alpha$ stimulates the endothelial cells to express adhesion ligands and thereby induces the recruitment of leukocytes onto and into the vessel wall. In vivo studies in the microcirculation have shown that E-selectin and $\mathrm{P}$ selectin are synthesized after stimulation with TNF- $\alpha$, but require 2 to 4 hours for functional expression (Bevilacqua, 1987; Abbassi, 1993; Hickey, 1998; Jung, 1999; Carvalho-Tavares, 2000). Unlike in the microcirculation, where TNF- $\alpha$ alone can induce endothelial upregulation, in large arteries a cocktail of both TNF- $\alpha$ and IL-1b is required to upregulate endothelial adhesion molecules (Eriksson, 2000). This study showed that P-selectin is critical for leukocyte capturing and rolling while Eselectin and $\alpha 4$-integrin appear to stabilize rolling interactions. The upregulation of endothelial adhesion ligands in the large arteries can be achieved by local stimula- 
tion, i.e., via direct addition of the cocktail onto the outer wall of the vessel of interest (Eriksson, 2000; Schramm, 2004). However, as shown in this thesis, systemic upregulation via intraperitoneal injection of TNF- $\alpha$ proofed to be effective: native leukocytes and bone marrow macrophages indeed adhered to the endothelium after stimulation (Chapter 6 ). Although cytokine-triggered arterial injury does not resemble any specific pathology, it is involved in the development of atherosclerosis.

One should also realize that during the 6 hour period of systemic TNF- $\alpha$ stimulation a large number of native blood leukocytes already occupied the binding sites, lowering the chance for bone marrow macrophage-endothelium interactions. Unfortunately, a one-to-one comparison of adhering native leukocytes and injected macrophages could not be achieved, because of overlapping emission spectra of the available fluorescent probes.

This study did not include quantitative wall shear stress measurements, as performed by Eriksson et al. in the mouse aorta (Eriksson, 2000). However, for a whole blood viscosity of $4 \mathrm{mPa} / \mathrm{s}$ in a murine common carotid artery with a circular geometry and a vessel diameter of $0.4 \mathrm{~mm}$ and a mean center stream velocity of $15 \mathrm{~cm} / \mathrm{s}$ (Hartley, 2004), the mean shear stress will be in the order of $6 \mathrm{~Pa}$. The rolling and adhering bone marrow macrophages at the site of interest indicate that loaded bone marrow macrophages are able to cope with these for the mouse normal shear stress levels (Reneman, 2006).

\section{Ultrasound molecular imaging of PFH loaded macrophages}

In Chapter 5 a monolayer of macrophages loaded with $2 \%$ and $4 \% \mathrm{v} / \mathrm{v}$ perfluorohexane emulsions resulted in a dose-dependent increase of 8 and $17 \mathrm{~dB}$, respectively. Injection of $7 \times 10^{6} \mathrm{PFH}$ loaded macrophages in $150 \mu$ l over a time interval of 30 seconds temporarily creates in the pulmonary artery a similar enhancement of echo level (Chapter 6). Subsequent mixing and dilution with native blood decreases the enhancement, although it remains visible in the carotid artery even after 2 minutes. The undulating pattern (Chapter 6 , figure 3 ) indicates that this is not a measurement artifact, but reflects recirculation and dilution.

In the current study we did not evaluate the effect of local accumulation of contrast agents on echogenicity. Selective and quantitative measurement of the enhancement with respect to a reference arterial segment requires quite a different study protocol and specific echo signal processing. The persistent enhancement of about $0.5 \mathrm{~dB}$ of the blood echo level due to the injected leukocytes loaded with perfluoro- 
hexane suggests that local accumulation will be detectable. It will strongly depend on the local adhesion, and hence accumulation, whether sufficient enhancement is reached to allow direct measurements. Accumulation can only be achieved, if the involved contrast agents are stable, a prerequisite loaded macrophages comply with. A possible alternative is provided by non-linear processing techniques to increase sensitivity as has been developed for air bubbles (Averkiou, 2003).

\section{Conclusions}

This thesis corroborates earlier findings that it remains difficult to determine which contrast agent, ligand or target combination would improve molecular ultrasound imaging of atherosclerosis in large vessels under physiological wall shear stress conditions. In the past, in vitro and in vivo studies have shown that under physiological conditions sufficient adhesion of ultrasound contrast agents to the endothelium of large arteries is difficult to achieve. In vitro studies with ultrasound contrast agents showed that they exhibited low capture and weak firm adhesion efficiency at low shear stresses due to their stiffness. Changing to deformable agents, to multiple contrast agent surface ligands or to pulsatile flow improved adhesion, but the improvements were limited (Weller, 2005; Rychak, 2006b; Kaufmann, 2007). In vitro, detachment studies with contrast agents were performed after static incubation (Takalkar, 2004), and those studying attachment of contrast agents were performed under low shear stress conditions (Weller, 2002; Takalkar, 2004; Rychak, 2006a; Kaufmann, 2007). In vivo, hardly any study on ultrasound contrast agent targeting has been performed in large arteries (e.g., carotid artery). Only Kaufmann et al. (Kaufmann, 2007) reported adhesion of VCAM-1 antibody labeled microbubbles to the mouse thoracic aorta. The low number of successful in vivo studies is not strange due to the complex hemodynamic situation in vivo and the relatively high shear stresses normally present in large arteries compared to the in vitro set-up. In Chapter 6 it was shown that under physiological shear stresses perfluorohexane loaded macrophages were able to adhere to the activated endothelium in the carotid artery. Whether adhesion reaches a steady state after longer periods of time needs to be investigated in future studies.

In vivo (quantitative) molecular imaging with ultrasound contrast agents involves a complex interplay between factors like bioavailability, sensitivity and selectivity to target sites in relation to local wall shear stress on the one hand (Takalkar, 2004; Weller, 2005) and the acoustic properties and eventual density of the contrast agent with implications for ultrasound reflectivity on the other (Couture, 2007; Dayton, 2007; Marsh, 2007) (Chapter 3). A possible lack of sensitivity with standard ultrasound systems and also the uncertainty if and when injected cells adhere at the 
site of interest may be limiting factors. In addition, the results obtained with high resolution ultrasound systems in mice can not easily be converted to humans, because contrast agent echogenicity highly depends on the ultrasound frequency used. The shallow penetration required for mice (a few millimeters) allows a high ultrasound frequency ( $30 \mathrm{MHz}$ ), while for the human carotid artery bulb an ultrasound frequency of $10 \mathrm{MHz}$ would likely be more feasible. A difference of a factor 3 in emission frequency converts into a factor of $3^{4}=81$ in echogenicity (Eq. 2.10).

Based on the findings in the present thesis, some recommendations for future research can be formulated. An important focus of future research should be the optimization of standard ultrasound contrast agents for targeting under physiological shear conditions. More insight into the dynamic behavior of ultrasound contrast agent loaded monocytes, under physiological shear conditions, can lead to important changes in the design (e.g., size, shape, adhesion molecules) of standard contrast agents. On the other hand, successful isolation, contrast agent loading and imaging of native blood cells, as seen in nuclear medicine, favors applicability in a clinical setting.

Another important focus is the enhancement of the target site of interest compared to the healthy environment, e.g., the relation between the number of perfluorohexane loaded macrophages at the target site and their reflectivity compared to the surrounding, untargeted area. Combined multi-modal imaging, e.g., intravital imaging (multiple fluorescent probes) and ultrasound (high resolution) in mice, can give more insight into the adhesion behavior and ultrasound reflectivity of the contrast agents at the target site compared to the surrounding area.

With the studies in this thesis, steps were made towards understanding the targeting mechanism of ultrasound contrast agents to the atherosclerotic wall under physiological shear conditions. Although future research is required to further increase this knowledge, the currently proposed model of blood cells as an ultrasound contrast agent vehicle appears as a feasible alternative in molecular ultrasound imaging. The ultimate question is whether this alternative ultrasound contrast is able to image gradual processes of atherogenesis, i.e., grading the atherosclerotic process from early development to vulnerable plaque. 


\section{References}

Abbassi O, Kishimoto TK, Mcintire LV, Anderson DC. Smith CW. E-selectin supports neutrophil rolling in vitro under conditions of flow. J Clin Invest 1993;92:2719-2730.

Averkiou M, Powers J, Skyba D, Bruce M, Jensen S. Ultrasound contrast imaging research. Ultrasound $Q$ 2003;19(1): 27-37

Bacabac R G, Smit TH, Cowin SC, Van Loon JJ, Nieuwstadt FT, Heethaar R, Klein-Nulend J. Dynamic shear stress in parallel-plate flow chambers. J Biomech 2005;38(1): 159-167.

Barnard S, Leen E, Cooke T, Angerson W. A contrast-enhanced ultrasound study of benign and malignant breast tissue. S Afr Med J 2008;98:386-391.

Basu S, Zhuang H, Torigian DA, Rosenbaum J, Chen W, Alavi A. Functional imaging of inflammatory diseases using nuclear medicine techniques. Semin Nucl Med 2009;39:124-145.

Bevilacqua MP, Pober JS, Mendrick DL, Cotran RS, Gimbrone MA, Jr. Identification of an inducible endothelial-leukocyte adhesion molecule. Proc Natl Acad Sci U S A 1987;84:9238-9242.

Bruce M, Averkiou M, Tiemann K, Lohmaier S, Powers J, Beach K. Vascular flow and perfusion imaging with ultrasound contrast agents. Ultrasound Med Biol 2004;30:735-743.

Carvalho-Tavares J, Hickey MJ, Hutchison J, Michaud J, Sutcliffe IT, Kubes P. A role for platelets and endothelial selectins in tumor necrosis factor-alpha-induced leukocyte recruitment in the brain microvasculature. Circ Res 2000;87:1141-1148.

Couture $O$, Cherin E, Foster FS. Model for the ultrasound reflection from micro-beads and cells distributed in layers on a uniform surface. Phys Med Biol 2007;52:4189-4204.

Dai G, Kaazempur-Mofrad MR, Natarajan S, Zhang Y, Vaughn S, Blackman BR, Kamm RD, Garcia-Cardena G, Gimbrone MA, Jr. Distinct endothelial phenotypes evoked by arterial waveforms derived from atherosclerosis-susceptible and -resistant regions of human vasculature. Proc Natl Acad Sci U S A 2004;101:14871-14876.

Dammers R, Stifft F, Tordoir JH, Hameleers JM, Hoeks APG, Kitslaar PJ. Shear stress depends on vascular territory: comparison between common carotid and brachial artery. J Appl Physiol 2003; 94(2): 485489.

Dayton PA, Rychak JJ. Molecular ultrasound imaging using microbubble contrast agents. Front Biosci 2007; 12:5124-5142.

Dirkx AE, Oude Egbrink MG, Kuijpers MJ, van der Niet ST, Heijnen VV, Bouma-ter Steege JC, Wagstaff J, Griffioen AW. Tumor angiogenesis modulates leukocyte-vessel wall interactions in vivo by reducing endothelial adhesion molecule expression. Cancer Res 2003;63:2322-2329.

Eriksson EE, Werr J, Guo Y, Thoren P, Lindbom L. Direct observations in vivo on the role of endothelial selectins and alpha(4) integrin in cytokine-induced leukocyte-endothelium interactions in the mouse aorta. Circ Res 2000;86:526-533.

Gunzer M, Riemann H, Basoglu Y, Hillmer A, Weishaupt C, Balkow S, Benninghoff B, Ernst B, Steinert M, Scholzen T, Sunderkotter C, Grabbe S. Systemic administration of a TLR7 ligand leads to transient immune incompetence due to peripheral-blood leukocyte depletion. Blood 2005;106:2424-2432.

Hartley C, Reddy AK, Madala S, Entman ML, Michael LH, Taffet GE. Noninvasive ultrasonic measurement of arterial wall motion in mice. Am J Physiol Heart Circ Physiol 2004;287:H1426-1432.

Hickey MJ, Issekutz AC, Reinhardt PH, Fedorak RN, Kubes P. Endogenous interleukin-10 regulates hemodynamic parameters, leukocyte-endothelial cell interactions, and microvascular permeability during endotoxemia. Circ Res 1998;83:1124-1131.

Jung $U$, Ley K. Mice lacking two or all three selectins demonstrate overlapping and distinct functions for each selectin. J Immunol 1999;162:6755-6762

Kaufmann BA, Sanders JM, Davis C, Xie A, Aldred P, Sarembock IJ, Lindner JR. Molecular imaging of inflammation in atherosclerosis with targeted ultrasound detection of vascular cell adhesion molecule1. Circulation $2007 ; 116: 276-284$. 
Kishikawa H, Shimokama T, Watanabe T. Localization of T lymphocytes and macrophages expressing IL-1, IL-2 receptor, IL- 6 and TNF in human aortic intima. Role of cell-mediated immunity in human atherogenesis. Virchows Arch A Pathol Anat Histopathol 1993;423(6): 433-442

Lawrence M B, Springer TA. Leukocytes roll on a selectin at physiologic flow rates: distinction from and prerequisite for adhesion through integrins. Cell 1991;65(5): 859-873.

Lei $X$, Buja LM. Detection and localization of tumor necrosis factor-alpha in WHHL rabbit arteries. Atherosclerosis 1996;125(1): 81-89.

Lindner JR, Dayton PA, Coggins MP, Ley K, Song J, Ferrara K, Kaul S. Noninvasive imaging of inflammation by ultrasound detection of phagocytosed microbubbles. Circulation 2000b;102:531-538.

Marsh JN, Partlow KC, Abendschein DR, Scott MJ, Lanza GM, Wickline SA. Molecular imaging with targeted perfluorocarbon nanoparticles: quantification of the concentration dependence of contrast enhancement for binding to sparse cellular epitopes. Ultrasound Med Biol 2007;33:950-958.

Reinhardt $\mathrm{PH}$, Kubes $\mathrm{P}$. Differential leukocyte recruitment from whole blood via endothelial adhesion molecules under shear conditions. Blood 1998;92(12): 4691-4699.

Reiss $Y$, Engelhardt B. T cell interaction with ICAM-1-deficient endothelium in vitro: transendothelial migration of different T cell populations is mediated by endothelial ICAM-1 and ICAM-2. Int Immunol 1999;11(9): 1527-39.

Reiss $Y$, Hoch G, Deutsch U, Engelhardt B. T cell interaction with ICAM-1-deficient endothelium in vitro: essential role for ICAM- 1 and ICAM-2 in transendothelial migration of $T$ cells. Eur 1 Immunol 1998;28:3086-3099.

Reneman RS, Arts T, Hoeks APG. Wall shear stress in the arterial system in vivo - Assessement, results and comparison with theory. Vascular hemodynamics rounds. P. Yim. New York, John Wiley \& Sons. 2008; 37-62.

Reneman RS, Arts T, Hoeks AP. Wall Shear Stress - an Important Determinant of Endothelial Cell Function and Structure - in the Arterial System in vivo. Discrepancies with Theory. J Vasc Res 2006;43:251 269.

Reneman RS, van Merode T, Hick P, Hoeks AP. Flow velocity patterns in and distensibility of the carotid artery bulb in subjects of various ages. Circulation 1985;71:500-509.

Reneman RS, Vink H, Hoeks APG. Wall shear stress revisited. Artery Research 2009;3(2): 5.

Rohnelt RK, Hoch G, Reiss $Y$, Engelhardt B. Immunosurveillance modelled in vitro: naive and memory $T$ cells spontaneously migrate across unstimulated microvascular endothelium. Int Immunol 1997;9:435-450.

Rovai D, Morales MA, Amyot R, L'Abbate A. Clinical experience with Sonovue in myocardial perfusion imaging. Echocardiography 2000;17:517-23.

Rychak JJ, Li B, Acton ST, Leppanen A, Cummings RD, Ley K, Klibanov AL. Selectin ligands promote ultrasound contrast agent adhesion under shear flow. Mol Pharm 2006a;3:516-524.

Rychak JJ, Lindner JR, Ley K, Klibanov AL. Deformable gas-filled microbubbles targeted to P-selectin. J Control Release 2006b;114:288-299.

Samijo SK, Willigers JM, Barkhuysen R, Kitslaar PJ, Reneman RS, Brands PJ, Hoeks AP. Wall shear stress in the human common carotid artery as function of age and gender. Cardiovasc Res 1998;39:515-522.

Schramm R, Menger MD, Schaefers HJ, Thorlacius H. Leukocyte adhesion in aorta and femoral artery in vivo is mediated by LFA-1. Inflamm Res 2004;53(10): 523-527.

Smith DJ, Kornbrust ES, Lane TA. Phagocytosis of a fluorescently labeled perflubron emulsion by a human monocyte cell line. Artif Cells Blood Substit Immobil Biotechnol 1994;22:1215-1221.

Takalkar AM, Klibanov AL, Rychak JJ, Lindner JR, Ley K. Binding and detachment dynamics of microbubbles targeted to P-selectin under controlled shear flow. J Control Release 2004;96:473-482.

van Hemert FJ, Thurlings R, Dohmen SE, Voermans C, Tak PP, van Eck-Smit BL, Bennink RJ. Labeling of autologous monocytes with $99 \mathrm{mTC}-\mathrm{HMPAO}$ at very high specific radioactivity. Nucl Med Biol 2007;34:933-938.

Weller GE, Villanueva FS, Klibanov AL, Wagner WR. Modulating targeted adhesion of an ultrasound contrast agent to dysfunctional endothelium. Ann Biomed Eng 2002;30:1012-1019. 
Weller GE, Villanueva FS, Tom EM, Wagner WR. Targeted ultrasound contrast agents: in vitro assessment of endothelial dysfunction and multi-targeting to ICAM-1 and sialyl Lewisx. Biotechnol Bioeng 2005;92:780-788.

Zhao SZ, Ariff B, Long Q, Hughes AD, Thom SA, Stanton, AV, Xu XY. Inter-individual variations in wall shear stress and mechanical stress distributions at the carotid artery bifurcation of healthy humans. J Biomech 2002;35(10): 1367-1377.

Zhao Y, Chien S, Weinbaum S. Dynamic contact forces on leukocyte microvilli and their penetration of the endothelial glycocalyx. Biophys J 2001;80:1124-1140. 


\section{Summary}


Atherosclerosis, an inflammatory disease of large and middle-sized arteries, is the primary cause of events like stroke or acute myocardial infarction. Molecular imaging of the molecular and cellular processes involved in atherosclerosis utilizes targeted contrast agents in combination with specific imaging modalities, such as ultrasound. Targeting of the atherosclerotic wall of large arteries under physiological circumstances imposes specific requirements on ultrasound contrast agents. They should be able to attach, roll and finally firmly adhere to the wall during oscillating shear stress to achieve sufficient accumulation and ultrasound imaging enhancement. The physiologically high shear forces acting on contrast agents, limiting eventual attachment, remain one of the major obstacles for clinical application. Notably, the adherence requirements for ultrasound contrast agents in small rodents are even more severe since wall shear stress is substantially higher in small animals than in humans. The objective of this thesis was to develop a method for molecular imaging by means of ultrasound contrast agents targeted to endothelial markers in large arteries.

In Chapter 2 the basic principles of ultrasound, contrast imaging, hemodynamics, and particle adhesion are discussed. It is established that high ultrasound echogenicity requires a high density of particles with a large size and a high acoustic impedance mismatch with the surrounding medium, i.e., the blood pool and endothelium. Interrogation of superficially located atherosclerotic regions is advantageous because it allows the use of a high ultrasound frequency, favoring the ratio of particle diameter and wavelength. On the other hand a large particle size is more susceptible to the hemodynamic forces exerted on the particle, i.e., shear stress.

The results obtained in the past with the current ultrasound contrast agents are thoroughly reviewed in Chapter 3. This chapter provides an overview of the commonly used ultrasound contrast agents, such as microbubbles, liposomes and emulsions with a size in the range of 0.1 to $6 \mu \mathrm{m}$. Most detachment studies with contrast agents were performed after static incubation, and those studying attachment of contrast agents were performed under low shear stress conditions. In animal models, contrast agents showed a short circulation time, because they were large, stiff and did not contain suitable shell membrane components. In vitro, stiff-shelled agents exhibited low capture and weak firm adhesion efficiency at low shear stresses. Changing to deformable agents, to multiple contrast agent surface ligands or to pulsatile flow improved adhesion, but the improvements were still limited.

Current ultrasound contrast agents exhibit a wide size distribution, prohibiting conversion from observed echogenicity enhancement to the number and density of particles involved, and, hence, to the density of binding sites as an indication of the stage of the atherosclerotic process rather than a yes/no decision. Chapter 4 de- 
scribes a study in which a membrane emulsification technique is used to create strictly monodisperse perfluorohexane emulsions with a preset size. The ability to produce well defined emulsions of different sizes will make it possible to explore the optimal emulsion droplet size for quantitative imaging in relation to shear stress and echogenicity. In this study monodisperse perfluorohexane emulsions with preselected sizes of $4 \mu \mathrm{m}$ and $12 \mu \mathrm{m}$ were produced. Ultrasound experiments demonstrated that the newly developed perfluorohexane emulsions exhibited the anticipated echogenic behavior. Further investigations are required to get more insight into the relationship between echogenicity and the local concentration and size of adhered ultrasound contrast agents in vivo.

Because of the low adhesion success rate of current standard ultrasound contrast agents the use of monocytes as a vehicle for ultrasound contrast agents was explored in Chapter $\mathbf{5}$. Isolated murine bone marrow cells were cultured into macrophages, which were allowed to take up contrast material (perfluorohexane). The uptake was easily controlled by the concentration of the contrast agents and duration of exposure. The uptake of contrast material increased echogenicity dosedependently by more than $10 \mathrm{~dB}(4 \% \mathrm{v} / \mathrm{v})$. The uptake process did not modify the expression of adhesion molecules (VLA-4, PSGL-1 and LFA-1), indicating that it does not affect binding potential. Moreover, under no shear stress conditions the loaded macrophages were able to adhere to stimulated endothelium.

The in vivo applicability of loaded macrophages as described in chapter 5 was studied in Chapter 6. Ultrasound examination showed that after intravenous injection perfluorohexane loaded bone marrow macrophages enhanced the echo level of arterial blood in mice. Moreover, injection via the tail vein of $2.5 \times 10^{6} 2 \% \mathrm{v} / \mathrm{v}$ loaded bone marrow macrophages was well tolerated by the animals. Intravital microscopy showed that injected bone marrow macrophages exhibited rolling and adhesion behavior at the TNF- $\alpha$ stimulated carotid artery endothelium, similar to native blood leukocytes. Furthermore, rolling behavior was not different between perfluorohexane loaded and unloaded bone marrow macrophages. Similarly, there was no difference in the number of adhering loaded and unloaded bone marrow macrophages. Future experiments are required to get more insight into the relationship between local expression of molecular markers on endothelial surfaces and the local concentration and diameter of adhered cell-based ultrasound contrast agents.

Finally, Chapter 7 integrates the results of the studies presented in this thesis and discusses the remaining challenges towards ultrasound molecular imaging in large arteries under (patho)physiological flow conditions. 


\section{Samenvatting}


Atherosclerose ("aderverkalking") is een ontstekingsziekte van de wand van de grote slagaders. Het is de voornaamste oorzaak van een beroerte of een hartinfarct. Atherosclerose is een langzaam en geleidelijk voortschrijdend proces waarbij de ontsteking leidt tot de ontwikkeling van een atherosclerotische plaque. Als gevolg daarvan produceert de binnenlaag van het vat (het endotheel) specifieke moleculen. Moleculaire beeldvorming ("molecular imaging") is gebaseerd op het zichtbaar maken van de moleculaire en cellulaire processen betrokken bij weefselveranderingen. Daartoe wordt gebruik gemaakt van contrastmiddelen die met een gegeven beeldvormende techniek, zoals ultrageluid (echografie), goed kunnen worden waargenomen. Selectieve hechting wordt bereikt door de contrastmiddelen te voorzien van moleculen die een binding aangaan met de moleculen die als gevolg van het atherosclerotische proces gevormd worden. De hechting moet zo stevig zijn dat ze vast blijven zitten ondanks de wrijvingskrachten die het stromend bloed erop uitoefent. De wrijvingskracht per eenheid van oppervlakte wordt de afschuifspanning of "shear stress" genoemd. Naarmate zich meer contrastmiddelen locaal ophopen zullen ze steeds beter zichtbaar worden op het ultrasonore echobeeld.

De afschuifspanning aan de wand, uitgeoefend op het contrastmiddel, belemmert de hechting. Dit is één van de grootste obstakels bij de toepassing van contrastmiddelen voor ultrageluid in slagaders bij de mens. Bovendien is het uittesten van moleculaire beeldvorming met behulp van ultrageluid bij kleine knaagdieren moeizaam. Juist in kleine dieren blijkt de shear stress aanzienlijk hoger zijn dan bij de mens. Het doel van dit proefschrift is een methode te ontwikkelen voor moleculaire beeldvorming met behulp van ultrageluid contrastmiddelen, die hechten aan specifieke moleculen in de arteriewand onder (patho)fysiologische stromingscondities.

In hoofdstuk 2 worden de basisprincipes van ultrageluid, contrast afbeelding, hemodynamica en hechting van contrastmiddelen in detail besproken. Daarin wordt onder andere vastgesteld dat een hoge reflectiviteit van het ultrageluidsignaal een hoge dichtheid vereist van contrastmiddelen met een grote diameter en een akoestische impedantie die sterk afwijkt van die van de omgeving, dat wil zeggen, het bloed en het endotheel. Bovendien is de reflectiviteit van een klein deeltje in belangrijke mate afhankelijk van de verhouding tussen zijn diameter en de golflengte van het gebruikte ultrageluid. Het heeft daarom zin om in de ontwikkelingsfase te kiezen voor een oppervlakkig gelegen slagader die gevoelig is voor atherosclerotische processen, zoals de halsslagader. Vanwege de geringe indringdiepte van ultrageluid $(30 \mathrm{~mm}$ ) heeft men minder last van verzwakking van het geluid en kan dus een hogere frequentie (7-10 $\mathrm{MHz}$ ) met een kortere golflengte gebruikt worden. Een complicerende factor is echter dat een contrastdeeltje met een grotere diameter gevoeliger is voor afschuifspanningen waardoor hechting aan de wand bemoeilijkt wordt. 
De ervaringen die eerder zijn opgedaan met de hedendaagse ultrageluid contrastmiddelen passeren in hoofdstuk 3 de revue. Dit hoofdstuk geeft een overzicht van de gebruikelijke ultrageluid contrastmiddelen, zoals microbubbels, liposomen en emulsies met een deeltjesformaat van 0,1 tot $6 \mu \mathrm{m}$. De meeste hechtingsstudies waren gericht op het los laten van de contrastmiddelen nadat ze eerst, zonder stroming, mochten hechten aan het doelgebied. Andere hechtingsstudies bestudeerden de hechting van contrastmiddelen bij aanzienlijk lagere afschuifspanningen dan die bij de mens in slagaders optreden. In diermodellen lieten de contrastmiddelen een korte circulatietijd zien, omdat ze te groot en te stijf waren en niet de geschikte membraan componenten bevatten. De contrastmiddelen met een stijve membraan hadden bij een lage afschuifspanning ook een lage hechtingsefficiëntie, terwijl de hechting weer gemakkelijk verbroken werd. Het gebruik van vervormbare contrastmiddelen, of contrastmiddelen met meerdere bindingsmoleculen op het membraan, of hechting van contrastmiddelen onder pulsatiele stromingscondities resulteerden in een matige verbetering.

De hedendaagse ultrageluid contrastmiddelen hebben eenbrede grootteverdeling waardoor het onmogelijk wordt om het waargenomen echosignaal te converteren naar het aantal en de dichtheid van de betrokken contrastmiddelen. Het is dan ook niet mogelijk om een indicatie te geven van het stadium waar het atherosclerotische proces in verkeert; men moet volstaan met een ja/nee beoordeling. Hoofdstuk 4 beschrijft een methode om met een membraan emulsificatie techniek perfluorhexaan emulsies te maken met een nauwe grootteverdeling en een vooraf gekozen diameter, bijvoorbeeld 4 en $12 \mu \mathrm{m}$. Het wordt daardoor mogelijk om de meest optimale emulsie druppelgrootte te kiezen voor kwantitatieve beeldvorming in relatie tot de karakteristieken van de afschuifspanning en het echosignaal. Ultrageluid experimenten bevestigden dat deze perfluorhexaan emulsies zichtbaar zijn met behulp van ultrageluid. Extra onderzoek is nodig om meer inzicht te krijgen in de relatie tussen het echosignaal en de lokale concentratie en het formaat van de ultrageluid contrastmiddelen zoals die zich ophopen op een atherosclerostische plaque in de halsslagader.

Vanwege de slechte hechtingseigenschappen van de huidige ultrageluid contrastmiddelen hebben wij in hoofdstuk 5 onderzocht of monocyten (witte bloedcellen; voorlopers van macrofagen) als voertuig voor ultrageluid contrastmiddelen kunnen worden gebruikt. Daartoe werden uit geïsoleerde beenmergcellen van muizen macrofagen gekweekt die contrastmiddelen opnemen. De opname kon gemakkelijk gecontroleerd worden door de concentratie van de contrastmiddelen (bijv. perfluorhexaan) in relatie tot de duur van de blootstelling. De opname van het contrastmiddel door de macrofaag liet een dosis-afhankelijke verhoging van het echosignaal zien van minstens een factor 3 (bij een dosis van $4 \% \mathrm{v} / \mathrm{v}$ ). De opname van perfluor- 
hexaan had geen invloed op de expressie van de bindingsmoleculen die normaal aanwezig zijn op het membraan van de macrofaag, zoals VLA-4, PSGL-1 en LFA-1. De opname van het contrastmiddel had geen invloed op de hechtingseigenschappen van de macrofagen.

In hoofdstuk 6 worden experimenten gepresenteerd waarin de toepasbaarheid van de in hoofdstuk 5 beschreven macrofagen in muizen onderzocht werd. Intraveneuze injectie van perfluorohexaan geladen beenmergmacrofagen resulteerde direct na injectie in een geringe maar duidelijk waarneembare toename van het ultrageluidsniveau van het bloed in de longslagader en vervolgens in de halsslagader. Verder bleek dat de geleidelijke injectie van 2.5 miljoen $2 \% \mathrm{v} / \mathrm{v}$ geladen beenmerg macrofagen via de staartvene door de muizen goed verdragen werd. Het atherosclerotisch proces werd gesimuleerd door de halslagader te stimuleren met TNF- $\alpha$. We hebben vervolgens met behulp een intravitaal microscoop vastgesteld dat de geïnjecteerde beenmerg macrofagen een rollend en hechtend gedrag vertoonden overeenkomstig met dat van de eigen witte bloedcellen van het dier. Bovendien hebben wij geen verschil in het rolgedrag en de hechting van de met perfluorhexaan geladen en de ongeladen beenmerg macrofagen vast kunnen stellen. Aanvullende experimenten zijn echter nodig, ondermeer om de relatie tussen de lokale expressie van moleculaire markers op het endotheel en de lokale concentratie en diameter van gehechte geladen monocyten vast te stellen, ten einde een definitieve conclusie te kunnen trekken over de bruikbaarheid van deze methode,

Tenslotte worden in hoofdstuk 7 alle resultaten geintegreerd en besproken. Daarbij wordt tevens aandacht besteed aan de resterende uitdagingen met betrekking tot moleculaire beeldvorming van atherosclerotische plaques met behulp van ultrageluid. 


\section{Dankwoord}


Na een periode van 2291 dagen, ofwel 327 weken, ofwel 75 maanden, ofwel 6 jaren is het gelukt, mijn proefschrift is af! Hier ben ik dan ook enorm trots op!

Allereerst wil ik graag iedereen enorm bedanken die bijgedragen heeft aan het tot stand komen van dit proefschrift! Onderstaande mensen wil ik in het bijzonder bedanken.

Beste professor Hoeks, Arnold, ik wil je als eerste bedanken voor de afgelopen jaren! Ik heb veel geleerd van jouw kennis op het gebied van onderzoek en natuurlijk vooral over ultrageluid. Je deur stond altijd open voor de vele gesprekken die we hebben gevoerd over mijn onderzoek, maar ook voor gesprekken over de alledaagse dingen in het leven zoals sport en sportblessures (knie, neus, enkels, etc). Ik heb met heel veel plezier in jouw groep gewerkt. En, zoals bij de meeste AlO's, zijn de uitdrukkingen "wat een ellende" en "heb je het weer verbeterd" nu ook een vast onderdeel geworden in mijn leven!

Beste professor Reneman, Rob, je kennis van wetenschap is onuitputtelijk. Daarnaast waren je commentaren op mijn schrijfwerk (met de welbekende rode pen) altijd helder en stimulerend. Hartelijk dank voor de vele leerzame en inspirerende momenten tijdens mijn promotie!

Beste Koen, je inspiratie en vertrouwen in mijn project waren enorm! Mijn tweede AlO periode, "een nieuwe start", heeft een mooi resultaat opgeleverd; hij had, achteraf gezien, nog veel meer moois kunnen opleveren als we meer tijd hadden gehad. Super bedankt voor je begeleiding maar ook voor je motiverende gesprekken die ik zo nu en dan goed kon gebruiken. Verder zal ik je Brabantse gezelligheid en wetenschappelijke vragen zoals "Heddegèdadgezeetgehadjoamindedawerkelikwoar hoedoedegèdahoedoedegèdahoeheddegèdagedoan" dan ook erg missen!

Geachte leden van de beoordelingscommissie, Dr. A Duijvestijn, Prof. T. Hackeng, Prof. N. de Jong, Dr. E. Lutgens, Prof. J. Wildberger, ik wil jullie hartelijk danken voor het kritisch beoordelen van het manuscript.

Ik wil in het bijzonder mijn ultrageluid collega's bedanken voor de leuke tijd die ik bij hen heb gehad. Evelien, je was naast collega ook mijn carpoolmaatje. Onze gezellige en goede gesprekken over het werk, privé, sauna's ;-) en onze (top)sportavonturen, met en zonder blessures, mis ik nu wel elke ochtend en middag in de auto. Beste Jeroen, jouw hulp bij het opzetten en draaiende houden van de opstellingen heb ik enorm gewaardeerd, super bedankt! Dennis, bedankt voor de leuke en interessante gesprekken over het werk en privé, bijvoorbeeld over je zoveelste vakantie van het jaar ;-). Succes met het afronden van je promotie! 
Verder wil ik ook de andere (oud-) collega's van de vakgroep Biomedische Technologie (voorheen Biofysica) bedanken voor hun ondersteuning, gesprekken, lab-uitjes en de heerlijke vlaaien! In het bijzonder ook Lenneke, het was fijn om met je te kunnen kletsen over de ditjes en datjes in het gewone en wetenschappelijke leven. Ook onze "shop"-momentjes waren enorm gezellig en die moeten we snel maar weer oppakken!

Danielle, via jou en Koen is er een brug geslagen tussen de afdeling Biofysica/BMT en Moleculaire Genetica. Hierdoor heb ik een nieuwe weg kunnen volgen in mijn AlO project wat heeft geleidt tot nieuwe mogelijkheden binnen molecular imaging! Ik wil je enorm bedanken voor je tijd, geduld en inzet!

Verder wil ik Jo Simons, Jan Meuldijk, Maartje Kemmere en Jos Keurentjes van de vakgroep Chemical Engineering and Chemistry van de Technische Universiteit Eindhoven bedanken voor de goede samenwerking!

Mijn dank gaat ook uit naar Menno De Winther, Alma Zernecke, Ben Janssen, Bernard van de Berg, en Mirjam Oude Egbrink. Hartelijk dank voor jullie expertise en dat ik mijn experimenten bij jullie kon verrichten.

Onmisbaar zijn de volgende mensen van andere vakgroepen voor mijn werk geweest: Viviane van Fysiologie, Agnieszka, Jacques, en Peter van Farmacologie; super bedankt jullie hulp en tijd! Ook de volgende (oud-)medewerkers van de vakgroepen Mol Gen (Menno, Marion, Inge, Monique, Patrick, Pieter, Chantal en Vivian), Pathologie (Mathijs Groeneweg en Natasja Kisters) en Radiologie (Eline Kooi, Robert-Jan Miserus en Marc Lobbes) wil ik bedanken voor jullie bijdragen en de gezellige en interessante gesprekken. Tevens gaat mijn dank ook uit naar Professor Arjan Griffioen voor de b.End5 cellen en de medewerkers van het CPV voor hun bijdrage.

Beste paranimfen, lieve vriendinnen, Veerle en Judith, wat een kreet en vreugdedans maakten jullie toen ik jullie beiden vroeg om mijn paranimfen te zijn. Dat bevestigde nog eens te meer dat ik een goede keuze had gemaakt om voor jullie te kiezen. Bedankt meiden voor jullie luisterend oor, steun en adviezen over werk en privé tijdens onze uitstapjes, AZM lunches, en diners!

Verder wil ik ook al mijn lieve vrienden, vriendinnen, (oud-) teamgenootjes en (schoon)familie enorm bedanken voor jullie interesse en steun, maar ook voor de ontspanning die jullie mij de afgelopen jaren geboden hebben!

Lieve pap en mam, altijd hebben jullie voor mij klaar gestaan en mij gesteund in mijn (studies) keuzes. Wie had ooit verwacht na mijn eerste schooldag op de MAVO 
dat ik ooit nog eens zou promoveren. Bedankt voor jullie onvoorwaardelijk vertrouwen in mij; dat betekent echt enorm veel voor me! Verder wil ik ook mijn lieve zus Leonie en schoonbroer Michel bedanken voor jullie steun en betrokkenheid in de afgelopen jaren! Luke en Amber, ik ben enorm trots dat ik jullie tante ben!

Lieve Nick, eindelijk, het is af! Je bent de afgelopen jaren een enorme steun voor me geweest en je stond altijd voor me klaar. Je rust, eerlijkheid, gezelligheid en humor zorgde voor een heerlijke thuisbasis! Bedankt voor alles!!! 


\section{Curriculum Vitae}




\section{About the author}

Liselotte Kornmann was born on May 23, 1979, in Willemstad, Curaçao, Netherlands Antilles. In 1995, she finished her secondary education at MAVO Koningshof in Veldhoven. In the same year, she attended secondary school at Van Maerlandtlyceum in Eindhoven, and received the HAVO diploma in 1997. Next, she studied from 1997 till 2001 Diagnostic Imaging and Radiation Therapy (MBRT) at the Fontys Hogescholen Eindhoven. From 2001 till 2003 she studied Biological Health Sciences at Maastricht University and received a Master's degree in Health Science in 2003. Her graduation work was done at the laboratory of the GG\&GD and at the Laboratory of Immunogenetics of the VU University Medical Centre, Amsterdam. In 2004, she started as a PhD student at the department of Biophysics (now Biomedical Engineering) at Maastricht University on the project "Ultrasound molecular imaging of endothelial functioning", which was part of the SenterNovum/BSIK project on "Molecular Imaging of Ischemic Heart Disease'. During this time she attended several CARIM and general education courses as well as international conferences, such as the joint Molecular Imaging Conference. As of July 1, 2009, she is working as Labelling Manager at Merck Sharp \& Dohme (MSD). 


\section{List of publications}

\section{Articles}

Kornmann LM, Zernecke A, Curfs DM, Janssen BJA, de Winther MP, Reneman RS, Reesink KD, Hoeks AP. The in vivo potential of echogenic perfluorohexane-loaded macrophages to detect activation of vascular adhesion. Submitted to Mol Imaging Biol.

Kornmann LM, Reesink KD, Reneman RS, Hoeks AP. Critical appraisal of targeted ultrasound contrast agents for molecular imaging in large arteries. Ultrasound Med Biol. 2010; 36(2):181-191.

Simons, J.M.M., Kornmann, L.M., Reesink, K.D., Hoeks, A.P.G., Kemmere, M.F., Meuldijk, J., Keurentjes, J.T.F. (2010). Monodisperse perfluorohexane emulsions for targeted ultrasound contrast imaging. J Mater Chem. 2010; 20:3918-3923.

Hermeling E, Reesink KD, Kornmann L.M., Reneman RS, Hoeks AP. The dicrotic notch as alternative time-reference point to measure local pulse wave velocity in the carotid artery by means of ultrasonography. J Hypertens. 2009; 27(10):2028-35.

Kornmann LM, Curfs DM, Hermeling E, van der Made I, de Winther MP, Reneman RS, Reesink KD, Hoeks AP. Perfluorohexane-loaded Macrophages as a Novel Ultrasound Contrast Agent: A Feasibility Study. Mol Imaging Biol. 2008; 10:264-270.

\section{Abstracts}

Kornmann LM, Zernecke A, Curfs DM, Janssen BJA, De Winther MP, Reneman RS, Hoeks APG, Reesink KD. In vivo targeting of mouse carotid endothelium using echogenic perfluorohexane loaded macrophages. $15^{\text {th }}$ European Symposium on Ultrasound Contrast Imaging 2010, Rotterdam, The Netherlands.

Kornmann LM, Curfs DM, De Winther MP, Reneman RS, Reesink KD, Hoeks APG. The use of monocytes as a novel ultrasound contrast agent. Joint Molecular Imaging Conference 2007, Providence, RI, USA. 
